Reviews in Mineralogy and Geochemistry

2017, Volume 82 Issue 1 Pages 601-656

http://dx.doi.org/10.2138/rmg.2017.82.14

http://archimer.ifremer.fr/doc/00379/49011/

(c) 2017 Mineralogical Society of America

\title{
Germanium Isotope Geochemistry
}

\author{
Rouxel Olivier ${ }^{1,2}$, Luais Béatrice ${ }^{3}$
}

1 IFREMER, Ctr Brest, Dept Phys Resources \& Deep Sea Ecosyst, F-29280 Plouzane, France.

${ }^{2}$ Univ Hawaii Manoa, Dept Oceanog, Honolulu, HI 96822 USA.

${ }^{3}$ Univ Lorraine, CNRS UMR 7358, CRPG, F-54501 Vandoeuvre Les Nancy, France.

Corresponding authors : Olivier Rouxel, email address : orouxel@hawaii.edu ; Béatrice Luais, email address : luais@crpg.cnrs-nancy.fr 


\section{INTRODUCTION}

Germanium (Ge) is a trace element in the Earth's crust and natural waters, averaging about 1.6 ppm in rocks and minerals (El Wardani 1957; Bernstein 1985) and 75 picomol/L in seawater (Froelich and Andreae 1981). The naturally-occurring oxidation states of Ge are +2 and +4 , with the +4 state forming the principal common and stable compounds. Germanium has outer electronic structure $3 \mathrm{~d} 10$ $4 \mathrm{~s} 24 \mathrm{p} 2$ and mainly occurs in the quadrivalent state, although in some minerals it is octahedrally coordinated. Germanium is chemically similar to silicon ( $\mathrm{Si}$ ), both belonging to the IVA group in the periodic table, with Ge immediately above Si. Germanium is classified as a semimetal, whereas $\mathrm{Si}$ is a nonmetal element. Because of nearly identical ionic radii and electron configurations for $\mathrm{Ge}$ and $\mathrm{Si}$, the crustal geochemistry of Ge is dominated by a tendency to replace Si in the lattice sites of minerals (Goldschmidt 1958; De Argollo and Schilling 1978b). These two elements exist in seawater as similar hydroxyacids, i.e., $\mathrm{Ge}(\mathrm{OH})_{4}$ and $\mathrm{Si}(\mathrm{OH})_{4}$ (Pokrovski and Schott 1998a) and the concentration profile of Ge is similar to that of $\mathrm{Si}$ (Froelich and Andreae 1981), thus making Ge/Si ratio an interesting tracer for biogenic silica cycling in the ocean. Although Ge and Si are geochemically similar, their behavior is different enough so that decoupling of Ge and Si can occur. Germanium commonly occurs in 4-fold (tetrahedral) coordination but in contrast to $\mathrm{Si}$, Ge has a stronger tendency for the 6-fold coordination. Unlike Si, Ge also forms methylated compounds, and high concentrations of monomethyl- and dimethyl-germanium have been detected in ocean waters, accounting for $>70 \%$ of the total Ge (Lewis et al. 1985).

Germanium is a particularly interesting element for geochemists since it exhibits siderophile, lithophile, chalcophile and organophile behaviors in different geologic environments (Bernstein 1985). The siderophile behavior of Ge is well reflected by the fact that it can achieve concentrations of up to 2000 ppm in iron meteorites (Wasson 1966; Wai and Wasson 1979) whereas its lithophile behavior is indicated by the strong geochemical coupling between $\mathrm{Si}$ and Ge during partial melting and fractional crystallization (De Argollo and Schilling 1978b). The chalcophile and organophile behaviors of Ge are also well demonstrated by the strong enrichment of Ge in some sphalerite-rich sulfide and coal deposits (Bernstein 1985; Holl et al. 2007; Belissont et al. 2014; Frenzel et al. 2014). In particular, Ge has one of the highest affinities for organic matter of all the elements commonly associated with coal and lignite (Valkovic 1983).

Germanium has five naturally occurring isotopes ${ }^{70} \mathrm{Ge},{ }^{72} \mathrm{Ge},{ }^{73} \mathrm{Ge},{ }^{74} \mathrm{Ge}$, and ${ }^{76} \mathrm{Ge}$ with relative abundance of 21.2, 27.7, 7.7, 35.9 and 7.5\% respectively (Green et al. 1986; Rosman and Taylor 1998; Chang et al. 1999). The possibility of significant Ge isotope fractionation in chemical reactions between various Ge compounds was recognized long ago by Brown and Krouse (1964). Despite the 
interest, there are less than a dozen of published studies reporting natural variations of Ge isotopes thus far. Early investigations of Ge isotopic compositions using thermal ionization mass spectrometry (TIMS) were limited to an uncertainty of several per mil (Shima 1963; Green et al. 1986) and no significant variations in Ge isotope composition were found. It was only with the advent of multiple collector magnetic sector inductively coupled plasma mass spectrometry (MC-ICP-MS) (Halliday et al. 1995) that progress was made for high precision measurement of Ge isotopic compositions. In a reconnaissance study, Hirata (1997), Xue et al. (1997) and Luais et al. (2000) analyzed the Ge isotopic composition of meteoritic materials and identified the first direct evidence for mass-dependent fractionation of $\mathrm{Ge}$ isotopes. Although further analytical developments were made to evaluate inherent instrumental artefacts in the analysis of Ge isotopes (Galy et al. 2003) and their use in cosmochemistry (Luais 2007), the natural variations of Ge isotopes on Earth remained unknown, mainly due to the lack of suitable analytical techniques to analyze silicate matrices and sub-microgram quantities of Ge. Subsequently, new techniques were developed to achieve precise determination of Ge isotopes in geological and aqueous matrices, including silicates and geothermal fluids (Rouxel et al. 2006; Siebert et al. 2006; Escoube et al. 2012; Luais 2012; Meng et al. 2015).

Using these new analytical capabilities, studies have reported Ge isotope variations in lowtemperature Earth surface environments (Rouxel et al. 2006; Siebert et al. 2006; Escoube et al. 2015); coal (Qi et al. 2011) and ore deposits (Escoube et al. 2012; Belissont et al. 2014; Escoube et al. 2015; Meng et al. 2015); as well as crustal rocks and meteorites (Rouxel et al. 2006; Luais 2007; Escoube et al. 2012; Luais 2012). These studies, together with experimental (Pokrovsky et al. 2014) and theoretical ( $\mathrm{Li}$ et al. 2009) determination of Ge isotope fractionation factors demonstrate the great potential of Ge isotopes to trace both high- and low-temperature geochemical processes. Although potential mechanisms for fractionation are still poorly kown, Ge isotopes appear particularly sensitive to complexing process with organic matter or sulfide compounds, biological uptake and equilibrium/kinetic isotope effects between fluid and minerals. This chapter summarizes what has been learned thus far in both high- and low-temperature geochemistry of Ge. It also presents some geochemical background on the application of Ge/Si ratios as geochemical tracers, which provide key insights into the isotopic systematics of Ge.

\section{METHODS}

\section{Early methods to measure Ge isotope ratios}

Early studies using thermal ionisation mass spectrometry (TIMS) were limited by the high ionization potential of $\mathrm{Ge}(7.899 \mathrm{eV})$ and a relatively poor precision of several per mil (at one standard deviation, 1 s.d.) precluding the resolution of natural variations of $\mathrm{Ge}$ isotope abundances (Reynolds 1953; Shima 1963). Later, Green et al. (1986) improved the TIMS technique using a double spike 
approach and improved the precision down to 0.5 per mil per mass unit. An ion-enhancing gel loading technique was also developed to enable microgram quantities of $\mathrm{Ge}$ to be analyzed. Within the limits of experimental error, no variations in Ge isotopic abundances were found in any of the reagents or minerals analyzed. The analytical capability of TIMS was not further improved, even in very recent studies (Gautier et al. 2012). In rare cases, gas source mass spectrometry (Graham et al. 1951; Kipphardt et al. 1999) and secondary ion mass spectrometry (Nishimura et al. 1988 ; Onishi et al. 2006) were also employed. Graham et al. (1951) reported the abundances of the Ge isotopes in germanium tetrachloride and tetrafluoride prepared from mineral samples of different geological and geographical origins. Natural variations of several per mil were tentatively found for the ${ }^{76} \mathrm{Ge} /{ }^{70} \mathrm{Ge}$ ratio. Nearly half a century later, Kipphardt et al. (1999) also used gas isotope mass spectrometry after Ge fluorination and determined the isotopic abundance of Ge in several terrestrial samples. Although no natural variations were reported, this study refined the atomic weight of Ge. Secondary ion mass spectrometry was also used in several studies (Nishimura et al. 1988 ; Onishi et al. 2006) but not widely applied.

Inductively Coupled Plasma Mass Spectrometry (ICPMS) has further improved the measurement of Ge isotopes over TIMS due to the increased ionisation efficiency of the plasma source. Xue et al. (1997) used Quadrupole ICPMS and found evidences for large variations of Ge isotope ratios during the evaporative loss from oxide rims of Canyon Diabolo spheroids. This technique involved the addition of Ga as internal standard to correct for drifts in instrumental mass bias. However the uncertainty was still too high to resolve sub per mil isotope variations. Multi Collector (MC) ICPMS was subsequently employed by Hirata (1997) and Luais et al. (2000). Instrumental mass bias was monitored using Ga-external correction technique while isobaric interferences were mitigated by purifying Ge from the sample matrix before isotope analysis. Variations in Ge isotopic ratios of three chemical reagents and germanite samples were found to be about $0.1-0.3 \%$ for ${ }^{70} \mathrm{Ge} /{ }^{73} \mathrm{Ge}$, whereas isotopic variations for meteoritic samples were about $4 \%$. An important result of this study was the demonstration that ${ }^{70} \mathrm{Ge} /{ }^{73} \mathrm{Ge}$ vs. ${ }^{72} \mathrm{Ge} /{ }^{73} \mathrm{Ge}$ ratios of meteorites and terrestrial samples have mass-dependent relationships (Luais et al. 2000; Luais 2003). Revisiting the measurement of Ge isotopes by MC-ICPMS, Galy et al. (2003) noted that the ${ }^{74} \mathrm{Ge} /{ }^{70} \mathrm{Ge}$ normalized to ${ }^{72} \mathrm{Ge} /{ }^{70} \mathrm{Ge}$ of Hirata (1997) was higher by $2 \%$ than the ${ }^{74} \mathrm{Ge} /{ }^{70} \mathrm{Ge}$ of Green et al. (1986) (Table 1). The isotope ratio repeatability of a mono-elemental Ge solution was better than $0.06 \%$ per mass unit at $95 \%$ confidence, confirming the superiority of MC-ICPMS over previously used mass spectrometry techniques. Galy et al. (2003) also demonstrated that the addition of $\mathrm{Na}$ and $\mathrm{K}$ to a standard solution of Ge having a known isotopic composition induces up to $4.4 \%$ decrease of ${ }^{74} \mathrm{Ge} /{ }^{70} \mathrm{Ge}$ ratio. This chemical bias is a result of a mass-dependent process and prevents the measurement of natural samples without chemical separation. 


\section{State of the art analytical methods}

Although significant differences in analytical techniques exist between different research groups (Rouxel et al. 2006; Siebert et al. 2006; Luais 2007), state-of-the-art measurements of Ge isotopes generally involve: (1) chemical purification of Ge through anion-exchange and/or cationexchange chromatographic columns; (2) hydride generation (HG) and gaseous Ge hydride introduction into the plasma torch; (3) correction of instrumental mass fractionation using either standard-sample bracketing or double spike approaches. The conjunction of HG technique with MCICPMS has been previously applied to other stable isotope systems such as $\mathrm{Se}$ and $\mathrm{Sb}$ isotopes (Rouxel et al. 2002; Rouxel et al. 2003a) and allowed high-precision isotope ratios for 10- to 100-fold decrease in analyte quantities. Luais et al. (2000) and Luais (2003) also provided high precision measurements of $\mathrm{Ge}$ isotopes in iron meteorites (2s.d. less than $0.25 \%$ ) using conventional sample introduction system and Ga correction. Rouxel et al. (2006) reported the isotopic results in the same manner as proposed by Galy et al. (2003) and Luais (2003) following the so called "standard-sample bracketing technique" which involves the measurement of the Ge standard solution, before and after each sample. This approach enabled the measurement of some of the first terrestrial Ge isotope ratios, using sample sizes as small as $15 \mathrm{ng}$ and with a precision of less than $0.2 \%$ on ${ }^{74} \mathrm{Ge} /{ }^{70} \mathrm{Ge}$ (Rouxel et al., 2006). This represented an important advance as, for the first time, it was possible to measure Ge isotope composition of a range of terrestrial samples, including igneous and sedimentary rocks as well as some marine clays and sponges. Rouxel et al. (2006) also provided a first estimate of the bulk silicate Earth Ge isotope ratio and seawater. In the same year, Siebert et al. (2006) used a double-spike isotope dilution MC-ICPMS technique for the determination of Ge isotope fractionation. Using this technique, they determined Ge isotope compositions of geothermal spring fluids and basalts. Although the double spike approach allowed correcting for instrumental mass bias and isotope fractionation during sample preparation, the external standard reproducibility on ${ }^{74} \mathrm{Ge} /{ }^{72} \mathrm{Ge}$ ratio was limited to 0.4\% (2s.d.), corresponding to 4 times the precision reported by Rouxel et al. (2006). Further analytical developments of Ge isotopic measurements were also carried out by Luais $(2007 ; 2012)$ for the measurement of iron meteorites, sulfides, and silicate rocks. Other groups adapted these available methods for the measurements of sulfide samples (Meng et al. 2015). Escoube et al. (2012) proposed an improved technique by using a double-spike approach, together with HG-MC-ICPMS and chromatographic separation. This study reported an interlaboratory comparison of Ge isotope composition of selected georeference materials and standard solutions. This allowed the definition of a new reference material NIST SRM 3120a to report natural Ge isotope variations. Finally, the most recent progress involved the development of preconcentration methods to measure Ge isotopes in seawater (Baronas et al. 2014; Guillermic et al. 2016).

\section{Sample dissolution issues}

Since Ge isotope measurements in rocks and minerals generally require a dissolution step to 
isolate $\mathrm{Ge}$ from the elements constituting the matrix, specific methods must be employed. In the case of sulfides (e.g. sphalerite, pyrite, chalcopyrite), Fe-oxyhydroxides and iron meteorites, the use of concentrated $\mathrm{HNO}_{3}$ was sufficient to achieve a complete dissolution and quantitative recovery of Ge in solution. After sample digestion, the solutions were evaporated in open Teflon beaker at temperatures ranging from $120^{\circ} \mathrm{C}$ (Meng et al. 2015), down to $80^{\circ} \mathrm{C}$ (Escoube et al. 2015) or $60^{\circ} \mathrm{C}$ (Luais 2007). In all cases, the use of $\mathrm{HCl}$ or $\mathrm{HClO}_{4}$ has to be avoided as tests showed that $\mathrm{Ge}$ is lost at $85 \%$ with $\mathrm{HClO}_{4}$ and at $100 \%$ with $\mathrm{HCl}$ even at medium temperature $80^{\circ} \mathrm{C}$ (Luais 2012) due to the formation of volatile $\mathrm{GeCl}_{4}$ species (Kaya and Volkan 2011). Dissolution of silicate rocks for Ge isotopic measurements is also complicated by the potential volatile behavior of Ge in the presence of hydrofluoric acid (HF) (Chapman et al. 1949), which is commonly used to digest silicate matrices. Previous studies have employed several strategies to address this issue. The method used by Rouxel et al. (2006) involved the dissolution of siliceous rocks in concentrated HF without the critical evaporation step. In short, the sample in powder form was first reacted with concentrated $\mathrm{HNO}_{3}$ and taken to dryness on hot plate. Total digestion was then achieved using concentrated HF and the solution, along with precipitates, was diluted with water to obtain a solution of $\sim 1 \mathrm{M} \mathrm{HF}$. Insoluble fluorides, containing mostly $\mathrm{Ca}, \mathrm{Mg}$ and $\mathrm{Al}$ and various trace elements (Yokoyama et al. 1999) were separated from the solution by centrifugation. The method used by Siebert et al. (2006) followed standard rock digestions techniques (i.e., mixture of concentrated $\mathrm{HF}$ and $\mathrm{HNO}_{3}$ ) digestion with the modification of having added double spike to the sample before digestion and evaporation. Luais (2012) used the approach of Ishikawa and Nakamura et al. (1990) for the purification of volatile boron, that consists of dissolving the sample powder in concentrated $\mathrm{HF}+\mathrm{HNO}_{3}$ on hot plate at $60^{\circ} \mathrm{C}$, until obtaining a white solution free of any visible particles. The solution was then centrifuged, and the supernatant containing Ge was transferred to another Teflon beaker. Complete Ge extraction from the residual fluorides was achieved through three HF-leaching/centrifugation steps, and then evaporation to dryness at temperatures between 60 and $65^{\circ} \mathrm{C}$ of all supernatant fractions. Luais (2012) evaluated in more detail the potential loss of $\mathrm{Ge}$ during $\mathrm{HF}$ digestion. It was found that Ge is quantitatively recovered after evaporation in $\mathrm{HNO}_{3}-\mathrm{HF}$ acid mixture, suggesting that no $\mathrm{Ge}$ is lost as $\mathrm{GeF}_{4}$ species at temperatures between 60 and $65^{\circ} \mathrm{C}$. This confirmed that higher temperatures (i.e. up to $300^{\circ} \mathrm{C}$ ) are needed to evaporate $\mathrm{GeF}_{4}$ (Kwasnik 1963). Finally, considering the organophile behavior of $\mathrm{Ge}$, Ge isotope analysis of organic-rich rocks, such as coal and black shales, should also involve the complete breakdown of organic matter. To address this issue, Qi et al. (2011) compared two techniques, one involving repeated evaporation of lignite samples with concentrated $\mathrm{HNO}_{3}$, and the other involving sample powder ashing at $600{ }^{\circ} \mathrm{C}$ for $24 \mathrm{~h}$ in a muffle furnace. Both methods yielded similar Ge concentrations and isotope compositions, suggesting that $\mathrm{Ge}$ does not form volatile species upon ashing. 


\section{Chemical purification of samples}

Before undertaking isotopic analysis by MC-ICPMS, it is customary to separate the analyte from (i) isobaric elements that can potentially interfere with the analysis and (ii) matrix elements that can affect the mass bias on the mass spectrometer and can form complex compounds that can also interfere with the element of interest. To achieve this goal, ion exchange chromatography provides the most versatile and convenient technique. Luais $(2000,2003,2007)$ adapted the method of Xue et al. (1997) and used cation exchange resin for the separation of Ge from metallic and sulfide matrices in diluted $\mathrm{HNO}_{3}$ medium. Sample solution in $0.5 \mathrm{~mL}$ of $0.5 \mathrm{M} \mathrm{HNO}$ was loaded onto $2 \mathrm{~mL}$ of AG50W$\mathrm{X} 8$ cationic resin. The extremely low partition coefficient for Ge (occurring as oxyanion) with $0.5 \mathrm{M}$ $\mathrm{HNO}_{3}$ allows the elution of Ge whereas all the matrix elements (occurring as cations) remain absorbed on the resin. Rouxel et al. (2006) reported a comprehensive chromatography method that is applicable to a range of geological samples and is summarized below:

(1) Samples are dissolved as described above such that a solution of Ge in a matrix of $1 \mathrm{M} \mathrm{HF}$ is obtained. The ion exchange resin AG1-X8 (Biorad, Hercules, Ca, USA) is loaded into polypropylene columns $(1.8 \mathrm{~mL}$ wet volume) and conditioned with repeated elution with $1 \mathrm{M} \mathrm{HF}$, $1.4 \mathrm{M} \mathrm{HNO}_{3}$ and mmQ water. The sample in $1 \mathrm{M} \mathrm{HF}$ is then loaded on the column which allows the binding of $\mathrm{Ge}$ to the resin in the form of $\left(\mathrm{GeF}_{6}\right)^{2-}$.

(2) Ge is eluted with diluted $\mathrm{HNO}_{3}$ (between $1.4 \mathrm{M}$ and $0.28 \mathrm{M}$ ) and the solution is dried down on hot plate and redissolved in $0.28 \mathrm{M} \mathrm{HNO}_{3}$.

(3) Although Ge may be further purified through cation-exchange resin as described in Rouxel et al. (2006) and Luais $(2000 ; 2003,2007,2012)$, it is possible to directly analyze the solution after step (2) only if the measurements by MC-ICPMS employ the hydride generation technique. However, because As may be partially eluted together with Ge and could form volatile hydrides, care should be taken to monitor potential isobaric interference from ${ }^{75} \mathrm{AsH}^{+}$on ${ }^{76} \mathrm{Ge}^{+}$when analyzed by MC-ICPMS.

Guillermic et al. (2016) recently reported a preconcentration method for the analysis of Ge isotope compositions of inorganic $\mathrm{Ge}$ in seawater. Germanium was co-precipitated with iron hydroxide with a yield better than $\sim 70 \%$. Germanium isotopic measurements were performed using a double-spike approach and a hydride generation system coupled to a MC-ICPMS modified from previous methods used for rock analysis (Rouxel et al. 2006; Escoube et al. 2012). An anion exchange resin was used to further purify $\mathrm{Ge}$ from $\mathrm{Fe}$ and remove potential matrix elements interfering with $\mathrm{Ge}$ hydride generation. Variations in ${ }^{74} \mathrm{Ge} /{ }^{70} \mathrm{Ge}$ ratios were obtained with an external reproducibility better than $0.2 \%$ ( 2 s.d.). Analytical accuracy was demonstrated using a standard addition method using internal seawater standard. Overall, the analytical method requires minimum Ge amounts of about 2.6 $\mathrm{ng}$, which is sufficient to measure the isotopic composition of inorganic Ge in surface seawater. 


\section{Hydride generation (HG) MC-ICPMS}

The generation of volatile metalloid hydride has long been the most suitable technique for online separation and speciation of ng to pg amounts of Ge, As, Se, Sb, and Sn (Dedina and Tsalev 1995). This method involves the reduction of the element in solution to volatile hydride species using strong reducing agent, such as $\mathrm{NaBH}_{4}$, generating $\mathrm{H}_{2}$ upon mixing with acidified sample solution. The separation of the evolved gas and remaining solution is performed using a Hydride Generation (HG) system (Figure 1). The continuous flow HG system has been successfully applied for the highprecision analysis of $\mathrm{Ge}$, Se and $\mathrm{Sb}$ isotopes (Rouxel et al. 2002; Rouxel et al. 2003a; LaytonMatthews et al. 2006; Rouxel et al. 2006; Zhu et al. 2008). Instrumental mass bias is generally corrected using either the "standard-sample bracketing" or the double-spike method. Important advantages of the use of HG-MC-ICPMS are: (1) higher sensitivity, lowering the total amount of element required for one analysis down to $10 \mathrm{ng}$ or less; (2) further separation of the analyte from its matrix, removing potential isobaric interferences (e.g., Zn). As already applied for $\mathrm{Hg}$ isotope analysis (Epov et al. 2008), it is possible to further increase detection limits through the preconcentration of Ge hydrides using either gas chromatography or cold trapping, as done in the past for low level determination of Ge species in seawater (Andreae and Froelich 1981; Hambrick et al. 1984). This new development would also permit the possibility for compound-specific Ge isotope analysis with important prospects for the study of natural environments.

\section{Interference issues}

Germanium isotope measurements by MC-ICPMS suffer from molecular interferences, such as ${ }^{35} \mathrm{Cl}^{35} \mathrm{Cl}$ on ${ }^{70} \mathrm{Ge} ;{ }^{40} \mathrm{Ar}^{16} \mathrm{O}_{2}$ and ${ }^{36} \mathrm{Ar}^{36} \mathrm{Ar}$ on ${ }^{72} \mathrm{Ge},{ }^{58} \mathrm{Ni}^{16} \mathrm{O}$ and ${ }^{38} \mathrm{Ar}^{36} \mathrm{Ar}$ on ${ }^{74} \mathrm{Ge}$ and ${ }^{38} \mathrm{Ar}^{38} \mathrm{Ar}$ and ${ }^{36} \mathrm{Ar}{ }^{40} \mathrm{Ar}$ on ${ }^{76} \mathrm{Ge}$, in addition to isobaric interferences of ${ }^{70} \mathrm{Zn}$ on ${ }^{70} \mathrm{Ge}$. The chemical purification step and hydride generation technique may remove some of these interferences, but it is clear that Ge isotopes overlap with a range of Ar-based interferences. However, it appears that all Ge isotopes, except ${ }^{76} \mathrm{Ge}$, can be measured without significant correction for interferences (Galy et al. 2001; Rouxel et al. 2006; Luais 2007). Hexapole-collision cell techniques together with soft extraction mode (Isoprobe instruments) have been also successful in eliminating argide interferences, using appropriate $\mathrm{H}_{2}$ and Ar fluxes in the collision cell (Luais 2007, 2012). Recently, analytical developments at medium mass resolution $(\mathrm{M} / \Delta \mathrm{M}=6000$, NeptunePlus $)$ consist of Ge isotope measurements on the left part of the Ge spectrum free of any interferences (El Korh et al., 2014, 2016). Since Zn is a ubiquitous source of contamination in laboratory materials, corrections for ${ }^{70} \mathrm{Zn}$ on ${ }^{70} \mathrm{Ge}$ are always recommended. Luais $(2007,2012)$ showed that a mixture of $25 \mathrm{ppb}$ of $\mathrm{Zn}+1 \mathrm{ppm}$ Ge in solution increases the $\delta^{74 / 70} \mathrm{Ge}$ ratios by at least $1 \%$.

\section{Notation}

Germanium isotope composition can be reported using several possible notations, such as: 


$$
\delta^{x / y} G e_{S T D}(\%)=\left(\frac{\left({ }^{x} G e l^{y} G e\right)_{\text {sample }}}{\left({ }^{x} G e l^{y} G e\right)_{S T D}}-1\right) \times 1000
$$

Where $\mathrm{x}=74,73$ or $72 ; \mathrm{y}=70$ or 72 and STD corresponds to the normalization to Gestandard. Currently, there is no consensus in the way to report Ge-isotope ratios. Siebert et al. (2006) reported $\delta^{74 / 72} \mathrm{Ge}$ when using a double spike with ${ }^{73} \mathrm{Ge}$ and ${ }^{70} \mathrm{Ge}$ to correct for mass bias. Galy et al. (2003) reported $\delta$ Ge per mass unit while Rouxel et al. (2006), Escoube et al. (2012) and Luais (2007) reported $\delta^{74 / 70} \mathrm{Ge}$ (together with $\delta^{73 / 70} \mathrm{Ge}$ and $\delta^{72 / 70} \mathrm{Ge}$ ). Due to larger abundances and minor isobaric interferences, ${ }^{74} \mathrm{Ge} /{ }^{70} \mathrm{Ge}$ ratio seems to be optimum for reporting Ge-isotopes. In order to improve interlaboratory comparisons, Ge isotope ratios should be reported as $\delta^{74 / 70} \mathrm{Ge}$ values relative to SRM3120a which is a Ge concentration standard produced in large amount by NIST and readily available.

\section{Analytical precision}

In the following, the analytical precision of the Ge isotope measurement is defined as the $2 \sigma$ (s.d.) of $\mathrm{n}$ replicate measurements of the same standard solution prepared repeatably and measured over several analytical sessions. This is distinct from the 'internal precision' which is a standard error generated by the instrument for a single isotope ratio measurement. The 'external precision' is determined as the standard deviation ( 2 s.d.) of $\mathrm{n}$ replicate measurements of the same sample (e.g., georeference material) processed through the entire chemical procedure. In general, the 'analytical' precision is dependent on the instrumental mass bias correction scheme. Instrumental mass bias may be corrected using several techniques:

(1) The sample-standard bracketing (referred as SSB) technique involves the measurement of a Ge standard solution, before and after each unknown sample (Galy et al. 2003; Rouxel et al. 2006). In general, individual Ge isotope analysis corresponds to the mean of up to three replicate measurements of individual bracketed samples. Standard and sample solutions should be also analyzed within $10 \%$ of the same concentration and carefully rinsed to avoid cross contamination. For routine analysis, Rouxel et al. (2006) used Ge concentrations ranging from 10 to $50 \mathrm{ppb}$, and obtained an overall precision of about $0.14 \%, 0.13 \%$ and $0.09 \%$ for $\delta^{74 / 70} \mathrm{Ge}, \delta^{73 / 70} \mathrm{Ge}$ and $\delta^{72 / 70} \mathrm{Ge}$, respectively (84 duplicates). The quantity of Ge used per analysis was between 15 and $150 \mathrm{ng}$. Compared to a previous investigation using the desolvation system (Galy et al., 2003), the HG technique requires a tenth of the Ge with a similar long-term reproducibility.

(2) The external normalization method involves using $\mathrm{Ga}$ isotopes (or $\mathrm{Cu}$ isotopes) (Hirata 1997; Galy et al. 2003; Siebert et al. 2006; Luais 2007) to monitor instrumental mass bias. The choice of $\mathrm{Ga}$ is based on several criteria, namely that mass 69 and 71 of Ga are within Ge masses (mass 70 to mass 76), the absence of any interferences on Ga masses, and the availability of an international isotopic Ga standard, the NBS SRM $994 \mathrm{Ga}$ reference international isotopic standard having ${ }^{69} \mathrm{Ga} /{ }^{71} \mathrm{Ga}=1.50676$ (Machlan et al. 1986). The long-term reproducibility on the first generation $\mathrm{Nu}$ 
Plasma instruments (Galy et al., 2003) has been evaluated to be better than $0.06 \%$ amu ( 2 s.d.) for 1 $\mu \mathrm{g}$ Ge (i.e., equivalent to $0.24 \%$ for $\delta^{74 / 70} \mathrm{Ge}$ ). A similar level of reproducibility, but for only $100 \mathrm{ppb}$ of $\mathrm{Ge}$, has been obtained when using the new generation of MC-ICPMS (Hexapole collision cell Isoprobe, Luais, 2007, 2012, and high resolution Neptune Plus, El Korh et al. 2014, 2016). Luais (2012) evaluated several mass bias correction schemes on the reproducibility of Ge isotope measurements: the SSB method as described above; the external correction method using Ga and assuming identical instrumental mass bias isotopic fractionation factors for $\mathrm{Ga}$ and $\mathrm{Ge}$ (defined as $f \mathrm{Ga}$ and $f \mathrm{Ge}$ respectively); and the regression method implying $f \mathrm{Ga} \neq f \mathrm{Ge}$ but constant $f \mathrm{Ga} / f \mathrm{Ge}$, which is similar to the method previously used for $\mathrm{Cu}$ and $\mathrm{Zn}$ isotope measurements by Maréchal et al. (1999). The later method implies external data reduction to evaluate the accuracy of the measurements that are quantified on the basis of excellent regression lines $\left(\mathrm{r}^{2}>0.99\right)$ and similar slopes in the $\mathrm{Ln}\left({ }^{71} \mathrm{Ga} /{ }^{69} \mathrm{Ga}\right)_{\text {measured }}-\mathrm{Ln}\left({ }^{\mathrm{x}} \mathrm{Ge} /{ }^{70} \mathrm{Ge}\right)_{\text {measured }}$ diagram. These three methods have been applied to the JMC and Aldrich Ge reference standards and on several iron meteorite samples, and they were found to be in excellent agreement (Luais, 2012) confirming the robustness of Ga mass fractionation correction for Ge isotopic measurements.

(3) The double spike (referred as DS) correction involves determining simultaneously the instrumental mass bias and natural fractionation factors. The double spike method can be visualized as a three-dimensional diagram where axes represent the three measured isotopic ratios. Line and plane intercepts, defined by isotopic compositions of the double spike, standard solution and unknown sample measured by MC-ICPMS, are used to determine fractionation factors between the measured and corrected isotopic ratios (Siebert et al. 2001; Albarede and Beard 2004). Previous studies have used a double spike prepared from ${ }^{73} \mathrm{Ge}$ and ${ }^{70} \mathrm{Ge}$ spikes and mixed in equal proportions with natural Ge (Siebert et al. 2006; Escoube et al. 2012) (Table 1). The analytical precision reported by Escoube et al. (2012) for $\delta^{74 / 70} \mathrm{Ge}$ was about $0.15 \%$ (2s.d.) over a spike/natural ratio between 0.8 and 3.5 and for $10 \mathrm{ng}$ sample size.

\section{Ge isotope standards and reference materials}

Germanium standards used in previous studies include NIST3120a (Lot \#000411, 1000 $\mu \mathrm{g} / \mathrm{g}$, Escoube et al. 2012); Spex (Lot \#11-160GE, Escoube et al. 2012); Aldrich (Lot \#01704KZ, Luais et al., 2000, Luais 2007), JMC (Johnson Mattey, Karlsruhe, Lot \# 301230Sn, Luais et al. 2007) and Aristar (same split used in Rouxel et al. 2006, but incorrectly reported as Aldrich standard solution). The average compositions of $\mathrm{Ge}$ isotope standards for different instrumental set-up and research groups are reported in Table 2. 'Aristar' and 'Spex' solutions showed an enrichment in the light isotope in approximately the same proportion $\left(\delta^{74 / 70} \mathrm{Ge}=-0.64 \pm 0.09 \%\right.$ and $-0.71 \pm 0.10 \%$ respectively $)$. The 'JMC' standard also presented light Ge isotope values, with a $\delta^{74 / 70} \mathrm{Ge}$ value of $-0.32 \pm 0.05 \%$. The 'Aldrich' standard showed the lightest $\delta^{74 / 70} \mathrm{Ge}$ values at $-2.01 \pm 0.11 \%$. Several sample introduction 
systems were tested, using either cyclonic spray chamber (CSC) and hydride generation (HG) for different instruments (Neptune, $\mathrm{Nu}$ plasma or Isoprobe), and no systematic differences were found (Table 2). It is also important to note that standard-sample bracketing, Ga normalization and doublespike corrections yielded similar results, both in terms of accuracy and precision.

Several georeference materials were also analyzed in previous studies allowing interlaboratory comparisons (Rouxel et al. 2006; Qi et al. 2011; Siebert et al. 2011a; Escoube et al. 2012; Luais 2012). Those include the following standards: AN-G (anorthosite, Fiskenaesset, Western Greenland), BCR-1 (basalt, Columbia River group USA), BE-N (basalt, Essey-la-Côte, Nancy, France), BHVO-2 (hawaiian basalt), BIR-1 (icelandic basalt), CLB-1 (Lower Bakerstown coal), DNC-1 (Braggtown dolerite, North Carolina, USA), DTS-1 (dunite, Hamilton, Washington), G-2 (granite, Rhode Island USA), GH (granite, Hoggar, Algeria), GLO (glauconite, Normandy France), IF-G (iron formation, West Greenland), Nod-P1 (manganese nodule, Deep Pacific Ocean), PCC-1 (peridotite, a partially serpentinized harzburgite, California USA), SDO-1 (Devonian black shale, Ohio Shale near Morehead, Kentucky), and UB-N (serpentine, Col des Bagenelles, Vosges, France). A compilation of published and unpublished values for these georeference materials is reported in Table 3.

The average $\delta^{74 / 70} \mathrm{Ge}$ value of basaltic rocks (BHVO-1\&2; BIR-1; BCR-1\&2, BE-N) is clustered at $0.56 \pm 0.08 \%$ (2s.d.). Granitic rocks displayed significant heterogeneity with $\delta^{74 / 70} \mathrm{Ge}$ ranging from 0.4 to $0.8 \%$ and ultramafic rocks, although less concentrated in Ge, presented similar composition as granitic and basaltic rocks. We observe that NIST3120a is the standard whose isotope composition is the closest to natural composition compared to other standard solutions used previously. Iron formation IF-G and marine sediment GL-O yielded heavier $\delta^{74 / 70} \mathrm{Ge}$ values at $1.03 \%$ $( \pm 0.1,2$ s.d. $)$ and $2.44 \%( \pm 0.14,2$ s.d. $)$ respectively.

\section{THEORETICAL CONSIDERATIONS AND EXPERIMENTAL CALIBRATIONS}

\section{Equilibrium fractionation factors}

Li et al. $(2009,2010)$ provided a thorough theoretical quantification of $\mathrm{Ge}$ isotopic equilibrium fractionation between aqueous fluids, mineral phases, and organic compounds. The theoretical quantification of $\mathrm{Ge}$ isotopic fractionation is based on the Bigeleisen-Mayer equation that considers isotope exchange reaction between two components $\mathrm{A}$ and $\mathrm{B}$ :

$\mathrm{A}+\mathrm{B}^{*} \Leftrightarrow \mathrm{A}^{*}+\mathrm{B}$

The isotopic fractionation factor $\alpha$ is defined as a function of the isotope equilibrium constant $\mathrm{K}_{\mathrm{eq}}$ of the exchange reaction (2), with $\alpha=\mathrm{K}^{1 / n}, n$ equal to the number of each exchanged atom. Li et al. (2009) used $n=1$ for the calculation of $\alpha$ values for different Ge species. Because $\mathrm{K}_{\mathrm{eq}}$ is a function 
of inverse temperature, the isotopic fractionation factor $\alpha$ depends on the temperature of equilibrium between the two phases. The isotopic fractionation factor $\alpha$ is calculated using the reduced partition function ratio (RPFR) or $\beta$-factor for each molecule, mainly taking into account the differences in vibrational energies $\left(\Delta F_{\text {motion }}\right)$ between molecules, such as:

$$
\begin{aligned}
\Delta G_{\text {reaction }}^{\circ} & \approx \Delta F_{\text {motion }}=-R T \ln \left(K_{\text {eq }}\right) \\
K_{\text {eq }} & =\exp \left(\frac{-\Delta F_{\text {motion }}}{R T}\right)=\frac{R P F R(A)}{\operatorname{RPFR}(B)}
\end{aligned}
$$

RPFR values are calculated using ab initio quantum chemistry method that allows computing harmonic vibrational frequencies.

\section{Silicate-fluid equilibrium reaction.}

Li et al. (2009) determined RPFR values for silicate minerals (quartz, albite, K-felsdpar, olivine) and aqueous Ge species. They found a negative correlation between RPFR and Ge-O bond lengths. This enrichment of heavier isotopes in components with shorter Ge-O lengths is in line with the principles of isotopic fractionation given by Schauble (2004). Using equation (4), $K \approx \alpha$, and the relation $1000 \ln \alpha=\Delta_{\mathrm{A}-\mathrm{B}}=\mathrm{A} * 10^{6} / \mathrm{T}^{2}+\mathrm{B}$, the isotopic fractionation $\Delta_{\mathrm{A}-\mathrm{B}}$ between silicate and aqueous species are calculated. Two important conclusions can be drawn from these calculations: (i) The isotopic fractionation between silicate minerals and aqueous fluids indicates that a fluid in equilibrium with olivine should be isotopically heavier than the solid, while fluids in equilibrium with Na-feldspar (albite), K-feldspar, quartz should be isotopically lighter than the solids. Such results may explain the elevated $\delta^{74} \mathrm{Ge}$ of serpentine compared to unaltered ultramafic rocks and basalts (Luais, 2012). (ii) The isotopic fractionation between crust-forming minerals (e.g. quartz-feldspar) and aqueous fluids leads to light isotopic signatures in the fluids. This would predict that the isotopic composition of rivers could be light, although recent studies suggest heavier Ge isotope composition in rivers compared to the crust (Baronas et al. 2014).

\section{Sulfide-fluid equilibrium reaction.}

Li et al. (2009) gave preliminary Ge isotope fractionation factors $\Delta^{74 / 70} \mathrm{Ge}_{\text {fluid-sulfide }}$ at $25^{\circ} \mathrm{C}$ for Ge-bearing sulfides having sphalerite-like structures. The calculated Ge isotopic fractionation factors $\left(\Delta^{74 / 70} \mathrm{Ge}_{\text {fluid-sulfide }}\right.$ at $\left.25^{\circ} \mathrm{C}\right)$ of +12.2 to $+11.5 \%$ for $\mathrm{Ge}$ (II) and $+11.4 \%$ for $\mathrm{Ge}$ (IV) clusters give an important estimation of the direction and the magnitude of Ge isotopic fractionation, with low $\delta^{74 / 70} \mathrm{Ge}$ in sulfide in equilibrium with heavy isotope-enriched fluids. No quantification of A and B parameters are given at this stage of the study that could be useful for modelling sulfide isotopic composition from high-T hydrothermal fluids. A first approximation for $\mathrm{T}$ determination can however be possible by extracting the $\alpha$ and A parameter values at $25^{\circ} \mathrm{C}$, considering a negligible value for $\mathrm{B}$. 


\section{Adsorption processes.}

$\mathrm{Li}$ and $\mathrm{Liu}$ (2010) calculated $\mathrm{Ge}$ isotopic fractionation factors during adsorption on Feoxides/hydroxides. The calculation was based on cluster models of two main surface structure complexes of $>\mathrm{Fe}_{2} \mathrm{O}_{\mathrm{n}} \mathrm{Ge}(\mathrm{OH})_{4-\mathrm{n}}$ and $>\mathrm{Fe}_{2} \mathrm{O}_{\mathrm{n}} \mathrm{GeO}(\mathrm{OH})^{-}{ }_{3-\mathrm{n}}$, corresponding to adsorption of either $\mathrm{Ge}(\mathrm{OH})_{4}$ or $\mathrm{GeO}(\mathrm{OH})_{3}{ }^{-}$species under acidic or basic conditions, respectively. Each surface complex presents specific geometries in term of $\mathrm{Ge}-\mathrm{O}, \mathrm{Fe}-\mathrm{Fe}, \mathrm{Ge}-\mathrm{Fe}$ bond lengths, with $\mathrm{Ge}$ remaining in tetrahedral coordination. It is assumed that Ge occurs in tetrahedral coordination and bonded to two corners of adjacent octahedral Fe, consistent with the EXAFS (Extended X-ray Absorption Fine Structure) spectroscopy measurements of Pokrovsky et al. (2006). The equilibrium Ge isotopic fractionation in term of calculated $\mathrm{RPFR} \approx \alpha$ values gave 1.02214 and 1.02149 for $\mathrm{Ge}(\mathrm{OH})_{4}$ aq and $\mathrm{GeO}(\mathrm{OH})_{3}{ }^{-}$aq respectively, which translates into a solid-solution fractionation factor $\Delta^{74 / 70} \mathrm{Ge}$ of $1.7 \%$ and $-1.6 \%$ for $>\mathrm{Fe}_{2} \mathrm{O}_{2} \mathrm{Ge}(\mathrm{OH})_{2}(2 \mathrm{C})(\mathrm{aq})-\mathrm{Ge}(\mathrm{OH})_{4}(\mathrm{aq})$ and $>\mathrm{Fe}_{2} \mathrm{O}_{2} \mathrm{GeOOH}^{-}(2 \mathrm{C})(\mathrm{aq})-$ $\mathrm{GeO}(\mathrm{OH})_{3}-(\mathrm{aq})$, respectively. Hence, adsorption onto Fe-oxide and Fe-hydroxide surfaces preferentially favors the light Ge isotopes, yielding a fluid with heavier isotope composition. The A, B parameters in the equation $1000 \ln \alpha=\Delta_{\mathrm{A}-\mathrm{B}}=\mathrm{A} * 10^{6} / \mathrm{T}^{2}+\mathrm{B}$ provide quantitative tools for modelling the isotopic fractionation in terms of temperature of equilibration between Ge in solution and adsorbed Ge.

Quantification of $\mathrm{Ge}$ isotopic fractionation during adsorption processes has been further confirmed by the adsorption and co-precipitation experiments of Pokrovsky et al. (2014). These authors show that $\mathrm{Ge}(\mathrm{OH})_{4}(\mathrm{aq})$ adsorption on goethite surface forms $>\left(\mathrm{FeO}-\mathrm{Ge}(\mathrm{OH})_{3}{ }^{\circ} \mathrm{aq}\right)$ or $>(\mathrm{FeO}-$ $\left.\mathrm{Ge}(\mathrm{OH})_{2}{ }^{-}\right)$complexes in acid or alkaline solutions, respectively, and induces a solid-solution isotopic fractionation factor $\Delta^{74 / 70} \mathrm{Ge}$ of $-1.7 \pm 0.1 \%$. The light Ge isotopic compositions on the surface of $\mathrm{Fe}$ oxy(hydr)oxides is due to changes in the atomic environment of Ge during adsorption-co-precipitation process that increases the distortion and disorder of the complex formed with longer Ge-O bonds, and consequently decreases their stability. In addition, Ge coprecipitation with Fe-oxy(hydr)oxides implies $\mathrm{Fe}^{2+}$ oxidation or $\mathrm{Fe}^{3+}$ hydrolysis. The $\mathrm{Ge} / \mathrm{Fe}$ ratio of the precipitated solid will then have a major role on the Fe-oxy(hydr)oxides crystalline structure, and lattice parameters. The X-ray spectroscopy results of Pokrovsky et al. (2006) showed that Ge-Fe complexes with $(\mathrm{Ge} / \mathrm{Fe})_{\text {solid }}<0.1$ is composed of both tetrahedrally coordinated Ge, and octahedrally coordinated $\mathrm{Ge}$ that occurs in substitution with octahedral Fe (Pokrovsky et al., 2006). The configuration of $\mathrm{GeO}_{6}$ has longer $\mathrm{Ge}-\mathrm{O}$ bond lengths and

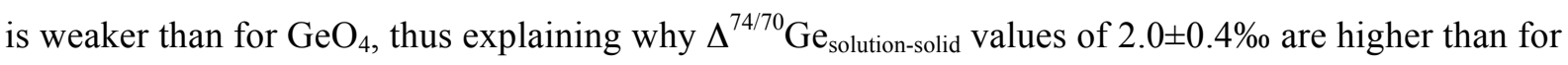
adsorption processes.

\section{Kinetic processes}

Isotopic kinetic processes relate to the unidirectional movement of isotopes of a given element from one phase into another one. Kinetic processes describe either diffusion between two components of contrasted elemental end isotopic compositions, or evaporation-condensation during high- or low- 
temperature processes. Kinetic isotope fractionation is essentially mass-dependant. According to the kinetic theory of gases, all molecules at the same temperature have the same energy KE, which depends on their mass and velocities: $\mathrm{KE}=1 / 2 \mathrm{mv}^{2}$. Consequently for two isotopes 1 and 2 of mass $\mathrm{m}$ with similar kinetic energy,

$$
\begin{aligned}
\mathrm{KE} & =1 / 2 m_{1} v_{1}=1 / 2 m_{2} v_{2} \\
\Rightarrow & \frac{v_{1}}{v_{2}}=\sqrt{\frac{m_{2}}{m_{1}}}
\end{aligned}
$$

If $\mathrm{m}_{2}>\mathrm{m}_{1}$, then $\mathrm{v}_{2}<\mathrm{v}_{l}$ suggesting that light isotopes will have higher velocities than heavy isotopes. As a result, during diffusion, light isotopes will migrate faster toward the low concentration region than heavy isotopes. Similarly, during evaporation processes, light isotopes will be lost preferentially to the vapor phase, leaving a residue that is enriched in heavy isotopes.

\section{Diffusion of Ge in silicate melts.}

Jambon (1980) established the law for diffusion between two isotopes of mass $m_{1}$ and $m_{2}$ and diffusion coefficient $\mathrm{D}_{1}$ and $\mathrm{D}_{2}$, of a given element, and Richter et al. (1999) defined the relative diffusivities between isotopes as:

$$
\mathrm{D}_{\text {rel }}=\left(\mathrm{D}_{1} / \mathrm{D}_{2}\right)=\left(m_{2} / m_{1}\right){ }^{\beta}
$$

The isotopic fractionation depends on the relative mass difference between two isotopes, and of $\beta$ factor, that is determined from experiments. As $\beta$ values $>0$, light isotopes will have higher diffusion coefficient (D) than heavy isotopes, and will migrate faster than heavy isotopes. Experimentally determined $\beta$ values are in general lower than $1 / 2$. Low value for $\beta$ also reflects the factor that the diffusing molecules are likely to have greater masses than unbonded isotopes (Davis and Richter, 2007). Richter et al. (1999) has shown that isotopic diffusion is not only mass-dependent, but also relies on concentration and isotopic contrasts between the two components. They experimentally studied the isotopic fractionation of Ge by diffusion between synthetic $\mathrm{GeO}_{2}$ melts of contrasting composition, as an analog for $\mathrm{Si}$ diffusion in silicate melts. Germanium isotopic interdiffusion was reported on synthetic $\mathrm{GeO}_{2}$ melts artificially enriched in specific Ge isotopes. The experimental design was to create two end-members with similar ${ }^{76} \mathrm{Ge} /{ }^{70} \mathrm{Ge}$ but very different ${ }^{74} \mathrm{Ge} /{ }^{70} \mathrm{Ge}$ allowing an evaluation of the mass differences and isotope concentration contrast on diffusion. The theoretical diffusion profiles indicated an isotopic mobility as inferred from a marked difference between ${ }^{74} \mathrm{Ge}$ profile, and ${ }^{70} \mathrm{Ge}-{ }^{76} \mathrm{Ge}$ profiles (Figure 2). A subtle isotopic fractionation in ${ }^{76} \mathrm{Ge} /{ }^{70} \mathrm{Ge}$ ratio along the diffusion profile would indicate faster diffusion of ${ }^{70} \mathrm{Ge}$ compared to ${ }^{76} \mathrm{Ge}$ (Figure 2). $\beta$ factors between 0.5 and 0.1 were considered. Laboratory experiments were performed on these $\mathrm{GeO}_{2}$ melts for $3 \mathrm{~h}$ at $1400^{\circ} \mathrm{C}$ and $0.5 \mathrm{GPa}$. The ${ }^{74} \mathrm{Ge} /{ }^{70} \mathrm{Ge}$ diffusion profiles measured by ion microprobe techniques are best fit with $\beta$ values $<0.025$, indicating much lower isotopic fractionation for diffusion than prediction based on the simple ratios of isotopic masses. 


\section{Diffusion of Ge in metal}

Several studies reported the diffusion of Ge in metal or Ge-Si alloys with important application to metallurgy and semi-conductor technologies (McVay and DuCharme 1974; Pike et al. 1974; Vogel et al. 1983). They concluded that Ge diffusion occurs through a lattice vacancy mechanism. In general, isotope diffusion in metal is higher than between silicate melts, as it occurs at lower temperature. Richter et al. (2009) determined $\beta$ values ranging from 0 to 0.4 , regardless of the element, temperature and diffusion type (self-diffusion, or between metal phases). Germanium isotope fractionation for selfdiffusion in Ge metal (Campbell 1975), and Ge diffusion in $\mathrm{Cu}$ metal (Hehenkamp et al. 1979) were determined using radioactive experiments. Quantification of $\beta$ values from these experiments indicate significantly higher $\beta$ values in metal than in silicate melts:

$$
\beta_{\mathrm{Ge}} \text { silicate }<0.025<<\beta_{\mathrm{Ge}} \mathrm{Ge}=0.127 \text { (self-diffusion) }<\beta_{\mathrm{Ge}} \mathrm{Cu}=0.215 \text { (Ge diffusion in } \mathrm{Cu} \text { ) }
$$

Diffusion can be an important mechanism constraining the elemental distribution of Ge between the taenite and kamacite phases of iron meteorites. The isotopic effect between these two phases, for example in taenite-kamacite forming Widsmanstätten textures remains unknown. At the bulk scale, kamacite only bearing Fe-meteorites $(\mathrm{Ni} \%<6 \%)$ or taenite-kamacite bearing Fe-meteorites ( $\mathrm{Ni} \%>6 \%)$ have similar Ge isotope composition (Luais, 2007, 2012), indicating that diffusion does not contribute to the whole isotopic signature of iron meteorites.

\section{Diffusion and evaporation processes between metal and silicate.}

Germanium is a moderately siderophile and thus has a large metal-silicate partition coefficient $\left(\mathrm{D}_{\mathrm{Ge}}\right)$ between 10 and $10^{4}$. It is strongly dependant on thermodynamic parameters $\left(f \mathrm{O}_{2}, \mathrm{P}, \mathrm{T}\right)$. The effect of oxygen fugacity is dominant, with variations in $\mathrm{D}_{\mathrm{Ge}}$ metal-silicate increasing as a factor 30 with reducing conditions of $3 \log f \mathrm{O}_{2}$ units (Schmitt et al. 1989). Germanium is volatile at high temperature, with a condensation temperature $\mathrm{T}_{\text {cond }}$ of $883^{\circ} \mathrm{C}$ at $10^{-4}$ bar (Lodders et al. 2009), corresponding to the temperature at which $50 \%$ of the element is in the condensed phase. Both diffusion and evaporation can induce elemental and isotopic fractionation during high temperature processes. The quantification of Ge isotopic fractionation during partitioning and evaporation are fundamental for understanding the thermodynamic conditions $\left(f \mathrm{O}_{2}, \mathrm{P}, \mathrm{T}\right)$ of core formation and accretion processes in the early history of the Earth and planets.

Laboratory experiments of $\mathrm{Ge}$ isotopic fractionation between metal and silicate phases have been undertaken at $1355^{\circ} \mathrm{C}$ under various $\mathrm{fO}_{2}(-4$ to $+2.5 \log$ units above IW buffer $)$ to simulate the $\mathrm{Ge}$ transfer from the oxidized silicate phase to a metal, and at different times (up to 60h) to evaluate the effect of chemical and isotopic re-equilibration between phases (Luais et al. 2007). The initial experimental set-up consisted of a pure Ni-capsule and a synthetic silicate phase of eutectic CMAS composition, doped with Ge Aldrich standard solution. Preliminary results showed a negative exponential fit of Ge content with $\mathrm{Ge}$ isotopic composition for both $f \mathrm{O}_{2}$-controlled and time series experiments that highlight two concomitant processes (Luais et al., 2007) : 
(i) very reducing conditions (IW-4) or short time duration both result in high Ge content and small enrichment in light isotopes $(-0.3 \%)$ in the metal phase, relative to the initial composition. This direction of isotope fractionation is in line with theoretical fractionation for diffusion, with preferential movement of light isotopes from the enriched Ge pole (silicate) toward the depleted pole (pure Ni capsule).

(ii) the progressive increase in $f \mathrm{O}_{2}$ (i.e. mildly reducing to oxidizing conditions) or longer time experiments produced strong depletion in $\mathrm{Ge}$ in the metal phase, associated with an exponential increase in $\delta{ }^{74 / 70} \mathrm{Ge}$ values, that can reach $+7 \%$ in the most oxidized conditions. These heavy isotope compositions are indicative of Ge loss due to evaporation.

Future experiments should be devoted to deconvoluting these two processes and to provide parameters for quantification of $\mathrm{Ge}$ isotopic fractionation in natural samples.

\section{Evaporation processes in environmental and industrial technologies}

The organophile behavior of Ge leads to significant enrichments in coal and lignite. Considering the melting point temperature of metal $\mathrm{Ge}$ of $937^{\circ} \mathrm{C}$, coal combustion may represent an important source of $\mathrm{Ge}$ in the environment (Froelich and Lesley 2003). In order to investigate possible Ge isotope fractionation during coal combustion, Qi et al. (2011) analyzed soot and cinder samples (i.e. solid waste of coal combustion) as well as various ashes of Ge-rich lignite prepared after ashing at 600 ${ }^{\circ} \mathrm{C}$ for $24 \mathrm{~h}$ in a muffle furnace (Figure 3). Although ashing experiments showed no Ge loss or Ge isotopic fractionation between coal and ash for combustion, industrial coal combustion at $\mathrm{T}>1400^{\circ} \mathrm{C}$ seems to fractionate Ge isotopes, with Ge isotopic compositions of soot being distinctly lighter (up to $2.25 \%$ ) than those of cinder (solid residue). The large Ge isotopic fractionation between residue and volatile components is best explained by evaporation during combustion, making Ge isotopes a powerful tool in detecting environmental pollution produced by mining industries.

\section{HIGH-TEMPERATURE GEOCHEMISTRY}

\section{Fundamentals of Ge high-temperature geochemistry}

Being siderophile, chalcophile and lithophile, Ge incorporates a wide range of crystallographic structures, including Fe-rich metal, sufides, and silicates. Germanium may occur in three oxidation states: $\mathrm{Ge}^{0}, \mathrm{Ge}^{2+}$ and $\mathrm{Ge}^{4+}$. Germanium is also a volatile element of particular importance in cosmochemistry. Hence, a significant number of studies have identified the main physical, crystallographic and chemical characteristics of Ge in various compounds, which serve as important guide to identify $\mathrm{Ge}$ isotopic fractionation in high-temperature processes leading to the formation of the Earth and planets. 


\section{Germanium in metal compounds.}

Germanium is strongly enriched in metal phase under highly reducing conditions. Only two natural origins for the metal phase are known:

(i) extraterrestrial origin, in particular in iron meteorites that are analogues for cores of planetesimals and planets. Germanium contents can vary from 20 ppb up to 2000 ppm (Wasson 1974).

(ii) terrestrial native Fe-Ni metal corresponding to an unusual phase occurring as inclusions in basaltic intrusions. Only three occurrences have been reported worldwide: Disko Island (Greenland) that is the more extensively studied (Ulff-Mølller 1985; Klöck et al. 1986), Siberian trap intrusions (Ryabov and Lapkovsky 2010), and Bühl basalt (Germany) (Medenbach and ElGoresy 1982). Disko Island native iron phases can contain up to $300 \mathrm{ppm}$ of Ge (Klöck et al., 1986). The crystallization of native iron implies strongly reduced conditions $\left(f \mathrm{O}_{2}<(\mathrm{FMQ})-6\right)$ that can be caused by magmatic assimilation of carbonaceous sediments or coal (Iacono-Marziano et al. 2012).

The Fe-Ni phases of extraterrestrial origin are Ni-rich taenite and Ni-poor kamacite $(\mathrm{Ni}<6 \%$ ), the latter can contain high Ge content. Cavell et al. (2004) have studied the incorporation of Ge and Ga in Fe-Ni kamacite phase of Canyon Diablo iron meteorite, using extended X-ray absorption fine structure spectroscopy (EXAFS), and simulate the spectra in a "super lattice" model. The EXAFS patterns describe the kamacite structure as bcc lattice structure (body center cubic) that contains a central atom of $\mathrm{Ge}, \mathrm{Ga}$, or $\mathrm{Ni}$ surrounded by Fe atoms. Germanium (and $\mathrm{Ga}$, or $\mathrm{Ni}$ ) are incorporated in the structure through substitution for Fe atoms. The central atom (e.g. Ge) is surrounded by eight nearest $\mathrm{Fe}$ atoms in the first shell. The XAFS quantifies the distances from the central atom to the first shell, for example Ge-Fe length of $2.494 \AA$ (Table 4). Knowledge of bond length parameters is essential for the theoretical prediction of isotopic fractionation between phases.

The taenite and kamacite phases of Fe-meteorites crystallize from a Fe-Ni metallic liquid. Experimental studies show that the incorporation of Ge in metallic crystal structure, which is quantified by the partition coefficient $\mathrm{D}$ between coexisting solid metal and liquid metal, is strongly controlled by concentrations of non-metallic elements, such as S, P, C in the metallic liquid (Jones and Walker 1991; Jana and Walker 1997; Liu and Fleet 2001; Chabot et al. 2003; Chabot and Jones 2003; Corrigan et al. 2009). Hence, increasing S, P, C contents in the metallic liquid metal leads to Ge being more compatible, e.g., $\mathrm{D}(\mathrm{Ge})$ solid metal/liquid metal increases strongly by two orders of magnitude for an increase in $\mathrm{S}$ up to $30 \%$, and to a lesser extent by a factor of 2 for $\mathrm{P}$, and $\mathrm{C}$. These results constitute some basis for the interpretation of elemental trends involving Ge in iron meteorites.

\section{Germanium in silicates.}

Germanium and silicon have similar crystallographic characteristics, including similar ionic $\left(\mathrm{R}_{\mathrm{Ge}}=0.39 \AA, \mathrm{R}_{\mathrm{Si}}=0.26 \AA\right)$, and covalent radius $\left(\mathrm{R}_{\mathrm{Ge}}=1.20 \pm 0.04 \AA, \mathrm{R}_{\mathrm{Si}}=1.11 \pm 0.02 \AA\right)$. Together with their similar oxidation state $\left(\mathrm{Ge}^{4+}, \mathrm{Si}^{4+}\right)$, this explains the incorporation of $\mathrm{Ge}$ in the tetrahedral site of silicate structures by isomorphic substitution for Si. Lattice parameters of Ge-O bonds have 
been determined by Li et al. (2009) in cluster models for a large range of silicate structures ranging from tectosilicate (quartz, K-feldspar) to nesosilicate (olivine) (Table 4). The Ge-O bond length

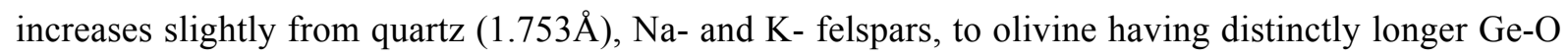
bond length $(1.79 \AA)$. Variations in Ge-O bond length are negatively correlated with theoretical Ge isotopic fractionation, meaning that distinct Ge isotopic signature can be expected between felsic and mafic natural samples.

Wickman (1943) initially suggested that $\mathrm{Ge} \Leftrightarrow \mathrm{Si}$ substitution would govern the Ge content in silicates, with lower Ge contents in the highest polymerized structures such as tectosilicate (quartz, felspar, $\left.\left[n \mathrm{SiO}_{2 n}\right]\right)<$ phyllosilicate (mica, $\left[\mathrm{Si}_{4} \mathrm{O}_{10}(\mathrm{OH})_{2}\right]^{6-}$ ) $<$ inosilicate (pyroxene, $\left[\mathrm{SiO}_{3}\right]_{2}$, amphibole $\left[\mathrm{Si}_{4} \mathrm{O}_{11}(\mathrm{OH})\right]^{7}$ ) and higher Ge contents in less polymerized structures such as nesosilicates (olivine, $\left[\mathrm{SiO}_{4}\right]^{4-}$, zircon, garnet). This would imply that ultramafic rocks with high olivine fractions should be enriched in Ge compared to crustal rocks (granite). This does not agree with the fairly homogeneous distribution of Ge in terrestrial silicate rocks (El Korh et al. 2016). The $\mathrm{K}_{\mathrm{d}}(\mathrm{Ge})$ for mineral-liquid partition coefficient in high temperature silicates (Table 5), also indicates, that diopside pyroxene has higher Ge contents than olivine (Malvin and Drake 1987). Thermodynamic parameters (T, P), in addition to $\mathrm{Ge} \Leftrightarrow \mathrm{Si}$ substitution, likely control Ge partitioning into silicates (Table 5). The temperature effect seems to be negligible on $\mathrm{K}_{\mathrm{d}}$ olivine/liquid (Capobianco and Watson 1982), but possibly significant on $\mathrm{K}_{\mathrm{d}} \mathrm{cpx} /$ liquid (Hill et al. 2000; Adam and Green 2006). The effect of pressure has been experimentally investigated by Malvin and Drake (1987) who reported lower Ge concentrations in olivine at higher pressure of $2 \mathrm{GPa}$. Davis et al. (2013) also determined lower $\mathrm{D}_{\mathrm{Ge}} \mathrm{Ol}$ at $3 \mathrm{GPa}$, which they attributed to a "garnet effect", the only silicate phase in which $\mathrm{Ge}$ is compatible $\left(\mathrm{D}_{\mathrm{Ge}}=1.51\right)$. The $\mathrm{K}_{\mathrm{d}}(\mathrm{Ge})$ for mineral-liquid pairs ranged from 0.4 to 0.9 (Table 5, and references therein), Bulk $\mathrm{D}(\mathrm{Ge})$ for partial melting was close to 1 (0.8-1.04), for different diopside/olivine ratios of peridotitic source (Malvin and Drake 1987), and a near-solidus of bulk $\mathrm{D}(\mathrm{Ge})$ of $0.66 \pm 0.01$ was calculated for garnet peridotite at 3GPa (Davis et al. 2013). These experimental results indicate that Ge is moderately incompatible during fractional crystallization process, and partial melting of peridotitic sources.

The latter findings have some important consequences in tracing source composition or source mineralogy. For example, no significant variations in Ge content was observed in volcanic suites from Hawaii, yielding molar Ge/Si=2.6*10 $0^{-6}$ (De Argollo and Schilling 1978b). Likewise, variations in $\mathrm{Ge} / \mathrm{Si}$ ratios in mantle and crustal rocks could trace mantle source compositions from different geodynamic settings (De Argollo and Schilling 1978b; a). New developments of Ge concentration measurements in ocean floor basaltic glass using isotopic dilution (Makishima and Nakamura 2009) and in situ laser ICP-MS (Avarelo and McDonough 2010; Jenner and O'Neill 2012); Davis and Humayun, 2013) have considerably extended the data set, with higher precision measurements (6\%, and 3\%, respectively). Avarelo and McDonough (2010) found distinctly higher $\mathrm{Ga} / \mathrm{Ge}$ ratios up to 20 in tholeiitic basalt from Hawaii compared to MORB $(\mathrm{Ga} / \mathrm{Ge}$ mean $\approx 10)$, which would reflect mantle 
source mineralogy (e.g. garnet vs. spinel).

\section{Germanium in sulfides.}

Germanium can be strongly and variably enriched in sulfide minerals (Bernstein 1985; Holl et al. 2007; Rosenberg 2009). Besides the rare occurences of sulfides that incorporate Ge at percent level (e.g. germanite, renierite, and briartite), Ge occurs at trace levels in $\mathrm{Zn}$ and $\mathrm{Fe}-\mathrm{Cu}$ sulfides. Germanium is incorporated in the lattice structure through a substitution mechanism with isovalent substitution $\mathrm{Ge}^{2+} \leftrightarrow \mathrm{Zn}^{2+}$ (Cook et al. 2009) or more complex substitutions involving monovalent elements $\left(\mathrm{Cu}^{+}, \mathrm{Ag}^{+}\right)$and trivalent $\left(\mathrm{Ga}^{3+}\right)$ with a vacancy (Johan 1988). Recently, on the basis of strong binary elemental correlations, Belissont et al. (2014) proposed coupled substitutions involving $\mathrm{Zn}$ and $\mathrm{Ag}$ as $3 \mathrm{Zn}^{2+} \leftrightarrow \mathrm{Ge}^{4+}+2 \mathrm{Ag}^{+}$.

$\mathrm{Li}$ et al. (2009) used three sulfide clusters models $\left[\mathrm{Ge}(\mathrm{II}) \mathrm{S}_{4} \mathrm{Zn}_{2}\right]^{2-},\left[\mathrm{Ge}(\mathrm{II}) \mathrm{S}_{4} \mathrm{Zn}_{4}\right]^{2+}$, and $\left[\mathrm{Ge}(\mathrm{IV}) \mathrm{S}_{4} \mathrm{Zn}_{2}\right]^{0}$ of sphalerite-like lattices that differ in their coordination and oxidation states $\left(\mathrm{Ge}^{2+}\right.$ and $\left.\mathrm{Ge}^{4+}\right)$. These two oxidation states are thought to be present in sulfide minerals. Calculated Ge-S bond lengths differ slightly from $2.257-2.267 \AA$ in Ge(II) structure to $2.275 \AA$ in Ge(IV) structure (Table 4). Cempirek and Groat (2013) have unambiguously identified the occurrence of $\mathrm{Ge}^{4+}$ in brunogierite, a spinel-type oxide, with a Ge-O bond length of $1.771 \AA$, which is shorter than Ge-S bonds.

State-of-art investigations of the Ge oxidation state in sulfides, using synchrotron $\mu$-X-ray absorption near edge spectroscopy ( $\mu$-XANES), have examined model compounds and samples from Tres Marias Zn deposit, Mexico (Cook et al. 2015) and St-Salvy Zn-Pb deposit, France (Belissont et al. 2016). Sphalerite from Tres Marias was strongly zoned, with (Ge-Fe)-poor and (Ge-Fe)-rich zones, having Ge contents of 252 and 1071 ppm, respectively (Cook et al. 2015). Sphalerite from St-Salvy displayed complex zoning: (1) rhythmic bands with alternation of Ge-poor (Ge=140ppm), Fe-rich dark bands, and Ge-rich (Ge=270 ppm), Fe-poor light bands, and (2) Ge-rich sector zones with the highest Ge contents (1100 ppm) (Belissont et al., 2014). Whatever the zones (Figure 4), these two studies established that only $\mathrm{Ge}^{4+}$ was present in sulfide (Cook et al., 2015; Belissont et al., 2016).

\section{Cosmochemistry of Ge isotopes}

Over the last decade, several studies have emphasized the importance of $\mathrm{Ge}$ and its isotopes as novel tracers in planetary sciences. Since the pioneering measurements of elemental Ge in metalsilicate experiments by INAA techniques in the late 60's (Wai et al. 1968), the application of Ge geochemistry has been left aside in favor of other geochemical tracers (e.g. highly siderophile elements). It is only in the recent years that a renewed interest for $\mathrm{Ge}$ as an elemental tool for understanding core formation of planetary bodies has been put forward, mainly in experimental cosmochemistry (Righter et al. 2011; Siebert et al. 2011b). Recently, Ge isotopes have added new 
constraints on metal-silicate segregation, with the identification of distinct Ge isotopic signatures in iron meteorites as analogues of planetesimal cores and silicate reservoirs (Luais, 2007, 2012).

\section{Germanium isotope signatures of iron meteorites}

Germanium, with $\mathrm{Ni}$ and Ir, is a key element for the classification of iron meteorites. Using the correlations between Ge and Ir with $\mathrm{Ni}$ and Au, Wasson et al. (1967; 2002) have identified 13 distinct groups, and more than 57 ungrouped meteorites, the minimum of individual members required for defining a group being five. The last identified group was group IIG with six members having the lowest Ni content of 4.2-4.6\% (Wasson and Choe 2009). Modelling of trace element variations within the individual groups using solid metal-liquid metal partition coefficients defined two main classes: (1) magmatic irons representing the cooling of metallic liquid core, (2) non-magmatic irons related to the mixing between impact melts formed at the sub-surface of undifferentiated bodies (Choi et al. 1995). Germanium-Ni correlations indicated small within-group variations for magmatic irons, resulting from $\mathrm{D}_{\mathrm{Ge}}$ solid metal-liquid metal $=0.64$, but large variations of 5 orders of magnitude between groups $(\mathrm{Ge}=0.01$ to $650 \mathrm{ppm})$. Wasson and collaborators suggested that each meteorite group represents the core of a distinct parent body. Since metal-silicate partitioning of Ge strongly depends on redox conditions, and variations in $\mathrm{Ge} / \mathrm{Ni}$ (and $\mathrm{Ga} / \mathrm{Ni}$ ) in iron meteorites may result from loss of Ge through volatility (Davis 2006), Ge isotopes can add strong constraints on thermodynamic conditions during parent body differentiation, and/or formation processes of iron meteorites. Luais (2007) analyzed the Ge isotopic composition of iron meteorites from different groups and classes (Figure 5) and showed that Ge isotopes bring new constraints on the classification of iron meteorites, with a decoupling between Ge content and its isotopes. Results showed constant $\delta^{74 / 70} \mathrm{Ge}_{\text {NIST3120a }}$ of $1.41 \pm 0.22 \%$ for magmatic irons, and $\delta^{74 / 70} \mathrm{Ge}$ ranging from -0.63 to $1.04 \%$ for non-magmatic irons.

Magmatic irons: The similarity in Ge isotopes of magmatic irons implies that they do not fractionate during fractional crystallization of metallic liquid, which is characterized by a large decrease in Ir contents from $70 \mathrm{ppm}$ in IIA irons to less than $0.01 \mathrm{ppm}$ in IIB irons. The lack of correlation between $\mathrm{Ge}$ isotopic composition and $\mathrm{Ni}$ content (and $\mathrm{Ge} / \mathrm{Ni}$ ), which is a proxy for redox parameter in metallic phase, would indicate similar $\mathrm{fO}_{2}$ conditions during metal crystallization. However, the specific occurrence of oxygen-bearing phases such as phosphates in IIIAB irons (Olsen et al. 1999), indicated some differences in redox conditions, the IIAB group being more reduced than the IIIAB ones. The constant Ge isotopic composition in magmatic irons, independent of Ge content and redox conditions in the parent body, are best explained by a near-complete partitioning of siderophile Ge into the metal phase that drives Ge isotopic composition close to the initial composition of the parent bodies (Luais, 2007). In light of experimental studies (Luais et al., 2007), this implies strong reducing conditions that avoid loss of Ge during iron meteorite formation. Small $\mathrm{fO}_{2}$ variations would not induce a detectable change in $\mathrm{Ge}$ isotopes. The constant $\mathrm{Ge}$ isotope compositions of magmatic iron meteorites implied some homogeneity in Ge isotope signatures among parent bodies. 
The lack of any correlation between $\delta^{74 / 70} \mathrm{Ge}$ values with variations in $\mathrm{Ge} / \mathrm{Ni}$ ratios, the latter quantifying nebular condensation processes at a given oxidation and fractionation state (Kelly and Larimer 1977) led Luais (2007) to propose that the homogeneous $\delta^{74 / 70} \mathrm{Ge}$ signature was established early in planet history, through nebular condensation and large-scale isotopic homogenization.

The IIB and IIG magmatic irons have slightly lower Ge isotopic composition than the average for magmatic irons (Figure 5). Their similar $\delta^{74 / 70} \mathrm{Ge}$ values of $0.97 \pm 0.16 \%$ for IIB irons and $0.93 \pm 0.02 \%$ for IIG (Luais, 2007, 2012, Luais et al., 2014) confirm their affiliation. Their low Ir contents (Ir IIB $=1$ to $0.01 \mathrm{ppm}$, Ir IIG $=0.2$ to $0.02 \mathrm{ppm}$ ), indicate that they represent differentiated metallic liquid. They are also characterised by large inclusions of troilite (FeS) and schreibersite $(\mathrm{FeNi})_{3} \mathrm{P}$, that are thought to be formed by late-stage exsolution of $\mathrm{P}$ and $\mathrm{S}$ during fractional crystallisation. Measured Ge contents were very low in schreibersite ( $\mathrm{Ge}=0.7$ to $1.8 \mathrm{ppm}$ ), and undetectable in troilite (Luais et al. 2014). This was explained by Ge being strongly compatible in metal solid, with $\mathrm{D}(\mathrm{Ge})$ solid metal/liquid metal increasing with increasing $\mathrm{S}$ and $\mathrm{P}$ in the metallic liquid during the late stage of fractional crystallisation. Thus far, Ge isotopic compositions have been measured in both metal and schreibersite, but not in troilite. $\delta^{74 / 70} \mathrm{Ge}$ values in the schreibersite were strongly negative with respect to the metal, giving $\Delta^{74}$ Ge metal-schreibersite $=+3.5$ to $+4.2 \%$ in Santa Luzia (IIB) and Tombigbee River (IIG) (Luais et al., 2014). These results highlight that Ge isotopic fractionation between $\mathrm{FeNi}$ liquid and $\mathrm{FeNi}+\mathrm{S}(\mathrm{P})$ liquid will have to be considered in a global model of early $\mathrm{Fe}-\mathrm{FeS}$ (and $\mathrm{P}$ ) metal segregation, preceding metal-silicate differentiation of planetesimals (Kruijer et al. 2014).

Non-magmatic irons: Impacts processes are involved in the formation of non-magmatic iron meteorites (Wasson et al. 1980; Choi et al. 1995). These IAB and IIE groups are characterized by the occurrence of silicate inclusions, which are absent in magmatic irons. Based on petrological, mineralogical and geochemical investigations, the commonly accepted hypothesis of formation is impact processes on chondritic or on already differentiated parent bodies that result in complex processes of parent-body break-up, hit-and-run collision and major silicate-metal mixing (Benedix et al. 2000; Takeda et al. 2000; McDermott et al. 2016). Luais (2007) showed that the Ge isotopic composition of these non-magmatic irons were distinctly lower than those of magmatic irons, and highly variable (Figure 5).

The IIE irons have highly variable $\delta^{74 / 70} \mathrm{Ge}_{\text {NIST3120a }}$ ranging from -0.63 to $+1.04 \%$ (Figure 6) that are inversely correlated with their Ge contents. This trend can be modelled by evaporation processes, leading to $\mathrm{Ge}$ loss that preferentially removes light isotopes of $\mathrm{Ge}$, leaving a residue enriched in heavy isotopes. However, loss of light Ge isotopes from IIE irons is smaller than predicted from pure Rayleigh evaporation model $(\beta=0.5)$, emphazing that the produced vapor is not simply lost, but continues to interact with particles. The smaller depletion in light isotopes than predicted by 
kinetic processes, commonly referred as suppressed isotope fractionation, would then reflect gasresidue interaction and back reaction (Cohen et al. 2004). Detailed investigations indicated that $\delta^{74 / 70} \mathrm{Ge}$ variations in IIE irons were not random, but were age-correlated: samples with lower $\delta^{74 / 70} \mathrm{Ge}$ values, the so called "Miles group", were older than the "Watson group" with higher $\delta^{74 / 70} \mathrm{Ge}$, (Bogard et al. 2000; Snyder et al. 2001). Therefore, increasing $\delta^{74 / 70} \mathrm{Ge}$ values from the oldest to the youngest IIE samples possibly reflects progressive and repeated impact events on parent body (Luais, 2007). Recently, McDermott et al. (2016) calculated the closure temperature from two-pyroxene geothermometry in silicate inclusions from IIE sample to determine the cooling rate. They found a correlation between the degree of differentiation of silicate inclusions and cooling rates, the less differentiated (chondritic) inclusions in the Watson sample having higher closure temperatures $\left(1120^{\circ} \mathrm{C}\right)$ and faster cooling rates than the more differentiated inclusions in the Miles group with lower closure temperatures $\left(\approx 1020^{\circ} \mathrm{C}\right)$ and lower cooling rates. It would be important to decipher if the cooling rate of silicate inclusions can be related to impact events. If so, this would be in line with $\mathrm{Ge}$ isotopic data, the high $\delta^{74 / 70} \mathrm{Ge}$-low Ge Watson sample having with faster cooling rates than high $\delta^{74 / 70} \mathrm{Ge}$-high Ge Miles group with slower cooling. Kinetics of isotopic fractionation would then demonstrate that fast cooling rate would produce more extensive evaporation and loss of light $\mathrm{Ge}$ isotopes, because of less vapor-residue interactions, thus generating a high $\delta^{74 / 70} \mathrm{Ge}$ in the metallic melt.

By contrast, the IAB-IIICD irons have constant $\delta^{74 / 70} \mathrm{Ge}_{\mathrm{NIST} 3120 \mathrm{a}}$ of $+0.79 \pm 0.16 \%$ (Figure 5), confirming that former IAB and IIICD groups can be merged into a single group named IAB (Wasson and Kallemeyn 2002). Their constant $\delta^{74 / 70} \mathrm{Ge}$ values would indicate they originate from a single melt pod, generated during a single large impact heating event, in full agreement with trace element interpretations of Wasson and Kalleymen (2002).

\section{Germanium isotopes as tracers of metal-silicate segregation}

Rouxel et al. (2006) and Luais (2012) analyzed Ge isotopes compositions of terrestrial silicates representing oceanic crust, continental crust, and mantle. A detailed discussion of these data is given in the following section. The mean $\delta^{74 / 70} \mathrm{Ge}$ composition for Earth silicate reservoir ranged from 0.53 to $0.64 \%$ (Rouxel et al., 2006, Luais, 2012, Escoube et al., 2012, see next section), indicating a light Ge isotopic composition with respect to core reservoir that is reasonably assumed to be that of magmatic Fe meteorites with $\delta^{74 / 70} \mathrm{Ge}=1.41 \%$. The isotopic fractionation factor of $\Delta^{74 / 70} \mathrm{Ge}_{\mathrm{Fe}-m e t-E a r t h}$ silicate $\approx 0.85 \%$ for the Earth system can be compared with theoretical prediction of equilibrium isotopic fractionation based on crystallographic configuration of $\mathrm{Ge}$ in metal and silicate, which depends on $\mathrm{Ge}$ oxidation state $\left(\mathrm{Ge}^{0}\right.$ in metal, $\mathrm{Ge}^{4+}$ in silicate), coordination (octahedral $\mathrm{Ge}$ in metal, and tetrahedral Ge in silicate), and length of Ge-Fe (metal) and Ge-O (silicate) bonds (Table 4). Considering that heavy isotopes should prefer shorter (i.e. stronger) bond length, higher oxidation 
state, and low coordination number, yielding $\Delta^{74} \mathrm{Ge}_{\mathrm{Fe}-\text { met-Earth silicate }}<0$, the measured Ge isotopic compositions of iron meteorites and silicate Earth is in contradiction with theoretical considerations. Such a discrepancy raises the question of metal-silicate equilibrium at the time of core formation, although it is known that modern Earth mantle is not in chemical and thermodynamic equilibrium with the Earth's core (e.g. Stevenson 1981; Jones and Drake 1986). While it is conceivable that the Femeteorites represent a suitable good proxy for the composition to the Earth's core, the use of accessible silicate Earth samples is more questionable. The influence of pressure on Ge crystallographic configuration in silicate, as well as the volatile behavior of Ge at high temperature must be taken into account in modelling metal-silicate isotopic fractionation of Ge. However, it must be emphasized that the large difference in Ge isotopic composition between Fe-meteorites and Earth mantle makes Ge an interesting tracer to explore the complex processes of accretion and core formation. An important goal for future studies would be to determine where Ge sits in the lower mantle and how it is coordinated. Germanium compatibility and coordination in such phases may influence the Ge isotopic mass balance in Earth mantle.

\section{Germanium isotope systematics in igneous and mantle-derived rocks, and metamorphic rocks}

\section{The Ge isotopic composition of the Earth silicate reservoirs}

Germanium isotopic compositions of Earth silicate samples determined by Rouxel et al. (2006), Luais (2012) and Escoube et al. (2012) are detailed in Figure 7. Samples are representative of mantle (peridotite, dunite) and altered lithologies (serpentine), basaltic crust (MORB, OIB : Hawaii, Iceland), continental basalts and continental crust (granite). Independent determinations of average composition for the Earth silicate reservoirs of $\delta^{74 / 70} \mathrm{Ge}=0.64 \pm 0.16 \%$ (recalculated to NIST3120a, Rouxel et al., 2006), $\delta^{74 / 70} \mathrm{Ge}=0.53 \pm 0.16 \%$ (Luais, 2012), $\delta^{74 / 70} \mathrm{Ge}=0.56 \pm 0.18 \%$ (Escoube et al., 2012) agreed within analytical errors, and the whole average composition of the bulk silicate Earth (BSE) converges toward $\delta^{74 / 70} \mathrm{Ge}=0.58 \pm 0.21 \%$ ( 2 s.d.). Overall, variations in the Ge isotopic composition of the silicate Earth reservoirs were small.

Using this sample set, ultramafic rocks were characterized by $\mathrm{Ge} / \mathrm{Si}$ ratios of around $1.8 \times 10^{-6}$ $\mu \mathrm{mol} / \mathrm{mol}$. By comparison, the average $\mathrm{Ge} / \mathrm{Si}$ ratios of basalts were higher, at around $2.5 \times 10^{-6}$ $\mu \mathrm{mol} / \mathrm{mol}$ which is in good agreement with previous estimates of the oceanic crust based on a much larger sample set (De Argollo and Schilling 1978b; Bernstein 1985). The average Ge/Si ratio of continental crust samples (around $1.8 \times 10^{-6}$ ) was significantly higher than previous estimates (Mortlock and Froelich 1987) which can be explained by the limited number of considered samples and potential lithological heterogeneities. The lack of relationship between the Ge/ $\mathrm{Si}$ and $\delta^{74 / 70} \mathrm{Ge}$ suggests that the estimate of bulk silicate Earth $\delta^{74 / 70} \mathrm{Ge}$ value given above was not significantly biased by sampling. 
There was no correlation of $\delta^{74 / 70} \mathrm{Ge}$ with differentiation index such as $\mathrm{SiO}_{2}$. Although Luais (2012) identifed some slight distinction in $\delta^{74 / 70} \mathrm{Ge}$ between petrologic types, our more recent compilation suggests that $\delta^{74 / 70} \mathrm{Ge}$ values of mantle ultramafics, basalts, and granites mainly overlap (Figure 7). Based on Fe isotope systematics, a distinction between fertile upper mantle and MORBOIB have been put forwards (Williams et al. 2005; Weyer and Ionov 2007) and interpreted on the basis that $\mathrm{Fe}^{\mathrm{III}}$ is more incompatible than $\mathrm{Fe}^{\mathrm{II}}$ during partial melting, resulting in heavier Fe isotopic composition in the melt (Dauphas et al. 2009; Dauphas et al. 2014). With only Ge (IV) occurring in silicates and silicate melt, a similar valence-dependent process should be excluded, even if the data suggest a progressive increase in $\delta^{74 / 70} \mathrm{Ge}$ from mantle ultramafics, to mantle-derived lithologies and igneous rocks through partial melting.

A corrrelation between $\delta^{74 / 70} \mathrm{Ge}$ and $\mathrm{NBO} / \mathrm{T}$ index, where NBO is the number of nonbridging oxygen atoms, was identified (Figure 8) suggesting a link between Ge isotope fractionation and the degree of polymerization of the silicate (Luais, 2012). Basic rocks (tholeiite) have higher NBO/T values (mean 1.8) than felsic rocks (rhyolite) with NBO/T close to 0 (Mysen 2004), integrating the $\mathrm{NBO} / \mathrm{T}$ values for minerals (NBO/T $=4$ for olivine, $\mathrm{NBO} / \mathrm{T}=0$ for quartz, Mysen, 2004). The $\delta^{74 / 70} \mathrm{Ge}$ values were found to be lower in rocks having a higher percentage of olivine (NBO/T=4) such as ultramafics, and higher in rocks having higher percentage of tectosilicates (quartz, felsdpar, $\mathrm{NBO} / \mathrm{T}=0$ ) as in granite (Figure 8). In addition, Ge-O bond lengths are longer in olivine (1.82 $\AA$ ) than in quartz (1.73-1.78 $\AA$ ) (Table 4) (Li et al., 2009). The direction of isotopic fractionation is in line with the theoretical predictions, in that heavy isotopes will be favored with stronger, shorter bonds, then ordering $\delta^{74 / 70} \mathrm{Ge}$ quartz $>\delta^{74 / 70} \mathrm{Ge}$ olivine. The variation in $\delta^{74 / 70} \mathrm{Ge}$ observed for mantle-derived and crustal samples, with $\delta^{74 / 70} \mathrm{Ge}_{\text {granite }}>\delta^{74 / 70} \mathrm{Ge}_{\text {basalt }}>\delta^{74 / 70} \mathrm{Ge}_{\text {ultramafics }}$ is consistent with equilibrium fractionation between mineral and silicate melt. This observation is remarkably similar to Si isotope systematics showing that continental crust is slightly heavy relative to the mantle (Savage et al. 2014). When considering the whole set of data for $\delta^{74 / 70} \mathrm{Ge}$ (Figure 7), this correlation is less clear. One reason is that the range of $\delta^{74 / 70} \mathrm{Ge}$ values is small and at the limit of reproducibility $(\approx 0.2 \%$ ).

Serpentinite exhibited significantly higher $\delta^{74 / 70} \mathrm{Ge}$ value of $+0.61 \%$ than fresh peridotite and dunite with $\delta^{74 / 70} \mathrm{Ge}$ values of 0.46 and $0.5 \%$, respectively. Serpentinite generally formed through hydrothermal interaction with ultrabasics, at high temperature (e.g. $\mathrm{T} \approx 260^{\circ} \mathrm{C}$, Deschamps et al. 2012). Heavier $\delta^{74 / 70} \mathrm{Ge}$ value could result from water-rock interactions, with the addition of Ge from hydrothermal fluids with higher $\delta^{74 / 70} \mathrm{Ge}$ values, as recently measured in seafloor hydrothermal systems (+1.55 $\pm 0.3 \%$; Escoube et al., 2015).

The Hawaiian basalt (BHVO) plots under the $\delta^{74 / 70} \mathrm{Ge}-\mathrm{NBO} / \mathrm{T}$ regression line (Figure 8). This sample from Kilauea volcano belongs to the "Kea Trend" that is characterised by low ${ }^{87} \mathrm{Sr} /{ }^{86} \mathrm{Sr}$ and ${ }^{208} \mathrm{~Pb} /{ }^{206} \mathrm{~Pb}$ and high ${ }^{143} \mathrm{Nd} /{ }^{144} \mathrm{Nd}$ ratio typical of the "PREMA" component. According to Weiss et al. (2011), the "Kea trend" could originate from the lower mantle. If it ascended without interaction, it 
may be sourced from the dense material that is recognized at the core-mantle boundary from geophysical investigations. Alternatively, the presence of garnet in the mantle source with high $\mathrm{Kd}$ (Ge) (Table 1), as well as the pressure effect on the equilibrium Ge isotopic fractionation will need to be investigated. If such, it would represent lower mantle Ge isotopic signature. Additional high precision Ge isotopic data are required to confirm this value.

\section{Germanium recycling into the mantle: an attempt to evaluate mantle homogeneity.}

Germanium isotopic data for mantle-derived samples have shown small detectable variations that question the extent of Ge homogeneity in the Earth's mantle. Subduction settings are important zones of intensive fluid-rock interaction driven by metamorphic reactions and dehydration of the subducted slab, then contributing to significant mass transfer into the mantle. Since Ge can be transported with aqueous fluids (Pokrovski and Schott 1998a), it is possible that Ge transport from the subducted slab to the mantle wedge can be associated with significant isotopic fractionation. To address this issue, El Korh et al. $(2014 ; 2016)$ measured the Ge isotopic composition of metamorphic rocks in a series of HP-LT rocks at peak P-T conditions $\left(\mathrm{P}=1.7-2.3 \mathrm{GPa}\right.$ and $\left.\mathrm{T}=500-600^{\circ} \mathrm{C}\right)$ from the Ile de Groix (France). The studied metabasites correspond to former MOR-type basalts that underwent pre-HP hydrothermal alteration, prograde metamorphism in blueschist and eclogite facies, and then retrograde metamorphism in greenschist facies at lower $\mathrm{T}\left(<450^{\circ} \mathrm{C}\right)$. El Korh et al. $(2015,2016)$ reported no Ge isotopic variation in blueschists and eclogites, with $\delta^{74 / 70} \mathrm{Ge}$ values $(+0.42$ to $+0.65 \%$ ) within the range of tholeiitic basalts $(+0.55-0.57 \%$; Luais, 2012). Germanium being mainly hosted in garnet $(\mathrm{Ge}=3.3$ to $8.2 \mathrm{ppm}$ ) and epidote (2.4 to $12 \mathrm{ppm}$ ) (El Korh et al., 2014), the lack of Ge isotopic fractionation indicated that Ge remains incorporated in different generations of garnet and epidote, that were stable during prograde metamorphism. By contrast, significant Ge isotopic variations were seen in retrograde greenschist samples that were free of garnet, with $\delta^{74 / 70} \mathrm{Ge}$ values up to $0.98 \%$. Hence, Ge isotopic fractionation was likely related to garnet breakdown and fluid interaction during retrogression at lower temperatures, that released Ge in solution. In addition, El Korh et al. (2016) demonstrated that the $\delta^{74 / 70} \mathrm{Ge}$ vs. $\left(\mathrm{Fe}^{2+} / \mathrm{Fe}_{\mathrm{tot}}\right)$ correlation, was indicative of intensive fluid - rock interaction under reducing conditions. This first study on $\mathrm{Ge}$ isotopic variations related to metamorphic processes emphasized that $\mathrm{Ge}$ isotopes can fractionate during the breakdown of Gebearing minerals, leading to the release of $\mathrm{Ge}$ in a fluid phase under reducing conditions. Slab dehydration with prograde metamorphism in the stability field of garnet did not fractionate Ge isotopes, meaning that subduction of oceanic crust would not produce significant mantle heterogeneities. 


\section{Ore deposits}

Understanding the formation of ore deposits, from crustal or mantle source to deposits, requires deciphering the distinct processes of element dissolution into the fluid phase, fluid transport and mineral precipitation under specific thermodynamics conditions. Whereas Ge is generally present at trace levels in ore deposits (Holl et al. 2007), its concentrations can vary from few ppm to thousands of ppm, with $\mathrm{ZnS}$ (sphalerite) being one of the main Ge-bearing mineral. These high concentrations contrast with those found in silicates (1.5-1.6 ppm in the crust and $1.1 \mathrm{ppm}$ in the mantle, e.g. Berstein, 1985). The recent analytical development of in situ measurements of Ge concentration and associated trace elements by laser ICPMS techniques has opened new fields of research, allowing detection of chemical variations at the mineral scale. It has been shown that optical zonation in sphalerite crystal are related to strong chemical zonings, with variation in Ge contents from hundred to thousands of ppm in single mineral (Belissont et al., 2014). These insights into fine-scale sphalerite structure has led to understanding the incorporation mechanism of Ge in sphalerite through coupled substitutions with other metal trace elements (Ga, In, Cd, Ag, Cu, Fe) (Johan 1988; Yee et al. 2007; Cook et al. 2009), with $\mathrm{Cu}$ providing the charge balance for the entire set of substitutions (Belissont et al. 2014). In turn, assessing fine-scale chemical variations provides important constraints, together with thorough statistical tools such as PCA (Belissont et al. 2014; Frenzel et al. 2016) for defining the thermodynamic conditions of sphalerite precipitation and sources.

Li et al. (2009) established the preliminary parameters of theoretical Ge isotope fractionation of sphalerite-like sulfides and calculated a fractionation factor $\Delta^{74 / 70} \mathrm{Ge}_{\text {sph-aqueous }}$ at $25^{\circ} \mathrm{C}$ of 12.2 to $11.5 \%$, indicating a very light isotopic composition in sphalerite compared to the fluid in equilibrium. Field data confirmed that sulfides are generally characterized by light Ge isotopic composition, with variable $\delta^{74 / 70} \mathrm{Ge}$ ranging from -5 to $+2 \%$ (Figure 9). Several studies reported $\delta^{74 / 70} \mathrm{Ge}$ values in sphalerites from continental and marine deposits, such as St-Salvy vein-type deposits (France), Irishtype $\mathrm{Zn}-\mathrm{Pb}$ Navan Deposits (Ireland), Lucky Strike seafloor hydrothermal vent, and in various sulfides (pyrite, sphalerite and galena) from several $\mathrm{Zn}-\mathrm{Pb}$ deposits in Southwest China (Luais 2007; Escoube et al. 2012; Luais 2012; Belissont et al. 2014; Meng et al. 2015). Overall, there were no systematic differences in $\delta^{74 / 70} \mathrm{Ge}$ between sulfide minerals, indicating that local source, or temperature-dependant mineral-mineral equilibrium control the Ge isotopic fractionation. Each case study must be discussed separately.

Sulfides from $\mathrm{Zn}-\mathrm{Pb}$ deposits in Southwest China (Meng et al., 2015) did not show any correlation between $\delta^{74 / 70} \mathrm{Ge}$ and Ge contents as a whole, or within each individual mineral phases. Meng et al. (2015) proposed that Rayleigh-type isotopic fractionation may account for the heavy isotopic composition of $\mathrm{Ge}$ in the late galena. However this temporal evolution cannot be confirmed when taking into account $\delta^{74 / 70} \mathrm{Ge}$ variations within each sulfide species, because of the large overlap of their $\delta^{74 / 70} \mathrm{Ge}$ values. Sphalerites from St-Salvy, Irish and Lucky Strike deposits, when reported 
together, displayed a well-defined positive trend between Ge contents and $\delta^{74 / 70} \mathrm{Ge}$ values, with the Irish and Lucky Strike samples having the lowest values (Figure 10). Belissont et al. (2014) demonstrated that this trend cannot be modelled by Rayleigh-type fractionation during the cooling of the mineralizing fluid; regardless of the exact $\alpha$ values $\left(\alpha_{\text {sph-fluid }}=0.999-0.995\right)$ and the hydrothermal fluid compositions $\left(\delta^{74 / 70} \mathrm{Ge}=+1\right.$ to +2.6 , in the range of data in Escoube et al., 2015), since the different modeling trends all resulted in a negative correlation between Ge concentrations and $\delta^{74 / 70} \mathrm{Ge}$ (Figure 11).

Redox state and temperature are two parameters that can control Ge isotopic fractionation. Li et al. (2009) proposed that redox effects on the theoretical Ge isotopic fractionation in sulfides are small, by calculating a slightly lower $\Delta^{74 / 70} \mathrm{Ge}$ GeIV sphalerite-aqueous of $11.4 \%$ than $\Delta^{74 / 70} \mathrm{Ge}_{\text {GeII sphalerite-aqueous }}$ of 12.2 and $11.5 \%$ o $\left(25^{\circ} \mathrm{C}\right)$. Belissont et al. (2016) investigated the Ge oxidation state in sphalerites using $K$-edge $\mu$ XANES synchrotron techniques and demonstrated that sphalerites from St-Salvy have incorporated only $\mathrm{Ge}^{4+}$, meaning that redox effect cannot constrain the $\delta^{74 / 70} \mathrm{Ge}-\mathrm{Ge}$ trends. The authors concluded that $\mathrm{Ge}$ isotopic variations were temperature-controlled. A $\Delta_{\text {sphalerite-fluid }}^{140^{\circ} \mathrm{C}}-\Delta_{\text {sphalerite-fluid }}^{80^{\circ} \mathrm{C}}$ giving $\delta^{74 / 70} G e_{\text {sphalerite }}^{140^{\circ} \mathrm{C}}-\delta^{74 / 70} G e_{\text {sphalerite }}^{80^{\circ} \mathrm{C}}$ of $2.98 \%$ can be reproduced for a temperature range of $70-150^{\circ} \mathrm{C}$, slightly larger than the $\mathrm{T}=80-140^{\circ} \mathrm{C}$ estimates of fluid inclusions in quartz belonging to the same paragenesis. This means that fluid temperature can partly explain $\delta^{74 / 70} \mathrm{Ge}$ variations in St-Salvy sphalerites.

\section{LOW TEMPERATURE GEOCHEMISTRY}

\section{Fundamentals of Ge low-temperature geochemistry}

\section{Speciation in aqueous systems.}

In natural environments, Ge may occur as both inorganic and organometallic forms. Germanate in aqueous solution includes $\mathrm{Ge}(\mathrm{OH})_{4}, \mathrm{GeO}(\mathrm{OH})_{3}{ }^{-}, \mathrm{GeO}_{2}(\mathrm{OH})_{2}{ }^{2-}$ and $\mathrm{H}_{2} \mathrm{GeO}_{3}$ species (Ingri 1963), with germanic acid $\mathrm{Ge}(\mathrm{OH})_{4}$ being the predominant inorganic form in natural waters. Organometallic Ge species exist in nature as methyl-Ge (MMGe) and dimethyl-Ge (DMGe) forms (Lewis et al. 1985; Lewis et al. 1989), representing more than $70 \%$ of the total Ge in the ocean. Although Hambrick et al. (1984) and Hirner et al. (1998) reported the presence of trimethyl-Ge (TMGe) in rainwater and geothermal waters, the occurrence of TMGe in rivers and seawater has not been demonstrated. In contrast to the inorganic form of Ge showing nutrient-type behavior in seawater, much like that of silicic acid, organometallic Ge species are rather conservative throughout the water column, averaging $345 \pm 22 \mathrm{pM}$ and $100 \pm 5 \mathrm{pM}$ for MMGe and DMGe respectively. The sources of methyl-Ge species are still poorly known, but likely involve microbial biomethylation (Lewis et al. 1985). 
Unlike $\mathrm{Si}, \mathrm{Ge}$ forms stable six fold coordination (octahedral) complexes with various organic ligands (Pokrovski and Schott 1998b). This property is particularly important for natural waters with high concentrations of humic substances and organics, as it may explain the strong decoupling of $\mathrm{Ge}$ vs. Si during continental weathering and run-off. The ability of Ge to form complexes with different organic ligands (e.g. humic and fulvic acids) is thus an important feature of Ge geochemistry in aqueous systems (Pokrovski and Schott 1998b; Pokrovski et al. 2000), possibly accounting for more than $95 \%$ of the total dissolved $\mathrm{Ge}$ at $\mathrm{pH} \geq 6-7$ in natural river waters. Germanium forms complexes of chelate type with the following functional groups: (a) carboxylic in acid solutions, (b) di-phenolic hydroxyls in neutral and basic solutions, and (c) alcoholic hydroxyls in very basic solutions (Rosenberg 2009).

According to Pokrovski (1998a), Ge does not form complexes with important inorganic ligands like $\mathrm{Cl}^{-}, \mathrm{HCO}_{3}^{-}, \mathrm{H}_{2} \mathrm{~S}, \mathrm{Na}^{+}$in natural environments, including hydrothermal systems. In hydrothermal systems of near-neutral $\mathrm{pH}$ and in the temperature range of $20-350^{\circ} \mathrm{C}$, Ge is mainly transported as the neutral hydroxide $\mathrm{Ge}(\mathrm{OH})_{4}$. According to available experimental data (Ciavatta et al. 1990), Ge-fluoride complexes can occur only in acid and fluor-rich solutions that are rarely found in hydrothermal environments. Although the enrichment of Ge in hydrothermal sulfide deposits may be taken as an indication that S-bearing Ge species may also form in some hydrothermal fluids, there is no evidence for the natural occurrence of thiogermanate complex $\left[\mathrm{GeS}_{4}\right]^{4-}$. Finally, the redox potential of most hydrothermal and surficial environments seems too high to cause significant formation of divalent $\mathrm{Ge}^{2+}$ species.

\section{Role in biological systems}

Germanium has been characterized by Babula et al. (2008) as a non-essential element for human, flora and fauna life. However, Ge can be toxic to plants at high levels (Halperin et al. 1995) and has recognized physiological functions at trace levels (Cakmak et al. 1995) that differ from those of Si (Epstein 1994). Opal phytoliths from higher plants (e.g. graminoids) generally display lower $\mathrm{Ge} / \mathrm{Si}$, which underlines a systematic discrimination against Ge during plant uptake (Derry et al. 2005; Blecker et al. 2007) as a likely defense against its toxicity (Puerner et al. 1990). In contrast, significant accumulation of $\mathrm{Ge}$ in roots has been observed in both more primitive and modern plants (e.g. horsetails and banana plants) (Delvigne et al. 2009). There is no evidence of any essential function in humans, and no Ge deficiency syndromes have been documented. Although its accute toxicity is low (Tan et al. 2015), there has been several reports of severe human cases linked to prolonged intake of Ge products, leading to renal failure and even death (Tao and Bolger 1997). In both human cases and animal studies, toxicity was associated with ingested Ge products such as $\mathrm{GeO}_{2}$ dioxide and organic Ge compounds (Schauss 1991). Although it is clear that Ge products present a potential, although poorly investigated, human health hazard, there also have been reports of therapeutic applications 
(Goodman 1988).

\section{Behavior during weathering processes}

Chemical weathering, especially of silicate minerals, has important roles in soil development, nutrient availability in terrestrial and marine ecosystems, buffering of acid rain, and long-term atmospheric $\mathrm{CO}_{2}$ regulation (Walker et al. 1981; Berner et al. 1983; Gaillardet et al. 1999; Berner 2003). Germanium and Si exhibit substantial geochemical differences during weathering and $\mathrm{Ge} / \mathrm{Si}$ ratios in stream waters appear to show systematic behavior related to weathering processes. Germanium is preferentially incorporated into weathering products such as clays in soils, leading to a lowering of river water $\mathrm{Ge} / \mathrm{Si}$ compared to bed-rock (Mortlock and Froelich 1987; Froelich et al. 1992; Kurtz et al. 2002; Anders et al. 2003). Germanium/silicon (Ge/Si) ratios in unpolluted streams vary from $\sim 0.3$ to $1.2 \mu \mathrm{mol} / \mathrm{mol}$ and are almost always lower than $\mathrm{Ge} / \mathrm{Si}$ of the bedrock they drain (Mortlock and Froelich 1987). The riverine dissolved Ge/Si ratio may exhibit seasonal variations (Mortlock and Froelich 1987) and appears to correlate positively with 1/Si (Murnane and Stallard 1990; Froelich et al. 1992). This suggests that Ge/Si ratios in steam could be approximated by mixing of Si from two sources (Figure 12), one derived from weathering of primary minerals and the other derived from weathering of secondary clays. The underlying assumption is that incongruent weathering is characterized by a clay/bedrock distribution coefficient $>1$ (Murnane and Stallard 1990) resulting in a high $\mathrm{Ge} / \mathrm{Si}$ component retained by soils and a low $\mathrm{Ge} / \mathrm{Si}$ component released to stream waters. According to this scheme, the Si source with high $\mathrm{Ge} / \mathrm{Si}$ is derived from dissolution of the Geenriched secondary minerals under more intense chemical weathering. The $\mathrm{Ge} / \mathrm{Si}$ ratio in rivers is therefore controlled by the mixing relationships of these two sources and varies as a function of weathering intensity (Kurtz et al. 2002).

\section{Hydrothermal and geothermal systems}

Seafloor hydrothermal vent fluids and continental geothermal fluids are typically enriched in Ge relative to Si compared to the source rocks (Arnorsson 1984; Criaud and Fouillac 1986; Mortlock et al. 1993; Evans and Derry 2002; Siebert et al. 2006; Escoube et al. 2015). Oceanic high- and lowtemperature systems exhibit $\mathrm{Ge} / \mathrm{Si}$ ratios that range from 0.9 - $45 \mu \mathrm{mol} / \mathrm{mol}$ (Mortlock et al. 1993; Escoube et al. 2015), and Ge concentrations which are up to 1000 times seawater concentrations. Continental geothermal systems exhibit an even larger range from $\sim 2-1100 \mu \mathrm{mol} / \mathrm{mol}$ (Arnorsson 1984; Criaud and Fouillac 1986; Evans and Derry 2002; Siebert et al. 2006). The overall enrichment of $\mathrm{Ge}$ in even low-temperature hydrothermal fluids contrasts remarkably with the depletion of $\mathrm{Ge}$ in rivers (i.e. relative to $\mathrm{Si}$ ) and may result from the preferential partitioning of $\mathrm{Ge}$ vs. Si in hydrothermal fluid, considering the contrasting thermodynamic properties of aqueous $\mathrm{Ge}(\mathrm{OH})_{4}$ and $\mathrm{Si}(\mathrm{OH})_{4}$ in equilibrium with Ge-bearing silicates (Arnorsson 1984; Pokrovski and Schott 1998a). Thermodynamic 
data showed that $\mathrm{Ge} / \mathrm{Si}$ ratio in hydrothermal fluid in equilibrium with quartz decreases with increasing temperature from $160 \mu \mathrm{mol} / \mathrm{mol}$ at $50^{\circ} \mathrm{C}, 43 \mu \mathrm{mol} / \mathrm{mol}$ at $250^{\circ} \mathrm{C}$ to about $30 \mu \mathrm{mol} / \mathrm{mol}$ at $400^{\circ} \mathrm{C}$ (Pokrovski and Schott 1998a; Evans and Derry 2002). In contrast, Ge/Si ratio in hydrothermal fluid in equilibrium with wollastonite was considered to increase with temperature (Pokrovski and Schott 1998a). The high-temperature results of the equilibrium model with quartz were globally consistent with data from Iceland wells, which have average $\mathrm{Ge} / \mathrm{Si}=42 \mu \mathrm{mol} / \mathrm{mol}$ at $235^{\circ} \mathrm{C}$ (Arnorsson 1984). Based on field data, Evans and Derry (2002) also proposed a model of progressive Si loss via precipitation of Ge-poor quartz (i.e. Rayleigh distillation) in order to explain the extreme increase of the $\mathrm{Ge} / \mathrm{Si}$ ratio in cooled hydrothermal fluids. This model, requiring a high level of Si loss along a reaction path in order to produce observed $\mathrm{Ge} / \mathrm{Si}$ ratios, is however not directly applicable to seafloor hydrothermal systems as discussed in Escoube et al. (2015). Other processes may also influence Ge/Si ratio in hydrothermal fluids including the precipitation/dissolution of sulfides and non-equilibrium behavior.

\section{Germanium isotope systematics in low-temperature marine environments}

\section{An estimate of the oceanic crust composition}

A crude estimate of the Ge isotopic composition of the Bulk Silicate Earth (BSE) has been estimated at $0.58 \pm 0.21 \%$ (see section "The Ge isotopic composition of the Earth silicate reservoirs") through the analysis of various mantle-derived rocks such as tholeiitic glasses from mid-ocean ridges, continental and volcanic islands basalts, peridotite and granite (Rouxel et al. 2006; Escoube et al. 2012; Luais 2012). Although slight differences in $\delta^{74 / 70} \mathrm{Ge}$ values are possibly observed between ultramafic, basaltic and felsic rocks (Figure 7 and 8 ), the homogeneity of their $\delta^{74 / 70} \mathrm{Ge}$ values compared to sedimentary rocks and biogenic materials is remarkable (Figure 13).

The Ge isotope compositions of deep-sea clays have been reported by Rouxel et al., (2006) using drilled core samples from ODP Site 1149 and 801 in the Western Pacific. The $\delta^{74 / 70} \mathrm{Ge}$ values of deep-sea clays (Figure 13), and to a lesser extent Ge/Si ratios, were homogeneous. The average $\delta^{74 / 70} \mathrm{Ge}$ value of deep-sea clays $\left(\delta^{74} \mathrm{Ge}=0.69 \%\right.$ $\pm 0.17 \%$, 2 s.d., $\left.\mathrm{n}=10\right)$ overlaps with the bulk crust value $\left(\delta^{74} \mathrm{Ge}=0.58 \pm 0.10 \%\right.$ ). Because deep-sea sediments are essentially composed of terrigenous materials with only minor biogenic (e.g. siliceous organisms) and authigenic components (e.g. Mn and Fe oxyhydroxides), it can be suggested that, as a whole, secondary clay formations do not significantly fractionate Ge isotopes. As these lithologies also comprise the major part of the deep-sea sediments (Plank and Langmuir 1998), these results suggested that the average $\delta^{74 / 70} \mathrm{Ge}$ value for the entire sedimentary section of the oceanic crust is similar to or slightly higher than the igneous value. Mesozoic deep-sea cherts selected by Rouxel et al. (2006) had $\delta^{74 / 70} \mathrm{Ge}$ values ranging from 0.04 to 
1.31\% (Figure 13), and had therefore Ge isotope values both lighter and heavier than crustal value, but systematically lighter than seawater value estimated at 3.1\%o (see discussion about seawater value below). Germanium/silicon $(\mathrm{Ge} / \mathrm{Si})$ ratios of deep-sea cherts varied between 0.34 to $1.1 \mu \mathrm{mol} / \mathrm{mol}$, on average slightly higher than found in other Mesozoic cherts, with $\mathrm{Ge} / \mathrm{Si}$ ratios ranging between $0.19 \times 10^{-6}$ to $0.72 \times 10^{-6}$ (Kolodny and Halicz 1988). The calculated amount of clay minerals relative to opal in each sample was generally below $10 \%$ and the overall lack of relationship between $\delta^{74 / 70} \mathrm{Ge}$ and $\mathrm{Ge} / \mathrm{Si}$ (or $1 / \mathrm{Ge}$ ) values for deep-sea cherts rules out simple binary mixing between biogenic and lithogenic pools for the explanation of the observed $1.3 \%$ range $\delta{ }^{74 / 70} \mathrm{Ge}$ values. Instead, Rouxel et al. (2006) proposed that Ge isotope fractionation occurs during opal diagenesis and lithification processes leading to chert formation. One thermal chert was also measured and yielded the highest $\delta^{74} \mathrm{Ge}$ value of $1.3 \%$. As this sample was silicified under abnormally high temperature conditions at the proximity of volcanic flows (Rouxel et al. 2003b), $\delta^{74 / 70} \mathrm{Ge}$ values might be influenced by hydrothermal fluid input at the sediment-basement interface, which is consistent with recent study of Escoube et al. (2015) and Siebert et al. (2011) showing enrichment of heavy Ge isotopes in low temperature hydrothermal fluids.

One sample of glauconite was analyzed by Rouxel et al. (2006) and showed a $\delta^{74 / 70} \mathrm{Ge}$ value at about 2.5\%, close to seawater value (Figure 13). Glauconite is an Fe-rich authigenic clay mineral, which forms in shallow marine environments at the sediment-water interface within a reducing microenvironment. A part of Ge incorporated in glauconite may be derived from detrital materials or Ge-rich primary mineral (such as biotite). However, the heavy $\delta^{74} \mathrm{Ge}$ value argues against the predominance of a terrigenous source of $\mathrm{Ge}$, and suggests rather that Ge also derives from seawater with heavy $\delta^{74 / 70} \mathrm{Ge}$ value.

Despite their interest for paleoceanography (Frank 2002), no published data are yet available on Ge isotope composition of authigenic or hydrogeneous $\mathrm{Mn}$ deposits such as ferromanganese (FeMn) crusts and nodules. Considering their very low growth rate (mm/Ma), FeMn crusts (and nodules) may provide a unique window into Ge biogeochemical cycles throughout the last 10 to 60 Ma of Earth's history. A preliminary analysis of the Ge isotope composition of Nod-P1, a composite Mn nodule from the deep Pacific Ocean with Ge content of $0.54 \mathrm{ppm}$ (Govindaraju 1994) yielded $\delta^{74 / 70} \mathrm{Ge}=-0.08 \pm 0.09 \%$ (S. Lalonde pers. comm.). This value is much lower than the bulk crust and seawater values estimated at about 3.1\% (Escoube et al. 2012), suggesting that Ge removal in hydrogenous Mn deposits favors the enrichment in the light Ge isotopes. This assumption is further supported by recent experimental and field studies showing the fractionation of $\mathrm{Ge}$ isotopes during $\mathrm{Ge}$ sorption onto Fe oxyhydroxides (Pokrovsky et al. 2014; Escoube et al. 2015). Hence, unlocking the history of Ge oceanic cycle through would require a good understanding of the mechanisms of $\mathrm{Ge}$ isotope fractionation during precipitation on FeMn deposits. 


\section{Germanium isotope composition of seawater}

Germanium has been long been considered as a "geochemical twin" of silicon. Dissolved inorganic Ge in seawater ranges from less than 2 to about $200 \mathrm{pM}$ and displays a correlation with dissolved silica that is remarkably consistent across the world's oceans, underlying its potential as a complementary tracer for marine silicon cycling (Froelich and Andreae 1981; Froelich et al. 1985a; Froelich et al. 1985b; Ellwood and Maher 2003). This coupling is demonstrated by the close correlation of $\mathrm{Ge}$ and $\mathrm{Si}$ in all oceanic basins, with a $\mathrm{Ge} / \mathrm{Si}$ of $0.7 \mu \mathrm{mol} / \mathrm{mol}$. The $\mathrm{Ge} / \mathrm{Si}$ ratio is also constant through most of the water column. However, there is a positive and significant Ge intercept for the Ge-to-Si relationship. The intercept value varies between 1.7 and $3.6 \mathrm{pM}$ depending on the analytical system used for $\mathrm{Ge}$ detection. The positive Ge intercept is thought to result from $\mathrm{Ge} / \mathrm{Si}$ fractionation during Si uptake (Murnane and Stallard 1988; Froelich et al. 1989; Ellwood and Maher 2003). Likewise, a fractionation factor $\left(K_{D}\right)$ of 0.36 was obtained at low Si concentrations $(<6 \mu \mathrm{M})$, assuming a Rayleigh distillation-like process (Ellwood and Maher 2003). Profiles for Ge/Si versus depth revealed also a subsurface maximum in the $\mathrm{Ge} / \mathrm{Si}$ data suggesting either that $\mathrm{Ge}$ is being recycled faster than $\mathrm{Si}$ from phytoplankton, or that $\mathrm{Ge} / \mathrm{Si}$ is fractionated at low $\mathrm{Ge}$ and $\mathrm{Si}$ concentration during uptake (Sutton et al. 2010). Such Ge/Si fractionation during Si and Ge uptake and/or regeneration is the most likely explanation for the positive Ge intercept seen for the global Ge versus Si relationship.

Like $\mathrm{Si}$, natural variation of $\mathrm{Ge}$ isotopes may provide additional insights into marine $\mathrm{Si}$ biogeochemical cycling and the Ge marine cycle. However, due to the low natural abundance of inorganic Ge in seawater (below $200 \mathrm{pM}$ ), the Ge isotope composition of seawater remains largely unconstrained. It was only until recently that new methods were developed for the measurements of Ge isotopes in seawater (Baronas et al. 2014; Guillermic et al. 2016). Guillermic et al. (2016) reported Ge isotope compositions of inorganic Ge across three depth profiles from the Southern Ocean and also from the deep Atlantic and Pacific Ocean. $\delta^{74 / 70} \mathrm{Ge}$ values along a water column profiles from the Southern Ocean are isotopically heavier in surface waters compared to deep waters, with a global range of $\delta^{74 / 70} \mathrm{Ge}$ from 2.4 to $3.7 \%$ (relative to NIST3120a). The results may suggest that diatoms, in particular during Ge uptake in soft tissues (Mantoura, 2006), take up lighter Ge isotopes leading to surface seawater that is isotopically heavier. However, according to Figure 15, the value for surface seawater $\left(\delta^{7 / 70} \mathrm{Ge}\right.$ up to $3.07 \pm 0.09 \%$ ) is not isotopically heavier (within error) than deep seawater which has a global $\delta^{74 / 70} \mathrm{Ge}=3.14 \pm 0.38 \%$ o (2s.d., $\mathrm{n}=27$ ). An important result of this preliminary study is that no differences could be identified between the North Atlantic, North Pacific or Southern Ocean.

Unlike $\mathrm{Si}$, a substantial amount of $\mathrm{Ge}$ is associated with organic species (Lewis et al. 1985; Lewis et al. 1989). The two dominant organic Ge species in the oceans, monomethyl and dimethyl germanium, have concentrations of $\sim 350$ and $100 \mathrm{pM}$, respectively. Both exhibit conservative distributions and appear to be highly stable in the marine environment. Because of their long residence 
times ( $>1$ million years) these species should not exert a strong influence on the budget for inorganic $\mathrm{Ge}$, which has a residence time of $\sim 10 \mathrm{kyr}$. The Ge isotope compositions of such species are still unknown.

\section{Germanium isotope composition of biogenic opal}

In a reconaissance study, Rouxel et al. (2006) reported the Ge isotope composition of opal sponge spicules obtained from live sponges growing on the seafloor (Table 6, Figure 13). Two deepsea specimens (NE Pacific) and one coastal marine sponge (California) were analyzed and yielded similar Ge concentrations (between 0.18 and $0.26 \mathrm{ppm}$ ) but variable ${ }^{74 / 70} \mathrm{Ge}$ values (between 1.6\% and $2.6 \%$ ). These results clearly demonstrate that $\delta^{74 / 70} \mathrm{Ge}$ values of modern marine sponges are enriched in heavy isotopes by more than $\sim 1.0 \%$ relative to the bulk crust. More recently, Guillermic et al. (2016) reported the Ge isotope composition of sponge spicules that were previously examined for Si isotopes (Hendry et al. 2010; Hendry and Robinson 2012). Samples were collected from the Southern Ocean along a transect across the Drake Passage and Scotia Sea to investigate the fractionation of $\mathrm{Ge}$ isotopes in sponges as a function of ambient $\left[\mathrm{Si}(\mathrm{OH})_{4}\right]$. Although no clear relationships could be derived between $\delta^{74 / 70} \mathrm{Ge}$ and oceanographic parameters (e.g. nutrient, water depth, temperature) or sponge species, the results confirmed earlier investigations suggesting heavy $\mathrm{Ge}$ isotope composition in biogenic opal. Sponges from the Southern Ocean showed an average $\delta^{74 / 70} \mathrm{Ge}$ value of $2.21 \pm 0.54 \%$ (2s.d., $\mathrm{n}=16$ ) (Table 6) which is about $1.0 \pm 0.1 \%$ lighter than coeval seawater deep water at the same location (Guilllermic et al. submitted). This suggests that sponges fractionate Ge isotopes during biomineralization, and discriminate against heavy isotopes as already observed for Si isotopes (De La Rocha 2003; Hendry and Robinson 2012). Sponges are considered to have a low affinity for silicic acid (Reincke and Barthel 1997) and the inefficient silicon uptake mechanism has been suggested to explain their preferential enrichment in the light $\mathrm{Si}$ isotope (De La Rocha 2003) and also Ge isotopes. However, further studies are needed to address whether Ge isotopes (and $\mathrm{Ge} / \mathrm{Si}$ ) in sponges could be used as both tracers of $\mathrm{Si}(\mathrm{OH})_{4}$ utilization and $\mathrm{Si}$ sources to the open ocean.

In an unpublished $\mathrm{PhD}$ Thesis, Mantoura (2006) carried out laboratory experiments to test whether diatoms fractionate Ge isotopes during biomineralization. Three species were grown at a range of $[\mathrm{Ge}]$ and $\mathrm{Ge} / \mathrm{Si}$, and no fractionation of $\mathrm{Ge}$ isotopes was observed between cleaned diatom opal and the initial culture media (Figure 14). It was concluded that diatom opal may record the $\delta^{74 / 70} \mathrm{Ge}$ value of seawater and therefore may be an accurate recorder of temporal changes in the marine $\mathrm{Ge}$ cycle. This is in marked contrast to $\mathrm{Si}$ isotopes which are significantly fractionated during diatom uptake, allowing Si isotopes in diatom opal to record Si utilisation in the surface ocean (e.g. (De La Rocha et al. 1997; De La Rocha et al. 1998; Sutton et al. 2013). However, there is some indication that fractionation of Ge isotopes may occur in diatom organic matter. Germanium isotopes may be fractionated upon incorporation into diatom organic matter with the preferential enrichment of 
light $\mathrm{Ge}$ isotopes of approximately $-1.5 \%$ (Figure 14). This suggests that the removal and remineralization of organic matter in the surface ocean may cause some local variation in $\delta^{74 / 70} \mathrm{Ge}$ of surface seawater. However, this effect is likely to be diminished due to the rapid remineralization of organic matter, compared to diatom opal, in intermediate waters.

Rouxel and De La Rocha (unpublished data) also measured the $\delta^{74 / 70} \mathrm{Ge}$ values for cleaned diatom opal over the penultimate glacial cycle (De La Rocha et al. 1998). The diatom samples were physically and chemically cleaned using a protocol adapted from Shemesh (1988). Since diluted HF was used for opal dissolution, the results may be potentially affected by remaining clay particles. Diatom samples were extracted from Core E50-11 located in the Indian Ocean at different depth below seafloor. Due to limited sample availability, clean diatom samples were pooled to provide sufficient material for Ge isotope analysis. The results in Table 6 and Figure 13 therefore correspond to average values and do not provide a paleoceanographic record. Yet they provide an important record of Holocene seawater, allowing calculating an average $\delta^{74 / 70} \mathrm{Ge}$ value of $2.8 \pm 0.4 \%$, confirming that seawater is enriched in heavy Ge isotopes (Baronas et al. 2014; Guillermic et al. 2016).

\section{Ge isotope fractionation during low temperature weathering}

In a recent study, Baronas et al. (2014) reported rivers with a wide range of $\delta^{74 / 70} \mathrm{Ge}$ values being 1.8 to $4.8 \%$ heavier than average crustal values. Based on a relatively limited dataset, river $\delta^{74 / 70} \mathrm{Ge}$ values seemed unrelated to $\mathrm{Ge} / \mathrm{Si}$ or Ge concentrations and bedrock lithology (Baronas et al. 2014). Scavenging or exchange reactions with particulate matter (clays, Fe-oxyhydroxide and organic matter) as well as soil and weathering processes are likely the main contributors to the observed isotopic variability in river water. Pokrovsky et al. (2014) investigated the fractionation of Ge isotopes during Ge adsorption on goethite and its coprecipitation with amorphous Fe oxy(hydr)oxides (see experimental section). Regardless of the $\mathrm{pH}$, surface concentration of adsorbed Ge or exposure time, the solution-solid enrichment factor for adsorption $\left(\Delta^{74 / 70} \mathrm{Ge}\right.$ solution-solid $)$ was $1.7 \pm 0.1 \%$. For

$(\mathrm{Ge} / \mathrm{Fe})_{\text {solid }}$ ratio $<0.1$, the $\Delta^{74 / 70} \mathrm{Ge}_{\text {solution-solid }}$ increased with the decrease of Ge concentration in the solid phase, with a value as high as $4.4 \pm 0.2 \%$ at $(\mathrm{Ge} / \mathrm{Fe})_{\text {solid }}<0.001$, corresponding to the majority of natural settings. These experimental data provide important guides for the cause of heavy Ge isotopes in continental run-off, including river and groundwater systems.

\section{Germanium isotope systematics of hydrothermal waters}

In an initial study, Siebert et al. $(2006 ; 2011$ a) analyzed geothermal spring fluids from the Cascades. These continental high-T hydrothermal fluids had a heavy Ge isotope composition relative to crustal value, with a range in $\delta^{74 / 70} \mathrm{Ge}$ between $1.1 \%$ and $1.9 \%$ (normalized relative to NIST3120a) 
for Ge concentrations ranging from 20 to $94 \mathrm{nM}$ (Figure 16). The data were interpreted as reflecting the preferential removal of heavy Ge isotopes out of solution during cooling of the hydrothermal fluid and subsequent precipitation of quartz. However, ab initio calculations of Ge isotope fractionation factors reported by Li et al. (2009) suggest that the heavier isotope should be sequestered in the quartz phase, implying that fluids should become lighter as they cool. Hence, alternative mechanisms should be considered, including the sequestration of isotopically light Ge into sulfides as fluids cool or kinetic isotope effects. The existing data sets are insufficient to further speculate about the exact processes driving Ge isotope fractionation in terrestrial hydrothermal fluids. However, these initial observations suggest that continental geothermal springs provide a source of heavy Ge isotopes to rivers and groundwaters and therefore to the oceans.

In a more recent study, Escoube et al. (2015) investigated hydrothermal vents from the Loihi Seamount (Pacific Ocean, $18^{\circ} 54^{\prime} \mathrm{N}, 155^{\circ} 15^{\prime} \mathrm{W}$ ) that were characterized by distinct chemistry with high $\mathrm{Fe}$ and Si concentrations and low sulfide concentration (Sedwick et al. 1992; Glazer and Rouxel 2009). Escoube et al. (2015) also investigated Ge isotope signatures of a well-studied hightemperature hydrothermal system from the East Pacific Rise (EPR) at $9^{\circ} 50^{\prime} \mathrm{N}$ (e.g. Von Damm 2004). The very young age of the lava flows along the axial summit trough of EPR at $9-10^{\circ} \mathrm{N}$ offers the opportunity to study Ge isotope systematics during the early stage of high-temperature hydrothermal venting and active formation of hydrothermal sulfide deposits. The high temperature hydrothermal fluids from EPR $9-10^{\circ} \mathrm{N}$ were enriched in Ge vs. Si compared to source rocks (i.e. basalt with $\mathrm{Ge} / \mathrm{Si}=$ $2.4 \mu \mathrm{mol} / \mathrm{mol}$ ) with $\mathrm{Ge} / \mathrm{Si}$ ratios between 3.7 and $8.5 \mu \mathrm{mol}^{\mathrm{mol}}{ }^{-1}$. Those values were lower than at Loihi Seamount (Ge/Si averaging $29.6 \pm 1.6 \mu \mathrm{mol} / \mathrm{mol}$ ) but consistent with other high temperature vent fluids from EPR $21^{\circ} \mathrm{N}$ and Juan de Fuca Ridge (Mortlock et al. 1993) (i.e. Ge/Si between 5 and $15 \mu \mathrm{mol} / \mathrm{mol}$ ) (Figure 16). Loihi vent fluids had $\delta^{74 / 70} \mathrm{Ge}$ values ranging from 0.6 to $2.2 \%$, averaging $1.68 \pm 0.70 \%$ (2s.d.) and were thus systematically heavier than basaltic values at $0.56 \%$. Those $\delta^{74 / 70} \mathrm{Ge}$ values were, however, lighter than seawater with $\delta^{74 / 70} \mathrm{Ge}$ about $3 \%$. High temperature vent fluids from EPR $9-10^{\circ} \mathrm{N}$ yielded $\delta^{74 / 70} \mathrm{Ge}$ values averaging $1.55 \pm 0.36 \%$ (2s.d., $\mathrm{n}=6$ ) and were similar, albeit slightly lower, than the average $\delta^{74 / 70} \mathrm{Ge}$ value of low temperature hydrothermal fluids at Loihi Seamount (Figure 16). Hence, despite their fundamental differences in temperature and chemical composition, high and low temperature hydrothermal vent fluids showed similar Ge isotope compositions characterized by a global enrichment in heavy Ge isotopes of about $1 \%$ relative to the basaltic source.

Escoube et al. (2015) further evaluated whether both high $\mathrm{Ge} / \mathrm{Si}$ ratios and heavy $\delta^{74 / 70} \mathrm{Ge}$ values of hydrothermal fluids compared to source rocks may be explained by mineral-fluid partitioning in the reaction zone (i.e. batch fractionation) or upflow zone (i.e. fractional distillation). Because Si concentration in high-temperature hydrothermal fluids is controlled by quartz solubility (Von Damm et al. 1991), higher Ge/Si ratios in hydrothermal fluids venting at the seafloor may be 
buffered by quartz in the reaction zone (Mortlock et al. 1993; Wheat and McManus 2005). However, the quartz-controlled solubility model cannot fully explain the data as it requires a large fractionation factor $\Delta^{74 / 70} \mathrm{Ge}_{\mathrm{Qz} \text {-fluid }}$ at about $-4 \%$. Hence both quartz and sulfide precipitation in the reaction zone may control Ge/Si and Ge-isotope signatures in the fluid. Subsurface cooling of the hydrothermal fluid may also affect $\mathrm{Ge} / \mathrm{Si}$ and $\delta^{74 / 70} \mathrm{Ge}$ signatures of the vent fluids if significant Si-rich mineral precipitation occurs along the flow path.

At Loihi Seamount, the distinct fluid chemistry, enriched in Fe and $\mathrm{Si}$ and depleted in $\mathrm{H}_{2} \mathrm{~S}$, led to the formation of extensive Fe-rich microbial mats and hydrothermal Fe-oxyhydroxide deposits at or below the seafloor (e.g. De Carlo et al. 1983; Karl et al. 1988; Emerson and Moyer 2002; Glazer and Rouxel 2009). The Fe-rich deposits at Loihi Seamount had low $\delta^{74 / 70} \mathrm{Ge}$ values from 0.16 down to $0.98 \%$, which corresponds to a maximum apparent $\Delta^{74 / 70} \mathrm{Ge}_{\text {deposit-fluid }}$ of $-2.81 \%$ (Figure 16). The largest fractionation factor between fluid and Fe-rich deposit was broadly consistent with experimental data for Ge coprecipitation with amorphous Fe-oxyhydroxide up to -4.4 \%o (Pokrovsky et al. 2014) (see also the section "Theoretical considerations and experimental calibrations"). Using $\alpha_{\text {sol-liq }}$ of about 0.996 as determined by Pokrovsky et al. (2014), Escoube et al. (2015) determined that Ge isotope composition of Fe-oxyhydroxide deposits corresponds to a loss of more than $30 \%$ of Ge from the hydrothermal fluid due to precipitation within Fe-rich deposits. This suggests that Fe-rich deposits provide a relatively efficient trapping of reactive elements coming from the diffuse vent fluids. This finding contrasts with high-temperature hydrothermal chimneys that behave as an open system relative to vent fluids; i.e., only a small fraction of elements is trapped within the chimney wall (Tivey 1995).

\section{A preliminary oceanic Ge budget}

Rivers supply most of Si to the modern ocean $\left(5.6 \times 10^{12} \mathrm{~mol} / \mathrm{yr}\right)$ with minor contributions from aeolian sources, hydrothermal input, and low-temperature basalt weathering, totaling $6.7 \times 10^{12}$ $\mathrm{mol} / \mathrm{yr}$ (Treguer et al. 1995; DeMaster 2002; Treguer 2002). The output term for Si is marine biogenic sediments (primarily as diatoms, sponges, and radiolaria) and totals $6.5-7.4 \times 10^{12} \mathrm{~mol} / \mathrm{yr}$ (Figure 17). In contrast to $\mathrm{Si}, \mathrm{Ge}$ has two primary sources: rivers, which contribute to $3.3 \times 10^{6} \mathrm{~mol} / \mathrm{yr}$, and hydrothermal inputs, which contribute $4.9 \times 10^{6} \mathrm{~mol} / \mathrm{yr}$ (Mortlock et al. 1993; Elderfield and Schultz 1996; King et al. 2000). Aeolian inputs and low-temperature basalt weathering reactions each produce between 0 to $0.4 \times 10^{6} \mathrm{~mol} / \mathrm{yr}$. Because the two dominant $\mathrm{Si}$ and Ge sources to the ocean carry very different $\mathrm{Ge} / \mathrm{Si}$ signatures, with $(\mathrm{Ge} / \mathrm{Si})_{\text {rivers }} \sim 0.4 \mu \mathrm{mol} / \mathrm{mol}$ and $(\mathrm{Ge} / \mathrm{Si})_{\text {hydrothermal }} \sim 8-14 \mu \mathrm{mol} / \mathrm{mol}$, it has been proposed that the Ge/Si ratio buried in biogenic siliceous tests on the seafloor reflects the present and past source strength of the river fluxes relative to hydrothermal fluxes (Murnane and Stallard 1988; Froelich et al. 1992; Elderfield and Schultz 1996). However, the use of Ge/Si as a monitor for the relative importance of these two sources through time remains uncertain as the Ge 
mass balance in the modern ocean is not well understood. Assuming steady state, the contemporary input fluxes from continents and hydrothermal sources require Ge removal with a $\mathrm{Ge} / \mathrm{Si}$ ratio of 1.6 $\mu \mathrm{mol} / \mathrm{mol}$, which is significantly greater than the observed opal burial ratio of $0.7 \mu \mathrm{mol} / \mathrm{mol}$ (Elderfield and Schultz, 1996). Identification and quantification of the so-called "missing Ge sink" has received great interest in the past decade and it is now proposed that Ge may be removed from the ocean in iron-rich reducing sediments of continental margins independently of Si (Hammond et al. 2000; King et al. 2000; McManus et al. 2003). This sink corresponds to about $55 \pm 9 \%$ of Ge within opal released by dissolution (Hammond et al. 2000). Considering the potential of Ge isotopes to fractionate during marine sediment diagenesis, for example during Ge precipitation with authigenic minerals, Ge isotope systematics should be a powerful tool to further constrain the missing sink through the establishment of a mass balance of Ge isotopes in the oceans.

In order to address these issues, Escoube et al. (2015) established a preliminary mass balance of $\mathrm{Ge}$ in seawater, using a one box ocean model based on $\mathrm{Ge} / \mathrm{Si}, \delta^{74 / 70} \mathrm{Ge}$ and the marine Ge source and sink fluxes (Figure 17). At steady state, the sum of input fluxes and output fluxes of Ge to the ocean are equal:

$$
\mathrm{F}_{\text {river }}+\mathrm{F}_{\text {atmospheric }}+\mathrm{F}_{\text {hydrothermal }}+\mathrm{F}_{\text {low-T basalt }}=\mathrm{F}_{\text {opal }}+\mathrm{F}_{\text {non-opal }}
$$

With, F, the flux of Ge of each of the inputs and outputs determined based on their $\mathrm{Ge} / \mathrm{Si}$ ratios and Si fluxes (From Hammond et al. 2000; King et al. 2000; McManus et al. 2003). Considering steady-state conditions, the mass balance of Ge isotopes in seawater is defined as:

$$
\sum_{\text {Source }}\left(F_{\text {Source }} \times \delta^{74 / 70} G e_{\text {Source }}\right)=\sum_{\text {Sink }}\left(F_{\text {Sink }} \times \delta^{74 / 70} G e_{\text {Sink }}\right)
$$

In order to determine the Ge isotope signature of the missing, non-opal Ge sink, Escoube et al., (2015) resolved equation (8) and (9) using estimated $\delta^{74 / 70} \mathrm{Ge}$ and $\mathrm{Ge} / \mathrm{Si}$ values of other $\mathrm{Ge}$ sinks and sources (Figure 17), such as:

(1) $\delta^{74 / 70} \mathrm{Ge}$ value of atmospheric deposition (i.e. aeolian particles) has been estimated to be identical to crustal values, with $\delta^{74 / 70} \mathrm{Ge}=0.56 \pm 0.20 \%$ as estimated by Escoube et al. (2012). Silicon and Ge fluxes from atmospheric deposition were taken from the estimation of King et al. (2000) .

(2) Ridge flanks Ge and Si fluxes, including the sum of warm $\left(40-75^{\circ} \mathrm{C}\right)$ hydrothermal systems and low-temperature seafloor basalt weathering were taken from Wheat and McManus (2005). Because of the large range of Ge/Si ratios in warm hydrothermal fluids from ridge flanks, an uncertainty of $50 \%$ should be considered for Ge flux. $\delta^{74 / 70} \mathrm{Ge}$ of ridge flank fluxes is also considered similar to the average value obtained at Loihi Seamount $\left(\delta^{74 / 70} \mathrm{Ge}=1.2 \pm 0.5 \%\right.$ ). Despite the relatively large uncertainties, the ridge flank Ge fluxes have a minor influence on global Ge oceanic cycle due to their small contribution representing less than $10 \%$ of the total Ge input. 
(3) The Si and Ge fluxes from rivers were taken from the estimation of King et al. (2000). $\delta^{74 / 70} \mathrm{Ge}$ values of rivers are still poorly known. Germanium/silicon $(\mathrm{Ge} / \mathrm{Si})$ in rivers are well known to be fractionated relative to bulk Earth (with a ratio around 0.58 versus 1.3 for the crust, Mortlock and Froelich 1987). Therefore, the Ge isotope composition of rivers is likely to be fractionated relative to the crust due to Ge sorption on clay or oxide minerals, as previously observed by Kurtz et al. (2002) and Scribner et al. (2006). Because rivers represent $37 \%$ of the global input of $\mathrm{Ge}$, it is clear that a better constraint on the riverine flux is important for establishing a reliable isotope mass balance in seawater.

(4) The $\delta^{74 / 70} \mathrm{Ge}$ value of the high-temperature (HT) hydrothermal flux is estimated as at 1.55 $\pm 0.36 \%$ based on average values obtained from high-temperature vent fluids from the EPR. The $\mathrm{Ge} / \mathrm{Si}$ of the HT hydrothermal flux is determined as $11 \pm 3 \mu \mathrm{mol} / \mathrm{mol}$ based on the compilation of $\mathrm{Ge} / \mathrm{Si}$ values for high-temperature hydrothermal vents (Mortlock et al. 1993; Escoube et al. 2015). It should also be recognized that $\mathrm{Ge}$ (and $\mathrm{Si}$ ) fluxes from acidic volcanic island arcs, which represent about $10 \%$ of the hydrothermal flux (Baker et al. 2008), and back arc spreading centers are poorly known and may contribute differently to Ge fluxes.

(5) The $\delta^{74 / 70} \mathrm{Ge}$ values of the opal sink are considered identical to seawater values as demonstrated in previous studies showing a lack of $\mathrm{Ge} / \mathrm{Si}$ and $\mathrm{Ge}$-isotope fractionation during diatom uptake (Shemesh et al. 1989; Bareille et al. 1998; Mantoura 2006). Mantoura (2006) reported $8^{7 / 70} \mathrm{Ge}$ values at around $3.3 \%$ for diatom opal from Holocene sediments while Guillermic et al. (2016) reported Ge isotope composition of deep Pacific and Atlantic waters at $3.14 \pm 0.38 \%$.

(6) The removal of elements in hydrothermal plumes through adsorption onto $\mathrm{FeOOH}$-rich particles is well recognized for seawater oxyanions such as V, As and P (Feely et al. 1990; Feely et al. 1991) but is probably negligible for Ge. In particular, it has been demonstrated that $\mathrm{Ge} /{ }^{3} \mathrm{He}$ ratios of the dispersing hydrothermal plume remain close to high-temperature hydrothermal vent end-member values, suggesting a near conservative behavior of Ge during seawater-hydrothermal fluid mixing (Mortlock et al., 1993).

The isotopic mass balance is solved using a box model using the parameters defined in Figure 17 and by applying an error propagation scheme (i.e. Monte Carlo simulation). Equations (8-9) are solved simultaneously in order to estimate the $\delta^{74 / 70} \mathrm{Ge}$ value of the missing, non-opal Ge sink for the cases of (i) riverine input at crustal values and (ii) riverine input identical to seawater values. In the first case, Escoube et al. (2015) determined the $\delta^{74 / 70} \mathrm{Ge}$ value of the non-opal Ge sink to be $-0.6 \pm 0.4$ $\%$, which is about $3.6 \%$ lighter than seawater. In the second case, Escoube et al. (2015) obtained heavier $\delta^{74 / 70} \mathrm{Ge}$ value at $0.9 \pm 0.3 \%$ for the missing Ge sink, which is about $2.1 \%$ lighter than seawater. These values corresponded well to the expected isotope fractionation produced by $\mathrm{Ge}$ adsorption onto Fe-oxyhydroxide. It is however important to note that both the Ge flux estimate and 
$\delta^{74 / 70} \mathrm{Ge}$ value of the non-opal Ge sink were highly sensitive to errors in the estimation of global hydrothermal Ge and Si fluxes. For example, at the lowest estimate of hydrothermal Si flux, the missing (non-opal) Ge sink became insignificant, leading to a very large uncertainty for its Ge isotope signature.

Based on this preliminary mass balance, it can be suggested that the "missing sink" of Ge in the oceans is likely controlled by the adsorption of Ge onto Fe-oxyhydroxide in marine sediments, as already proposed in previous studies (Hammond et al. 2000; King et al. 2000; McManus et al. 2003). It is however important to note that Ge isotope fractionation in authigenic clays remains unknown. Sulfides are also characterized by very light $\delta^{74 / 70} \mathrm{Ge}$ values (Escoube et al. 2012; Luais 2012; Meng et al. 2015) which can potentially provide a sink for isotopically light Ge in the ocean. However, the amount of Ge sequestrated in sedimentary sulfides is probably insignificant compared to the opal and authigenic Fe oxyhydroxide sinks. This assumption is supported by the lack of Ge removal in the sulfidic and anoxic waters of the Baltic Sea (Andreae and Froelich 1984). The importance of Ge removal with organic matter, however, will need to be further assessed considering the large $\mathrm{Ge}$ enrichment factors and the range of Ge isotope compositions in organic-rich rocks and compounds ( $\mathrm{Li}$ et al. 2009; Li and Liu 2010, this study).

\section{The potential for paleoceanography and the rock record}

\section{Biogenic Opal}

The incorporation of Ge into diatom opal has been previously used to reconstruct changes in the Si water column cycle over time (Shemesh et al. 1988; Shemesh et al. 1989; Mortlock et al. 1991; Froelich et al. 1992; Bareille et al. 1998). The $\mathrm{Ge} / \mathrm{Si}$ signature of diatom opal ( $\mathrm{Ge} / \mathrm{Si}$ opal $)$ from the past 450,000 years revealed systematic changes that were coherent with glacial-interglacial cycles (Mortlock et al. 1991). Interpretation of the $\mathrm{Ge} / \mathrm{Si}_{\text {opal }}$ record has varied. Initially, it was thought that the decrease in $\mathrm{Ge} / \mathrm{Si}_{\text {opal }}$ from an interglacial value of $0.72 \mu \mathrm{mol} / \mathrm{mol}$ to a glacial value of $0.55 \mu \mathrm{mol} / \mathrm{mol}$ indicated a reduction in Ge uptake relative to $\mathrm{Si}$ as a result of lower Si utilisation during glacial times (Mortlock et al. 1991). However, diatom growth experiments have shown that diatoms grown at high Si concentrations $(100 \mu \mathrm{M})$ did not fractionate Ge/Si significantly leading Froelich et al. (1992) to suggest that glacial ocean Si concentrations were higher than the present day. More recently, the assumption that diatoms do not discriminate Ge versus Si has been challenged by Ellwood and Maher (2003). Because silica is biolimiting in today's ocean, complete consumption of Ge and $\mathrm{Si}$ in a Rayleigh distillation surface ocean could camouflage fractionation effects in the opal burial record (Murnane and Stallard 1988). Alternatively, Hammond et al. (2004) demonstrated that the change in $\mathrm{Ge} / \mathrm{Si}$ for the ocean could be explained by temperature dependent changes in the non-opal sink during 
glacial times. The fraction of opal dissolution occurring on the seafloor should increase, causing more Ge sequestration in the non-opal sink (Hammond et al. 2004). Clearly, there is a need to understand the processes involved in the uptake and incorporation of $\mathrm{Ge}$ into biogenic opal before the $\mathrm{Ge} / \mathrm{Si}_{\text {opal }}$ record can be correctly interpreted.

In an attempt to resolve some of the controversy in the paleorecord of $\mathrm{Ge} / \mathrm{Si}$ ratios in biogenic opal, Mantoura (2006) investigated Ge isotopes $\left(\delta^{74 / 70} \mathrm{Ge}\right.$ opal pattern) over the penultimate glacial cycle (Figure 18). The diatom samples were physically and chemically cleaned using a protocol adapted from Shemesh (1988). For opal dissolution, $\mathrm{Na}_{2} \mathrm{CO}_{3}$ was used instead of diluted HF in order to prevent the dissolution of potentially remaining clay particles. Using samples from the South Atlantic sector of the Southern Ocean (ODP Site 1094), Mantoura (2006) investigated the (Ge/Si) opal and $\delta^{74 / 70} \mathrm{Ge}$ opal record and found no difference between average glacial and average interglacial $\delta^{74 / 70} \mathrm{Ge}$ opal values. The average $\delta^{74 / 70} \mathrm{Ge}_{\text {opal }}$ value over 68 to 178 ka period, was determined at $3.35 \pm$ $0.29 \%$ (2s.d., $\mathrm{n}=29$ ). $\delta^{74 / 70} \mathrm{Ge}_{\text {opal }}$ rises from a glacial value of approximately $3.2 \%$ to a maximum of $3.6 \%$ during the termination and then falls again to approximately $3.3 \%$ later during the interglacial (Figure 18). Although the changes are barely outside the analytical error, there appears to be a perturbation in $\delta^{74 / 70} \mathrm{Ge}$ opal on the termination. Both increased biological productivity and more efficient uptake of upwelled nutrients in high-latitude oceans have been proposed (Martin 1990) as mechanisms responsible for the glacial reduction in atmospheric concentrations of carbon dioxide. Hence, the possibility to combine $\delta^{74 / 70} \mathrm{Ge}_{\text {opal }}$, with $\delta^{30} \mathrm{Si}_{\text {opal }}$ and $\mathrm{Ge} / \mathrm{Si}_{\text {opal }}$ should provide new insights into the variability of $\mathrm{Si}$ (and $\mathrm{Ge}$ ) utilisation of the surface ocean during glacial-interglacial periods.

\section{Iron Formations}

As pure chemical sediments largely free of detrital contamination, the $\mathrm{Fe}$ - and Si-rich precipitates that form Banded Iron Formations (BIF) are expected to record elemental and isotopic signatures of ancient seawater by sorption and co-precipitation reactions (Bekker et al. 2010). This assumption relies on the predictable nature of metal adsorption reactions occurring at the surface of the authigenic hydrous ferric oxides that would have precipitated from contemporaneous seawater. Although there has been significant work on the sources of silica in BIFs, basic aspects of silica deposition in iron formations and the Precambrian Si cycle remain poorly known (Hamade et al. 2003; Fischer and Knoll 2009; Bekker et al. 2010). Iron formations typically contain 34 to 56 wt.\% $\mathrm{SiO}_{2}$ (Klein 2005) and, potentially, represent a major sink for dissolved Si in the geological past. Although it is generally accepted that the source of silica in BIF was ambient seawater during most of the Precambrian, when the biological sink for seawater silica was presumably absent (Siever 1992), the source of silica to the oceans of that time period remains uncertain.

In order to better constrain silica sources, a growing number of studies have investigated the $\mathrm{Si}$ isotope composition of Precambrian iron formations and cherts (André et al. 2006; Robert and 
Chaussidon 2006; van den Boorn et al. 2007; Steinhoefel et al. 2009; Marin-Carbonne et al. 2014). Since hydrothermal fluids and rivers have very different Ge/Si ratios (Froelich et al., 1985; Mortlock et al., 1993), Ge/Si systematics in iron formations may provide constraints on the source of Si to the Precambrian oceans. On the basis of co-variation of $\mathrm{Ge} / \mathrm{Si}$ ratios with silica content in the ca. $2.5 \mathrm{Ga}$ Dales Gorge Member of the Brockman Iron Formation (Hamersley Group, Western Australia), Hamade et al. (2003) proposed a decoupling of $\mathrm{Fe}$ and $\mathrm{Si}$ sources, with $\mathrm{Si}$ being predominantly derived from riverine waters having low $\mathrm{Ge} / \mathrm{Si}$ ratios due to weathering of continental landmasses. Caution is required, however, due to the strong Ge fractionation relative to $\mathrm{Si}$ by sorption onto $\mathrm{Fe}-$ oxyhydroxides (Pokrovsky et al. 2006) or quartz precipitation (Evans and Derry 2002). In addition, release of Ge to porewaters may also affect $\mathrm{Ge} / \mathrm{Si}$ ratios during chert lithification (Rouxel et al. 2006). In either case, $\mathrm{Ge} / \mathrm{Si}$ ratios in cherts may not reflect seawater composition but instead record multiple, unrelated and geologically protracted processes.

Escoube et al. (2012) and Luais (2012) reported the composition of Ge isotopes in a single BIF sample (IF-G, from Isua, West Greenland) and found $\delta{ }^{74 / 70} \mathrm{Ge}$ values of $1.03 \pm 0.09 \%$, and $1.01 \pm$ $0.13 \%$, respectively. Germanium was also found enriched relative to crustal values with $\mathrm{Ge} / \mathrm{Si}$ ratios of $27 \mu \mathrm{mol} / \mathrm{mol}$. Luais et al. (2011) called attention to the measurements of Ge contents on bulk IF-G sample that exhibit petrographic evidence of fluid-induced metamorphism. They performed in situ LA-ICPMS measurements of Ge concentrations of individual minerals in both quartz and magnetite bands. Germanium/silicon (Ge/Si) ratios of quartz range from 6 to $10 \mu \mathrm{mol} / \mathrm{mol}$, which is significantly smaller than previously reported data of $\mathrm{Ge} / \mathrm{Si}>20 \mu \mathrm{mol} / \mathrm{mol}$ on individual bands (Frei and Polat 2007). They found that the occurrence of amphibole with Ge content up to $100 \mathrm{ppm}$ biases the Ge budget and the Ge/Si ratio (and probably the Ge isotopic composition) of individual "bulk" samples. Since Ge adsorbed onto Fe-oxyhydroxide is enriched in light isotopes (Li and Liu 2010; Pokrovsky et al. 2014; Escoube et al. 2015), the heavy $\delta^{74 / 70} \mathrm{Ge}$ values for IF-G is best explained by the heavy isotope composition of their Ge sources. Although alternative interpretations are possible, such as metamorphic overprinting, the slightly lighter values for IF-G compared to seawater may result from a higher contribution of hydrothermal Ge to Archaean oceans.

In an unpublished study, Lalonde et al. (2012) reported Ge and Si isotope compositions of Precambrian iron formations. Although the data set is still limited, both $\delta^{74 / 70} \mathrm{Ge}$ and $\delta^{30 / 28} \mathrm{Si}$ data demonstrated a nearly 3\%o variation over geological time. Archean Iron Formations (2.5 Ga to $3.2 \mathrm{Ga}$ old) displayed $\delta^{74 / 70} \mathrm{Ge}$ values ranging from $0.6 \%$ to $2.3 \%$. These Ge isotope data appeared unrelated to $\mathrm{Ge} / \mathrm{Si}$ and $\mathrm{Fe} / \mathrm{Si}$ ratios, suggesting that mineralogy or $\mathrm{Si}$ sources were not the primary factors controlling Ge isotope composition. Lalonde et al. (2012) also performed a detailed study of $\delta^{74 / 70} \mathrm{Ge}$ variations through an entire $355 \mathrm{~m}$ core section of the Joffre Member of the Brockman Iron Formation. This $\sim 2.45$ billion year old unit is by volume the largest single known banded iron formation (BIF) in the world, providing a window to Paleoproterozoic seawater chemistry (Haugaard et al. 2016). Results showed significant $\delta^{74 / 70} \mathrm{Ge}$ variations from 0.97 to $2.27 \%$, yielding an average of $1.67 \pm 0.68 \%$ o 
(2s.d., $\mathrm{n}=28$ ). The large variability suggests that local deposition environment and postdepositional effects should be well understood before reconstructing the long-term variations of Ge isotopes across the Precambrian.

\section{Carbonaceous rocks}

Trace-metal concentrations of laminated, organic-rich shales have long been used to draw inferences concerning paleoredox conditions as well as metal inventory in ancient oceans (Algeo et al. 2004; Brumsack 2006; Lyons and Severmann 2006; Lehmann et al. 2007) with potential constraints on past atmospheric oxygenation, weathering intensity, marine productivity, global volcanic and hydrothermal events and ocean redox structure. In general, the enrichment of redox-sensitive metals (e.g. Mo, Re, U) in organic-rich sedimentary rocks is highly sensitive to seawater redox conditions, sulfate concentrations, and depositional/post-depositional conditions. As Ge is not redox-sensitive, its behavior in anoxic sedimentary rocks is likely to differ from other elements. However, the utility of Ge enrichment factors in black shales has been the subject of a very limited number of studies. In general, elevated $\mathrm{Ge} / \mathrm{Si}$ ratios in cherts above $\sim 0.10 \mu \mathrm{mol} / \mathrm{mol}$ are commonly regarded as evidence of a hydrothermal component (Rouxel et al. 2006; Escoube et al. 2015; Slack et al. 2015). In organic-rich black shales, Ge and Si can also fractionate in sulfidic pore fluids during diagenesis (Tribovillard et al. 2011), producing anomalously high $\mathrm{Ge} / \mathrm{Si}$ ratios unrelated to a hydrothermal signature. Hence, the possiblity of authigenic Ge enrichment in sedimentary rocks deposited under more or less severely reducing conditions open new perspectives for using Ge isotope systematics in paleoceanography.

In contrast to Ge enrichment in black shales, Ge enrichment during coal formation has received significant interest (Holl et al. 2007). Despite the high concentration of Ge in coal, ash and lignified wood (Bernstein 1985), important questions still remain about the origin of Ge in lignite and coal deposits, which is considered to be mainly epigenetic due to migration of Ge-bearing fluids. To adress this issue, Qi et al. (2011) investigated the Ge isotopic composition of Ge-rich lignite samples from China in order to provide important constraints on the mechanisms of Ge enrichment in coal. Result show that Ge-rich lignite samples yield large Ge isotopic fractionation $\left(\delta^{74 / 70} \mathrm{Ge}\right.$ values range from $-2.59 \%$ to $4.72 \%$ ). Lignite samples with low Ge concentrations (500 ppm) tend to show heaviest $\delta^{74 / 70} \mathrm{Ge}$ values, indicating a preferential enrichment of light Ge isotopes in coal in an open system (i.e. Rayleigh-type fractionation). Considering that Russia and China host the largest Gebearing coal deposits, increasing anthropogenic input of Ge in the environments should be considered when investigating natural Ge cycling in surface environments. Hence, Ge isotopes may provide useful tracers of sources of heavy metal pollution caused by high temperature industrial processes (coal combustion and $\mathrm{Pb}-\mathrm{Zn}$ refining) in the environment. 


\section{CONCLUSION}

For decades, Ge has been considered as an element of significant interest in Earth Sciences, including cosmochemistry with the characterization of meteorites and Apollo return samples, mantle geochemistry with the study of Iceland and Hawaiian mantle sources, and marine biogeochemistry with important paleoceanographic implications. In this context, Ge isotopes provide new tracers that show great promise to solve fundamental questions related to both high- and low-temperature geochemistry. Although scarce, theoretical and experimental studies have highlighted two distinct modes of enrichment processes leading to significant Ge isotopic fractionations: (i) incorporation in crystal lattice structure of silicate or metal, or (ii) adsorption processes onto Fe-oxides or $\mathrm{Fe}$ hydroxides minerals. Being volatile, Ge isotopes are also affected by evaporation/condensation processes. The absolute range of $\delta^{74 / 70} \mathrm{Ge}$ values in rocks and minerals is more than $8 \%$, which is comparable or even larger than most non-traditional stable isotope systems (e.g., Anbar and Rouxel 2007; this volume).

The knowledge of processes that induce high-temperature Ge isotope fractionation is essential for understanding the accretion-collision and differentiation history of planetary bodies. Indeed, the siderophile and volatile behavior of Ge lead to major differences in Ge isotope composition between deep core and mantle-crust reservoirs of planets, unlike other isotopic systems (e.g. Fe, Si). It is expected that further insights into Ge isotopic fractionation mechanisms will provide a key tool for the quantification of metal-silicate segregation in different planetary bodies, when compared to geophysical constraints on core formation of planetary bodies. Initial studies of mantle Ge isotope geochemistry emphasize broad homogeneity in the composition of the bulk silicate Earth. Further investigations at a smaller scale, and in various geodynamic settings will provide constraints into recycling processes into the mantle and crust formation processes. Significant advances have been made in understanding the incorporation of Ge in sulfides and other ore-forming minerals. Germanium isotopes as tracers of kinetic and equilibrium processes of mineral precipitation will undoubtly provide new clues into the mechanisms of formation of large ore deposits.

The promise of low-temperature Ge-isotope geochemistry derives from the close association between Ge and Si biogeochemical cycles. Yet at the same time major Si sources to the ocean (i.e. rivers and hydrothermal sources) have different $\mathrm{Ge} / \mathrm{Si}$ ratios. Initial work on the Ge-isotope composition of marine environments has revealed striking variations of Ge isotope ratios among Earth surface reservoirs (e.g. seawater, biogenic silica) and sources (e.g. rivers, hydrothermal vents). We hypothesize that coupled $\mathrm{Ge} / \mathrm{Si}, \mathrm{Si}$ isotopes and $\mathrm{Ge}$ isotope systematics provide i) a better understanding of the nature of modern marine silica fluxes with the identification of the "missing" Ge 
sink that prevents closure of the modern marine Ge budget; ii) new approaches to explore the longterm evolution of the marine silica cycle, from ancient silica-rich oceans dominated by inorganic silica cycling to modern oceans effectively Si-stripped by the biological silica pump. 


\section{ACKNOWLEDGMENTS}

Rouxel's research on Ge isotopes would not have been possible without support from the National Science Foundation, Europole Mer, LabexMer (ANR-10-LABX-19-01), University of Cambridge, Woods Hole Oceanographic Institution and Ifremer. Critical help and inspiration were provided by coworkers, students and colleagues over the years, notably Jotis Baronas, Andrey Bekker, Christina De La Rocha, Olivier Donard, Vesselin Dekov, Katrina Edwards, Harry Elderfield, Raphaelle Escoube, Albert Galy, Maxence Guillermic, Doug Hammond, Stefan Lalonde, Samia Mantoura, Emmanuel Ponzevera, Huawen Qi, Ed Sholkovitz. Béatrice Luais acknowledges fundings from CNRS-INSU research programs (CESSUR, DYETI-SYSTER, PNP), the French National Research Agency through the national program "Investissements d'avenir" with the reference ANR-10-LABX21-LABEX RESSOURCES21, the Observatoire Terre Environnement Lorraine (OTELo) program. Germanium isotope research of these last ten years benefited from assistance, interaction, and fruitful discussions with Françoise Ali, Rémi Belissont, Damien Cividini, Etienne Deloule, Afifé El Korh, Alexis Filia, Thibault de Gournay, Aymeric Schumacher, Laurent Tissandier, Mike Toplis, John Wasson. This manuscript benefited from the constructive reviews of Stefan Weyer, Doug Hammond, Nicolas Dauphas and one anonymous reviewer. 


\section{LITERATURE CITED}

Adam J, Green T (2006) Trace element partitioning between mica-and amphibole-bearing garnet lherzolite and hydrous basanitic melt: 1 . Experimental results and the investigation of controls on partitioning behaviour. Contrib Mineral Petrol 152:1-17

Albarede F, Beard B (2004) Analytical Methods for Non-Traditional Isotopes. In: Geochemistry of Non-Traditional Stable Isotopes. Vol 55. Johnson CM, Beard BL, Albarede F, (eds). Mineralogical Society of America; Geochemical Society, p 113-152

Algeo TJ, Schwark L, Hower JC (2004) High-resolution geochemistry and sequence stratigraphy of the Hushpuckney Shale (Swope Formation, eastern Kansas): implications for climato-environmental dynamics of the Late Pennsylvanian Midcontinent Seaway. Chem Geol 206:259-288

Anders AM, Sletten RS, Derry LA, Hallet B (2003) Germanium/Silicon ratios in the Copper River Basin, Alaska: Weathering and partitioning in periglacial versus glacial environments. J Geophys Res 108(F1):1-9

André L, Cardinal D, Alleman LY, Moorbath S (2006) Silicon isotopes in 23.8 Ga West Greenland rocks as clues to the Eoarchaean supracrustal Si cycle. Earth Planet Sci Lett 245:162-173

Andreae MO, Froelich PN (1981) Determination of germanium in natural waters by graphite furnace atomic absorption spectrometry with hydride generation. Anal Chem 53:287-291, doi:10.1021/ac00225a037

Andreae MO, Froelich PN (1984) Arsenic, antimony, and germanium biogeochemistry in the Baltic Sea. Tellus Series B-Chemical and Physical Meteorology 36:101-117

Arnorsson S (1984) Germanium in Icelandic geothermal systems. Geochim Cosmochim Acta 48:2489-2502

Avarelo RJ, McDonough WF (2010) Gallium and germanium abundances in MORB and OIB: Evidence for pyroxenitic source components? In Book Gallium and germanium abundances in MORB and OIB: Evidence for pyroxenitic source components? Editor, (ed)^(eds), A32

Babula P, Adam V, Opatrilova R, Zehnalek J, Havel L, Kizek R (2008) Uncommon heavy metals, metalloids and their plant toxicity: a review. Environmental Chemistry Letters 6:189-213, doi:10.1007/s10311-008-0159-9

Baker ET, Embley RW, Walker SL, Resing JA, Lupton JE, Nakamura K, de Ronde CEJ, Massoth GJ (2008) Hydrothermal activity and volcano distribution along the Mariana arc. J Geophys Res-Solid Earth 113, doi:10.1029/2007jb005423 
Bareille G, Labracherie M, Mortlock RA, Maier-Reimer E, Froelich PN (1998) A test of (Ge/Si)(opal) as a paleorecorder of $(\mathrm{Ge} / \mathrm{Si})$ (seawater). Geology 26:179-182, doi:10.1130/00917613(1998)026<0179:atogso $>2.3 . c o ; 2$

Baronas JJ, Hammond DE, McManus J, Siebert C, Wheat G (2014) Marine budget for Germanium stable isotopes. Ocean Sciences Meeting, Honolulu, 24-28th February 2014:Abstract ID:13978

Bekker A, Slack JF, Planavsky N, Krapez B, Hofmann A, Konhauser KO, Rouxel OJ (2010) Iron Formation: The Sedimentary Product of a Complex Interplay among Mantle, Tectonic, Oceanic, and Biospheric Processes. Economic Geology 105:467-508

Belissont R, Boiron MC, Luais B, Cathelineau M (2014) LA-ICP-MS analyses of minor and trace elements and bulk Ge isotopes in zoned Ge-rich sphalerites from the Noailhac - Saint-Salvy deposit (France): Insights into incorporation mechanisms and ore deposition processes. Geochim Cosmochim Acta 126:518-540, doi:10.1016/j.gca.2013.10.052

Belissont R, Muñoz M, Boiron M-C, Luais B, Mathon O (2016) Distribution and oxidation state of $\mathrm{Ge}, \mathrm{Cu}$ and $\mathrm{Fe}$ in sphalerite by -XRF and K-edge -XANES: insights into Ge incorporation, partitioning and isotopic fractionation. Geochim Cosmochim Acta doi:10.1016/j.gca.2016.01.001

Benedix GK, McCoy TJ, Keil L, Love SG (2000) A petrological study of the IAB iron meteorites : constraints on the formation of the IAB-Winonaite parent body. Meteoritics and Planetary Science $35: 1127-1141$

Berner RA (2003) The long-term carbon cycle, fossil fuels and atmospheric composition. Nature 426:323-326, doi:10.1038/nature02131

Berner RA, Lasaga AC, Garrels RM (1983) The carbonate-silicate geochemical cycle and its effect on atmospheric carbon dioxide over the past 100 million years. Am J Sci 283:641-683

Bernstein LR (1985) Germanium geochemistry and mineralogy. Geochim Cosmochim Acta 49:24092422

Blecker SW, King SL, Derry LA, Chadwick OA, Ippolito JA, Kelly EF (2007) The ratio of germanium to silicon in plant phytoliths: quantification of biological discrimination under controlled experimental conditions. Biogeochemistry 86:189-199, doi:10.1007/s10533-007-9154-7

Bogard DD, Garrison DH, McCoy TJ (2000) Chronology and petrology of silicates from IIE iron meteorites: evidence of a complex parent body evolution. Geochim Cosmochim Acta 64:2133-2154

Brown HM, Krouse HR (1964) Fractionation of Germanium Isotopes in Chemical Reactions. Can J Chem 42:1971-1978, doi:10.1139/v64-290

Brumsack H-J (2006) The trace metal content of recent organic carbon-rich sediments: Implications for Cretaceous black shale formation. Palaeogeogr, Palaeoclimatol, Palaeoecol 232:344-361

Cakmak I, Kurz H, Marschner H (1995) Short-term effects of boron, germanium and high light intensity on membrane permeability in boron deficient leaves of sunflower. Physiol Plant 95:11-18, doi:10.1034/j.1399-3054.1995.950102.x 
Campbell DR (1975) Isotope effect for self-diffusion in Ge. Physical Review B 12:2318

Capobianco C, Watson E (1982) Olivine/silicate melt partitioning of germanium: an example of a nearly constant partition coefficient. Geochim Cosmochim Acta 46:235-240

Cavell RG, Barne EM, Arboleda PH, Cavell PA, Feng R, Gordon RA, Webb MA (2004) An X-ray and electron microprobe study of $\mathrm{Fe}, \mathrm{Ni}, \mathrm{Ga}$, and Ge distribution and local structure in a section of the Canyon Diablo iron meteorite. Am Miner 89:519-526

Cempirek J, Groat LA (2013) Note on the formula of brunogeierite and the first bond-valence parameters for Ge2+. Journal of Geosciences 58:71-74

Chabot NL, Jones JH (2003) The parameterization of solid metal-liquid metal partitioning of siderophile elements. Meteoritics \& Planetary Science 38:1425-1436

Chabot NL, Campbell AJ, Jones JH, Humayun M, Agee CB (2003) An experimental test of Henry's Law in solid metal-liquid metal systems with implications for iron meteorites. Meteoritics and Planetary Science 38:181-196

Chang T-L, Li W-J, Qiao G-S, Qian Q-Y, Chu Z-Y (1999) Absolute isotopic composition and atomic weight of germanium. Internation Journal of Mass Spectrometry 189:205-211

Chapman FW, Marvin GG, Tyree SY (1949) Volatilization of Elements from Perchloric and Hydrofluoric Acid Solutions. Anal Chem 21:700-701

Choi B, Ouyang X, Wasson J (1995) Classification and origin of IAB and IIICD iron meteorites. Geochim Cosmochim Acta 59:593-612

Ciavatta L, Iuliano M, Porto R, Vasca E (1990) Fluorogermanate(IV) equilibria in acid-media. Polyhedron 9:1263-1270, doi:10.1016/s0277-5387(00)86762-5

Cohen BA, Hewins RH, Alexander CMOD (2004) The formation of chondrules by open-system melting of nebular condensates. Geochim Cosmochim Acta 68:1661-1675

Cook NJ, Ciobanu CL, Pring A, Skinner W, Shimizu M, Danyushevsky L, Saini-Eidukat B, Melcher F (2009) Trace and minor elements in sphalerite: A LA-ICPMS study. Geochim Cosmochim Acta $73: 4761-4791$

Cook NJ, Etschmann B, Ciobanu CL, et al. (2015) Distribution and Substitution Mechanism of Ge in a Ge-(Fe)-Bearing Sphalerite. Minerals 5:117-132, doi:10.3390/min5020117

Corrigan CM, Chabot NL, McCoy TJ, McDonough WF, Watson HC, Saslow SA, Ash RD (2009) The iron, nickel, phosphorus system: effects on the distribution of trace elements during the evolution of iron meteorites. Geochim Cosmochim Acta 73:2674-2691

Criaud A, Fouillac C (1986) Study of CO2-rich thermomineral waters from the French massif central. 2. Behavior of some trace-metals, arsenic, antimony and germanium. Geochim Cosmochim Acta 50:1573-1582, doi:10.1016/0016-7037(86)90120-1 
Dauphas N, Craddock PR, Asimow PD, Bennett VC, Nutman AP, Ohnenstetter D (2009) Iron isotopes may reveal the redox conditions of mantle melting from Archean to Present. Earth Planet Sci Lett 288:255-267

Dauphas N, Roskosz M, Alp EE, et al. (2014) Magma redox and structural controls on iron isotope variations in Earth's mantle and crust. Earth Planet Sci Lett 398:127-140, doi:10.1016/j.eps1.2014.04.033

Davis AM (2006) Volatile evolution and loss. Meteorites and the early solar system II 1:295-307

Davis FA, Humayun M, Hirschmann MM, Cooper RS (2013) Experimentally determined mineral/melt partitioning of first-row transition elements (FRTE) during partial melting of peridotite at 3GPa. Geochim Cosmochim Acta 104:232-260

De Argollo RM, Schilling JG (1978a) Ge/Si and Ga/Al variations along the Reykjanes Ridge and Iceland. Nature 276:24-28

De Argollo RM, Schilling JG (1978b) Ge-Si and Ga-Al fractionation in Hawaiian volcanic rocks. Geochim Cosmochim Acta 42:623-630

De Carlo EH, McMurtry GM, Yeh H-W (1983) Geochemistry of hydrothermal deposits from the Loihi submarine volcano, Hawaii. Earth Planet Sci Lett 66:438-449

De La Rocha C (2003) Silicon isotope fractionation by marine sponges and the reconstruction of the silicon isotope composition of ancient deep water. Geology 31:423-426

De La Rocha C, Brzezinski MA, De Niro MJ (1997) Fractionation of silicon isotopes by marine diatoms during biogenic silica formation. Geochim Cosmochim Acta 61:5051-5056

De La Rocha CL, Brzezinski MA, De Niro MJ, Shemesh A (1998) Silicon-isotope composition of diatoms as an indicator of past oceanic change. Nature 295:680-683

Dedina J, Tsalev DL (1995) Hydride generation atomic absorption spectrometry. Wiley

Delvigne C, Opfergelt S, Cardinal D, Delvaux B, Andre L (2009) Distinct silicon and germanium pathways in the soil-plant system: Evidence from banana and horsetail. Journal of Geophysical Research-Biogeosciences 114, doi:10.1029/2008jg000899

DeMaster DJ (2002) The accumulation and cycling of biogenic silica in the Southern Ocean: revisiting the marine silica budget. Deep-Sea Res 49:3155-3167

Derry LA, Kurtz AC, Ziegler K, Chadwick OA (2005) Biological control of terrestrial silica cycling and export fluxes to watersheds. Nature 433:728-731, doi:10.1038/nature03299

El Korh A, Luais B, Boiron M-C, Deloule E (2014) Ge and Ga abundances and Ge isotope ratios in high-pressure metamorphic rocks: a Q-ICPMS and MC-ICPMS study. . In Book Ge and $\mathrm{Ga}$ abundances and $\mathrm{Ge}$ isotope ratios in high-pressure metamorphic rocks: a Q-ICPMS and MC-ICPMS study. . Editor, (ed)^(eds), Münster (Allemagne) 
El Korh A, Luais B, Boiron M-C, Deloule E (2016) Tracing fluid-related HP metamorphism in subduction zones using $\mathrm{Ge}$ and $\mathrm{Ga}$ trace elements and $\mathrm{Ge}$ isotopes: implications for the fore-arc mantle wedge composition. Geochim Cosmochim Acta

El Wardani SA (1957) On the geochemistry of Germanium. Geochim Cosmochim Acta 13:5-19

Elderfield H, Schultz A (1996) Mid-ocean ridge hydrothermal fluxes and the chemical composition of the ocean. Ann Rev Earth Planet Sci 24:191-224

Ellwood MJ, Maher WA (2003) Germanium cycling in the waters across a frontal zone: the Chatham Rise, New Zealand. Mar Chem 80:145-159

Emerson D, Moyer CL (2002) Neutrophilic Fe-oxidizing bacteria are abundant at the Loihi seamount hydrothermal vents and play a major role in Fe oxide deposition. Appl Environ Microbiol 68:30853093

Epov VN, Rodriguez-Gonzalez P, Sonke JE, Tessier E, Amouroux D, Bourgoin LM, Donard OFX (2008) Simultaneous Determination of Species-Specific Isotopic Composition of $\mathrm{Hg}$ by Gas Chromatography Coupled to Multicollector ICPMS. Anal Chem 80:3530-3538

Epstein E (1994) The anomaly of silicon in plant biology. Proceedings of the National Academy of Sciences of the United States of America 91:11-17, doi:10.1073/pnas.91.1.11

Escoube R, Rouxel OJ, Luais B, Ponzevera E, Donard OFX (2012) An Intercomparison Study of the Germanium Isotope Composition of Geological Reference Materials. Geostand Geoanal Res 36:149159, doi:Doi 10.1111/J.1751-908x.2011.00135.X

Escoube R, Rouxel O, Edwards K, Glazer B, Donard O (2015) Coupled Ge/Si and Ge isotope ratios as geochemical tracers of seafloor hydrothermal systems: case studies at Loihi Seamount and East Pacific Rise $9^{\circ} 50^{\prime} \mathrm{N}$. Geochim Cosmochim Acta 167:93-112

Evans MJ, Derry LA (2002) Quartz control of high germanium/silicon ratios in geothermal waters. Geology 30:1019-1022

Feely RA, Trefry JH, Massoth GJ, Metz S (1991) A comparison of the scavenging of phosphorus and arsenic from seawater by hydrothermal iron oxyhydroxides in the Atlantic and Pacific Oceans. Deep Sea Res (I Oceanogr Res Pap) 38:617-623, doi:10.1016/0198-0149(91)90001-v

Feely RA, Massoth GJ, Baker ET, Cowen JP, Lamb MF, Krogslund KA (1990) The effect of hydrothermal processes on midwater phosphorus distributions in the northeast Pacific. Earth Planet Sci Lett 96:305-318, doi:10.1016/0012-821x(90)90009-m

Fischer WW, Knoll AH (2009) An iron shuttle for deepwater silica in Late Archean and early Paleoproterozoic iron formation. Geological Society of America Bulletin 121:222-235, doi:10.1130/b26328.1

Frank M (2002) Radiogenic isotopes: Tracers of past ocean circulation and erosional input. Rev Geophys 40, doi:1001

$10.1029 / 2000$ rg000094 
Frei R, Polat A (2007) Source heterogeneity for the major components of similar to 3.7 Ga Banded Iron Formations (Isua Greenstone Belt, Western Greenland): Tracing the nature of interacting water masses in BIF formation. Earth Planet Sci Lett 253:266-281, doi:10.1016/j.eps1.2006.10.033

Frenzel M, Ketris MP, Gutzmer J (2014) On the geological availability of germanium. Mineralium Deposita 49:471-486, doi:10.1007/s00126-013-0506-z

Frenzel M, Hirsch T, Gutzmer J (2016) Gallium, germanium, indium, and other trace and minor elements in sphalerite as a function of deposit type - A meta-analysis. Ore Geology Reviews 76:52-78

Froelich PN, Andreae MO (1981) The marine geochemistry of germanium - Ekasilicon. Science 213:205-207

Froelich PN, Lesley MP (2003) Tracing Germanium contamination from coal-fired power plant down the Chattahoochee-Apalachicola Rivers: Implications for the toxic metalloids Arsenic and Selenium. In Book Tracing Germanium contamination from coal-fired power plant down the ChattahoocheeApalachicola Rivers: Implications for the toxic metalloids Arsenic and Selenium. Editor, (ed)^(eds), University of Georgia

Froelich PN, Mortlock RA, Shemesh A (1989) Inorganic germanium and silica in the Indian Ocean: Biological fractionation during (Ge/Si)OPAL formation. Global Biogeochem Cycles, 3:79-88

Froelich PN, Hambrick GA, Andreae MO, Mortlock RA, Edmond JM (1985a) The geochemistry of inorganic germanium in natural waters. Journal of Geophysical Research-Oceans 90:1133-1141, doi:10.1029/JC090iC01p01133

Froelich PN, Hambrick GA, Kaul LW, Byrd JT, Lecointe O (1985b) Geochemical behavior of inorganic germanium in an unperturbed estuary. Geochim Cosmochim Acta 49:519-524

Froelich PN, Blanc V, Mortlock RA, Chillrud SN, Dunstan W, Udomkit A, Peng TH (1992) River Fluxes of Dissolved Silica to the Ocean Were Higher during Glacials: Ge/Si In Diatoms, Rivers, and Oceans. Paleoceanography 7:739-767, doi:10.1029/92pa02090

Gaillardet J, Dupre B, Louvat P, Allegre CJ (1999) Global silicate weathering and CO2 consumption rates deduced from the chemistry of large rivers. Chem Geol 159:3-30, doi:10.1016/s00092541(99)00031-5

Galy A, Belshaw NS, Halicz L, O'Nions RK (2001) High-precision measurement of magnesium isotopes by multiple-collector inductively coupled plasma mass spectrometry. Int J Mass spectrom 208:89-98

Galy A, Pomiès C, Day JA, Pokrovsky OS, Schott J (2003) High precision measurement of germanium isotope ratio variations by multiple collector- inductively coupled plasma -mass spectrometry. Journal of analytical and atomic spectrometry 18:115-119

Gautier E, Garavaglia R, Lobo A, Fernandez M, Farach H (2012) Isotopic analysis of germanium by thermal ionization mass spectrometry. J Anal At Spectrom 27:881-883, doi:10.1039/c2ja10305b 
Glazer BT, Rouxel OJ (2009) Redox Speciation and Distribution within Diverse Iron-dominated Microbial Habitats at Loihi Seamount. Geomicrobiol J 26:606-622, doi:Doi $10.1080 / 01490450903263392$

Goldschmidt VM (1958) Geochemistry. Oxford Univ. Press, London

Goodman S (1988) Therapeutic effects of organic Germanium. Medical Hypotheses 26:207-215, doi:10.1016/0306-9877(88)90101-6

Govindaraju K (1994) compilation of working values and sample description for 383 geostandards. Geostandard Newsletter 18:158

Graham RP, MacNamara J, Crocker IH, MacFarlane RB (1951) The Isotopic Constitution of Germanium. Can J Chem 29:89-102

Green MD, Rosman KJR, deLaeter JR (1986) The isotopic composition of germanium in terrestrial samples. International Journal of Mass Spectromety and Ion Processes 68:15-24

Guillermic M, Lalonde SV, Hendry KR, Rouxel O (2016) The isotopic composition of inorganic Germanium in seawater and deep sea sponges. Geochim Cosmochim Acta submitted

Halliday AN, Lee DC, Christensen JN, Walder AJ, Freedman PA, Jones CE, Hall CM, Yi W, Teagle D (1995) Recent developments in inductively coupled plasma magnetic sector multiple collector mass spectrometry. Int J Mass Spectrom Ion Processes 146:21-33, doi:10.1016/0168-1176(95)04200-5

Halperin SJ, Barzilay A, Carson M, Roberts C, Lynch J (1995) Germanium accumulation and toxicity in barley. J Plant Nutr 18:1417-1426, doi:10.1080/01904169509364991

Hamade T, Konhauser KO, Raiswell R, Goldsmith S, Morris RC (2003) Using Ge/Si ratios to decouple iron and silica fluxes in Precambrian banded iron formations. Geology 31:35-38

Hambrick GA, Froelich PN, Andreae MO, Lewis BL (1984) Determination of methylgermanium species in natural waters by graphite furnace atomic absorption spectrometry with hydride generation. Anal Chem 56:421-424, doi:10.1021/ac00267a027

Hammond DE, McManus J, Berelson WM (2004) Oceanic germanium/silicon ratios: Evaluation of the potential overprint of temperature on weathering signals. Paleoceanography 19:doi:10.1029/2003PA000940

Hammond DE, McManus J, Berelson WM, Meredith C, Klinkhammer GP, Coale KH (2000) Diagenetic fractionation of $\mathrm{Ge}$ and $\mathrm{Si}$ in reducing sediments: The missing Ge sink and a possible mechanism to cause glacial/interglacial variations in oceanic Ge/Si. Geochim Cosmochim Acta 64:2453-2465

Haugaard R, Pecoits E, Lalonde SV, Rouxel OJ, Konhauser KO (2016) The Joffre Banded Iron Formation, Hamersley Group, Western Australia: Assessing the Palaeoenvironment through detailed Petrology and Chemostratigraphy. Precambrian Res 273:12-37 
Hehenkamp T, Lodding A, Odelius H, Schlett V (1979) Isotope effect in the diffusion of the stable germanium isotopes in copper. Acta Metall 27:829-832

Hendry KR, Robinson LF (2012) The relationship between silicon isotope fractionation in sponges and silicic acid concentration: Modern and core-top studies of biogenic opal. Geochim Cosmochim Acta 81:1-12, doi:10.1016/j.gca.2011.12.010

Hendry KR, Georg RB, Rickaby REM, Robinson LF, Halliday AN (2010) Deep ocean nutrients during the Last Glacial Maximum deduced from sponge silicon isotopic compositions. Earth Planet Sci Lett 292:290-300, doi:10.1016/j.eps1.2010.02.005

Hill E, Wood BJ, Blundy JD (2000) The effect of Ca-Tschermaks component on trace element partitioning between clinopyroxene and silicate melt. Lithos 53:203-215

Hirata T (1997) Isotopic variations of germanium in iron and stony iron meteorites. Geochim Cosmochim Acta 61:4439-4448

Hirner AV, Feldmann J, Krupp E, Grumping R, Goguel R, Cullen WR (1998) Metal(loid)organic compounds in geothermal gases and waters. Org Geochem 29:1765-1778, doi:10.1016/s01466380(98)00153-3

Holl R, Kling M, Schroll E (2007) Metallogenesis of germanium - A review. Ore Geology Reviews 30:145-180, doi:10.1016/j.oregeorev.205.07.034

Iacono-Marziano G, Gaillard F, Scaillet B, Polozov AG, Marecal V, Pirre M, Arndt NT (2012) Extremely reducing conditions reached during basaltic intrusion in organic matter-bearing sediments. Earth Planet Sci Lett 357:319-326

Ingri $\mathrm{N}$ (1963) Equilibrium studies of polyanions and polygermanates in $\mathrm{NaCl}$ medium. Acta Chem Scand 17:597-616

Ishikawa T, Nakamura E (1990) Suppression of boron volatilization from a hydrofluoric acid solution using a boron-mannitol complex. Anal Chem 62:2612-2616, doi:10.1021/ac00222a017

Jambon A (1980) Isotopic fractionation: A kinetic model for crystals growing from magmatic melts. Geochim Cosmochim Acta 44:1373-1380

Jana D, Walker D (1997) The influence of sulfur on partitioning of siderophile elements. Geochim Cosmochim Acta 61:5255-5277

Jenner FE, O'Neill HSC (2012) Analysis of 60 elements in 616 ocean floor basaltic glasses. Geochem Geophys Geosyst 13

Johan Z (1988) Indium and germanium in the structure of sphalerite : an example of coupled substitution with copper. Mineralogy and Petrology 39:211-229

Jones JH, Drake MJ (1986) Geochemical constraints on core formation in the Earth. Nature 322:221228, doi: $10.1038 / 322221 \mathrm{a} 0$ 
Jones JH, Walker D (1991) Partitioning of siderophile elements in the Fe Ni S system: 1 bar to 80 kbar. Earth Planet Sci Lett 105:127-133

Karl DM, McMurtry GM, Malahoff A, Garcia MO (1988) Loihi Seamount, Hawaii: a mid-plate volcano with a distinctive hydrothermal system. Nature 335:532-535, doi:10.1038/335532a0

Kaya M, Volkan M (2011) Germanium determination by flame atomic absorption spectrometry: An increased vapor pressure-chloride generation system. Talanta 84:122-126, doi:10.1016/j.talanta.2010.12.029

Kelly WR, Larimer JW (1977) Chemical fractionations in meteorites--VIII. Iron meteorites and the cosmochemical history of the metal phase. Geochim Cosmochim Acta 41:93-111

King SL, Froelich PN, Jahnke RA (2000) Early diagenesis of germanium in sediments of the Antartic South Atlantic: In search of the missing Ge sink. Geochim Cosmochim Acta 64:1375-1390

Kipphardt H, Valkiers S, Henriksen F, De Bievre P, Taylor PDP, Tolg G (1999) Measurement of the isotopic composition of germanium using GeF4 produced by direct fluorination and wet chemical procedures. Int J Mass spectrom 189:27-37, doi:10.1016/s1387-3806(99)00047-0

Klein C (2005) Some Precambrian banded iron-formations (BIFs) from around the world: Their age, geologic setting, mineralogy, metamorphism, geochemistry, and origin. Am Miner 90:1473-1499, doi: $10.2138 / \mathrm{am} .2005 .1871$

Klöck W, Palme H, Tobschall HJ (1986) Trace elements in natural metallic iron from Disko Island, Greenland. Contrib Mineral Petrol 93:273-282

Kolodny Y, Halicz L (1988) The geochemistry of germanium in deep-sea cherts. Geochim Cosmochim Acta 52:2333-2336

Kruijer TS, Touboul M, Fischer-Gödde M, Bermingham KR, Walker RJ, Kleine T (2014) Protracted core formation and rapid accretion of protoplanets. Science 344:1150-1154

Kurtz AC, Derry LA, Chadwick OA (2002) Germanium-silicon fractionation in the weathering environment. Geochim Cosmochim Acta 66:1525-1537

Kwasnik W (1963) Section 4. Fluorine compounds. In: Handbook of Preparative Inorganic Chemistry. Brauer G, (ed) Academic Press Inc., New York, p 150

Lalonde S, Konhauser K, Rouxel O (2012) Germanium and silicon isotopic evolution of seawater inferred from Precambrian Iron Formations. Goldschmidt 2012 Conference, Mineralogical Magazine

Layton-Matthews D, Leybourne MI, Peter JM, Scott SD (2006) Determination of selenium isotopic ratios by continuous-hydride generation dynamic-reaction-cell inductively coupled plasma-mass spectrometry. J Anal At Spectrom 21:41-49

Lehmann B, Nägler TF, Holland HD, Wille M, Mao J, Pan J, Ma D, Dulski P (2007) Highly metalliferous carbonaceous shale and Early Cambrian seawater. Geology 35:403-406 
Lewis BL, Froelich PN, Andreae MO (1985) Methylgermanium in natural waters. Nature 313:303305, doi:10.1038/313303a0

Lewis BL, Andreae MO, Froelich PN (1989) Sources and sinks of methylgermanium in natural waters. Mar Chem 27:179-200, doi:10.1016/0304-4203(89)90047-9

Li XF, Liu Y (2010) First-principles study of Ge isotope fractionation during adsorption onto Fe(III)oxyhydroxides surfaces. Chem Geol:10.1016/j.chemgeo.2010.1005.1008.

Li XF, Zhao H, Tang M, Liu Y (2009) Theoretical prediction for several important equilibrium Ge isotope fractionation factors and geological implications. Earth Planet Sci Lett 287:1-11, doi:10.1016/j.eps1.2009.07.027

Liu M, Fleet ME (2001) Partitioning of siderophile elements (W, Mo, As, Ag, Ge, Ga, and Sn) and Si in the Fe-S system and their fractionation in iron meteorites. Geochim Cosmochim Acta 65:671-682

Lodders K, Palme H, Gail HP (2009) 4.4 Abundances of the elements in the Solar System. In: Solar system. Springer, p 712-770

Luais B (2003) Germanium isotope systematics in meteorites. Meteoritics and Planetary Science Supplement 38:5048

Luais B (2007) Isotopic fractionation of germanium in iron meteorites: Significance for nebular condensation, core formation and impact processes. Earth Planet Sci Lett 262:21-36, doi:10.1016/j.epsl.2007.06.031

Luais B (2012) Germanium chemistry and MC-ICPMS isotopic measurements of Fe-Ni, Zn alloys and silicate matrices: Insights into deep Earth processes. Chem Geol 334:295-311, doi:10.1016/j.chemgeo.2012.10.017

Luais B, Ali F, Wasson JT (2014) Low Germanium Isotopic Composition of IIG Iron Meteorites: Relationship with IIAB Irons and Influence of Sulfur and Phosphorus. Meteoritic and Planetary Sciences 49, Supp:A239

Luais B, Framboisier X, Carignan J, Ludden JN (2000) Analytical development of Ge isotopic analyses using multi-collection plasma source mass spectrometry: Isoprobe MC-Hex-ICP-MS (Micromass). In Book Analytical development of Ge isotopic analyses using multi-collection plasma source mass spectrometry: Isoprobe MC-Hex-ICP-MS (Micromass). Editor, (ed)^(eds), p 45-46

Luais B, Toplis MJ, Roskosz M, Tissandier L (2007) Experimental determination of germanium isotopic fractionation during metal-silicate segregation. Eos Trans AGU 88:Fall Meet. Suppl., Abstract V51E-0833

Luais B, Lach P, Tomassot E, Chaussidon M, Boiron MC (2011) Preliminary high-resolution Ge/Si data in early Archaean BIFs. Mineralogical Magazine 75:1362

Lyons TW, Severmann S (2006) A critical look at iron paleoredox proxies: New insights from modern euxinic marine basins. Geochim Cosmochim Acta 70:5698-5722, doi:10.1016/j.gca.2006.08.021 
Machlan LA, Gramlich JW, Powell LJ, Lambert GM (1986) Absolute isotope abundance ratio and atomic weight of a reference sample of gallium. Journal of Research of the National Bureau of Standards 91:323-331

Makishima A, Nakamura E (2009) Determination of Ge, As, Se and Te in Silicate Samples Using Isotope Dilution-Internal Standardisation Octopole Reaction Cell ICP-QMS by Normal Sample Nebulisation. Geostand Geoanal Res 33:369-384

Malvin G, Drake M (1987) Experimental determination of crystal-melt partitioning of $\mathrm{Ga}$ and $\mathrm{Ge}$ in the system forsterite-anorthite-diopside. Geochim Cosmochim Acta 51:2117-2128

Mantoura S (2006) Development and Application of Opal Based Paleoceanographic Proxies. Doctor of Philosophy University of Cambridge, Cambridge

Maréchal C, Télouk P, Albarède F (1999) Precise analysis of copper and zinc isotopic compositions by plasma-source mass spectrometry. Chem Geol 156:251-273

Marin-Carbonne J, Robert F, Chaussidon M (2014) The silicon and oxygen isotope compositions of Precambrian cherts: A record of oceanic paleo-temperatures? Precambrian Res 247:223-234, doi:10.1016/j.precamres.2014.03.016

Martin JH (1990) Glacial-interglacial CO2 change: the iron hypothesis. Paleoceanography 5:1-13, doi:10.1029/PA005i001p00001

McDermott KH, Greenwood RC, Scott ERD, Franchi IA, Anand M (2016) Oxygen isotope and petrological study of silicate inclusions in IIE iron meteorites and their relationship with H chondrites. Geochim Cosmochim Acta 173:97-113

McManus J, Hammond DE, Cummins K, Klinkhammer GP, Berelson WM (2003) Diagenetic Ge-Si fractionation in continental margin environments: Further evidence for a nonopal sink. Geochim Cosmochim Acta 67:4545-4557

McVay GL, DuCharme AR (1974) Diffusion of Ge in SiGe alloys. Physical Review B 9:627

Medenbach O, ElGoresy A (1982) Ulvöspinel in native iron-bearing assemblages and the origin of these assemblages in basalts from Ovifak, Greenland, and Bühl, Federal Republic of Germany. Contrib Mineral Petrol 80:358-366

Meng YM, Qi HW, Hu RZ (2015) Determination of germanium isotopic compositions of sulfides by hydride generation MC-ICP-MS and its application to the $\mathrm{Pb}-\mathrm{Zn}$ deposits in SW China. Ore Geology Reviews 65:1095-1109, doi:10.1016/j.oregeorev.2014.04.008

Mortlock RA, Froelich PN (1987) Continental weathering of germanium: Ge/Si in the global discharge. Geochim Cosmochim Acta 51:2075-2082

Mortlock RA, Froelich PN, Feely RA, Massoth GJ, Butterfield DA, Lupton JE (1993) Silica and germanium in Pacific Ocean hydrothermal vents and plumes. Earth Planet Sci Lett 119:365-378 
Mortlock RA, Charles CD, Froelich PN, Zibello MA, Saltzman J, Hays JD, Burckle LH (1991) Evidence for lower productivity in the Antartic Ocean during the last glaciation. Nature 351:220-223, doi:10.1038/351220a0

Murnane RJ, Stallard RF (1988) Germanium/silicon fractionation during biogenic opal formation. Paleoceanography 3:461-469, doi:10.1029/PA003i004p00461

Murnane RJ, Stallard RF (1990) Germanium and silicon in rivers of the Orinoco drainage basin. Nature 344:749-752, doi:10.1038/344749a0

Mysen BO (2004) Element partitioning between minerals and melt, melt composition, and melt structure. Chem Geol 213:1-16

Nishimura H, Takeshi H, Okano J (1988 ) Isotopic Abundances of Germanium Determined by Secondary Ion Mass Spectrometry. J Mass Spectrom Soc Jpn 36:197-202

Olsen E, Kracher A, Davis AM, Steele IM, Hutcheon ID, Bunch TE (1999) The phosphates of IIIAB iron meteorites. Meteoritics and Planetary Science 34:285-300

Onishi F, Inatomi Y, Tanaka T, Shinozaki N, Watanabe M, Fujimoto A, Itoh K (2006) Time-of-flight secondary mass spectrometry analysis of isotope composition for measurement of self-diffusion coefficient. Japanese Journal of Applied Physics Part 1-Regular Papers Brief Communications \& Review Papers 45:5274-5276, doi:10.1143/jjap.45.5274

Pike GE, Camp WJ, Seager CH, McVay GL (1974) Percolative aspects of diffusion in binary alloys. Physical Review B 10:4909

Plank T, Langmuir CH (1998) The chemical composition of subducting sediment and its consequences for the crust and mantle. Chem Geol 145:325-394

Pokrovski GS, Schott J (1998a) Thermodynamic properties of aqueous Ge(IV) hydroxide complexes from 25 to $350^{\circ} \mathrm{C}$ : Implications for the behavior of germanium and the $\mathrm{Ge} / \mathrm{Si}$ ratio in hydrothermal fluids. Geochim Cosmochim Acta 62:1631-1642

Pokrovski GS, Schott J (1998b) Experimental study of the complexation of silicon and germanium with aqueous organic species: Implications for germanium and silicon transport and $\mathrm{Ge} / \mathrm{Si}$ ratio in natural waters. Geochim Cosmochim Acta 62:3413-3428

Pokrovski GS, Martin F, Hazemann J-L, Schott J (2000) An X-ray absorption fine structure spectroscopy study of germanium-organic ligand complexes in aqueous solution. Chem Geol 163:151165

Pokrovsky OS, Pokrovski GS, Schott J, Galy A (2006) Experimental study of germanium adsorption on goethite and germanium coprecipitation with iron hydroxide: X-ray absorption fine structure and macroscopic characterization. Geochim Cosmochim Acta 70:3325-3341

Pokrovsky OS, Galy A, Schott J, Pokrovski GS, Mantoura S (2014) Germanium isotope fractionation during Ge adsorption on goethite and its coprecipitation with $\mathrm{Fe}$ oxy(hydr)oxides. Geochim Cosmochim Acta 131:138-149, doi:10.1016/j.gca.2014.01.023 
Puerner NJ, Siegel SM, Siegel BZ (1990) The experimental phytotoxicology of germanium in relation to silicon. Water Air and Soil Pollution 49:187-195, doi:10.1007/bf00279520

Qi HW, Rouxel O, Hu RZ, Bi XW, Wen HJ (2011) Germanium isotopic systematics in Ge-rich coal from the Lincang Ge deposit, Yunnan, Southwestern China. Chem Geol 286:252-265, doi:Doi 10.1016/J.Chemgeo.2011.05.011

Reincke T, Barthel D (1997) Silica uptake kinetics of Halichondria panicea in Kiel Bight. Mar Biol 129:591-593

Reynolds JH (1953) The Isotopic Constitution of Silicon, Germanium, and Hafnium. Physical Review 90:1047-1049

Richter FM, Liang Y, Davis AM (1999) Isotope fractionation by diffusion in molten oxides. Geochim Cosmochim Acta 63:2853-2861

Richter FM, Watson EB, Mendybaev R, Dauphas N, Georg B, Watkins J, Valley J (2009) Isotopic fractionation of the major elements of molten basalt by chemical and thermal diffusion. Geochim Cosmochim Acta 73:4250-4263, doi:10.1016/j.gca.2009.04.011

Righter K, King C, Danielson L, Pando K, Lee CT (2011) Experimental determination of the metal/silicate partition coefficient of Germanium: Implications for core and mantle differentiation. Earth Planet Sci Lett 304:379-388, doi:10.1016/j.epsl.2011.02.015

Robert F, Chaussidon M (2006) A palaeotemperature curve for the Precambrian oceans based on silicon isotopes in cherts. Nature 443:969-972, doi:10.1038/nature05239

Rosenberg E (2009) Germanium: environmental occurrence, importance and speciation. Rev Environ Sci Biotechnol 8:29-57

Rosman KJR, Taylor PDP (1998) Isotopic compositions of the elements 1997 (Technical Report). Pure Appl Chem 70:217-235

Rouxel O, Ludden J, Fouquet Y (2003a) Antimony isotope variations in natural systems and implications for their use as geochemical tracers. Chem Geol 200:25-40, doi:Doi 10.1016/S00092541(03)00121-9

Rouxel O, Galy A, Elderfield H (2006) Germanium isotopic variations in igneous rocks and marine sediments. Geochim Cosmochim Acta 70:3387-3400, doi:Doi 10.1016/J.Gca.2006.04.025

Rouxel O, Dobbek N, Ludden J, Fouquet Y (2003b) Iron isotope fractionation during oceanic crust alteration. Chem Geol 202:155-182, doi:Doi 10.1016/J.Chemgeo.2003.08.011

Rouxel O, Ludden J, Carignan J, Marin L, Fouquet Y (2002) Natural variations of Se isotopic composition determined by hydride generation multiple collector inductively coupled plasma mass spectrometry. Geochim Cosmochim Acta 66:3191-3199, doi:Pii S0016-7037(02)00918-3

Doi 10.1016/S0016-7037(02)00918-3 
Ryabov VV, Lapkovsky AA (2010) Native iron (-platinum) ores from the Siberian Platform trap intrusions. Aust J Earth Sci 57:707-736

Savage PS, Armytage RMG, Georg RB, Halliday AN (2014) High temperature silicon isotope geochemistry. Lithos 190:500-519, doi:10.1016/j.lithos.2014.01.003

Schauble EA (2004) Applying stable isotope fractionation theory to new systems. Reviews in Mineralogy \& Geochemistry 55:65-111

Schauss AG (1991) Nephrotoxicity and neurotoxicity in humans from organogermanium compounds and germanium dioxide. Biol Trace Elem Res 29:267-280

Schmitt W, Palme H, Wanke H (1989) Experimental determination of metal/silicate partition coefficients for $\mathrm{P}, \mathrm{Co}, \mathrm{Ni}, \mathrm{Cu}, \mathrm{Ga}, \mathrm{Ge}, \mathrm{Mo}$, and $\mathrm{W}$ and some implications for the early evolution of the Earth. Geochim Cosmochim Acta 53:173-185

Scribner AM, Kurtz AC, Chadwick OA (2006) Germanium sequestration by soil: Targeting the roles of secondary clays and Fe-oxyhydroxides. Earth Planet Sci Lett 243:760-770, doi:10.1016/j.eps1.2006.01.051

Sedwick PN, McMurtry GM, Macdougall JD (1992) Chemistry of hydrothermal solutions from Pele's Vents, Loihi Seamount, Hawaï. Geochim Cosmochim Acta 56:3643-3667

Shemesh A, Mortlock RA, Froelich PN (1989) Late cenozoic Ge/Si record of marine biogenic opal : implications for variations of riverine fluxes to the ocean. Paleoceanography 4:221-234, doi:10.1029/PA004i003p00221

Shemesh A, Mortlock RA, Smith RJ, Froelich PN (1988) Determination of Ge/Si in marine siliceous microfossils: separation, cleaning and dissolution of diatoms and radiolaria. Mar Chem 25:305-323

Shima M (1963) Isotopic composition of germanium in meteorites. Journal of Geophysical Research B: Solid Earth 68:4289-4292

Siebert C, Nagler TF, Kramers JD (2001) Determination of molybdenum isotope fractionation by double-spike multicollector inductively coupled plasma mass spectrometry. Geochem Geophy Geosy 2:art. no.-2000GC000124

Siebert C, Ross A, McManus J (2006) Germanium isotope measurements of high-temperature geothermal fluids using double-spike hydride generation MC-ICP-MS. Geochim Cosmochim Acta 70:3986-3995

Siebert C, Hammond DE, Ross A, McManus J (2011a) Germanium isotope measurements of hightemperature geothermal fluids using double-spike hydride generation MC-ICP-MS (vol 70, pg 3986, 2006). Geochim Cosmochim Acta 75:6267-6269, doi:10.1016/j.gca.2011.07.032

Siebert J, Corgne A, Ryerson FJ (2011b) Systematics of metal-silicate partitioning for many siderophile elements applied to Earth's core formation. Geochim Cosmochim Acta 75:1451-1489 
Siever R (1992) The silica cycle in the Precambrian. Geochim Cosmochim Acta 56:3265-3272, doi:10.1016/0016-7037(92)90303-z

Slack JF, Selby D, Dumoulin JA (2015) Hydrothermal, Biogenic, and Seawater Components in Metalliferous Black Shales of the Brooks Range, Alaska: Synsedimentary Metal Enrichment in a Carbonate Ramp Setting. Economic Geology 110:653-675

Snyder GA, Lee DC, Ruzicka AM, Prinz M, Taylor LA, Halliday AN (2001) Hf-W, Sm-Nd, and Rb$\mathrm{Sr}$ isotopic evidence of late impact fractionation and mixing of silicates on iron meteorite parent bodies. Earth Planet Sci Lett 186:311-324

Steinhoefel G, Horn I, von Blanckenburg F (2009) Micro-scale tracing of Fe and Si isotope signatures in banded iron formation using femtosecond laser ablation. Gechimica et Cosmochimica Acta $73: 5343-5360$

Stevenson DJ (1981) Models of the Earth's Core. Science 214:611-619, doi:10.1126/science.214.4521.611

Sutton J, Ellwood MJ, Maher WA, Croot PL (2010) Oceanic distribution of inorganic germanium relative to silicon: Germanium discrimination by diatoms. Global Biogeochem Cycles 24, doi:10.1029/2009gb003689

Sutton JN, Varela DE, Brzezinski MA, Beucher CP (2013) Species-dependent silicon isotope fractionation by marine diatoms. Geochim Cosmochim Acta 104:300-309, doi:10.1016/j.gca.2012.10.057

Takeda H, Bogard DD, Mittlefehldt DW, Garrison DH (2000) Mineralogy, petrology, chemistry, and $39 \mathrm{Ar}-40 \mathrm{Ar}$ and exposure ages of the Caddo County IAB iron: evidence for early partial melt segregation of a gabbro area rich in plagioclase-diopside. Geochim Cosmochim Acta 64:1311-1327

Tan CJ, Xiao L, Chen WL, Chen SM (2015) Germanium in ginseng is low and causes no sodium and water retention or renal toxicity in the diuretic-resistant rats. Exp Biol Med 240:1505-1512, doi: $10.1177 / 1535370215571874$

Tao SH, Bolger PM (1997) Hazard assessment of germanium supplements. Regul Toxicol Pharmacol 25:211-219, doi:10.1006/rtph.1997.1098

Tivey MK (1995) Modeling Chimney Growth and Associated Fluid Flow at Seafloor Hydrothermal Vent Sites. In: Seafloor hydrothermal Systems: Physical, Chemical, Biological, and Geological Interactions. Vol Geophysical Monograph 91. Humphris SE, Zierenberg RA, Mullineaux LS, Thomson RE, (eds). American Geophysical Union, p 158-177

Treguer P (2002) Silica and the cycle of carbon in the ocean. C R Geoscience 334:3-11

Treguer P, Nelson DM, Van Bennekom AJ, Demaster DJ, Leynaert A, Queguiner B (1995) The silica balance in the world ocean: A re-estimate. Science 268:375-379

Tribovillard N, Bout-Roumazeilles V, Riboulleau A, Baudin F, Danelian T, Riquier L (2011) Transfer of germanium to marine sediments: Insights from its accumulation in radiolarites and authigenic 
capture under reducing conditions. Some examples through geological ages. Chem Geol 282:120-130, doi:10.1016/j.chemgeo.2011.01.015

Ulff-Mølller F (1985) Solidification history of the Kitdlit Lens: immiscible metal and sulphide liquids from a basaltic dyke on Disko, central West Greenland. Journal of Petrology 26:64-91

Valkovic V (1983) Trace Elements in Coal. CRC Press

van den Boorn S, van Bergen MJ, Nijman W, Vroon PZ (2007) Dual role of seawater and hydrothermal fluids in Early Archean chert formation: Evidence from silicon isotopes. Geology 35:939-942, doi:10.1130/g24096a.1

Vogel G, Hettich G, Mehrer H (1983) Self-diffusion in intrinsic germanium and effects of doping on self-diffusion in germanium. Journal of Physics C: Solid State Physics 16:6197

Von Damm KL (2004) Evolution of the hydrothermal system at East Pacific Rise 9 degrees 50 ' N: Geochemical evidence for changes in the Upper Oceanic Crust. In: Mid-Ocean Ridges: Hydrothermal Interactions between the Lithosphere and Oceans. Vol 148. German CR, Lin J, Parson LM, (eds). p 285-304

Von Damm KL, Bischoff JL, Rosenbauer RJ (1991) Quartz solubility in hydrothermal seawater: An experimental study and equation describing quartz solubility for up to $0.5 \mathrm{M} \mathrm{NaCl}$ solutions. Am J Sci 291:977-1007

Wai CM, Wasson JT (1979) Nebular condensation of Ga, Ge and Sb and the chemical classification of iron-meteorites. Nature 282:790-793, doi:10.1038/282790a 0

Wai CM, Wetherill GW, Wasson JT (1968) The distribution of trace quantities of germanium between metal, silicate and sulflde phases. Geochim Cosmochim Acta 32:1269-1278

Walker JCG, Hays PB, Kasting JF (1981) A negative feedback mechanism for the long-term stabilization of Earth's surface temperature. Journal of Geophysical Research-Oceans and Atmospheres 86:9776-9782, doi:10.1029/JC086iC10p09776

Wasson J, Choe W (2009) The IIG iron meteorites: Probable formation in the IIAB core. Geochim Cosmochim Acta 73:4879-4890

Wasson JT (1966) Butler, Missouri: An iron meteorite with extremely high Germanium content. Science 153:976-978

Wasson JT (1974) Meteorites, classification and properties. Springer-Verlag, Berlin Heildelberg New York

Wasson JT, Kimbeblin J (1967) The chemical classification of iron meteorites-II. Irons and pallasites with germanium concentrations between 8 and 100 ppm. Geochim Cosmochim Acta 31:2065-2093

Wasson JT, Kallemeyn GW (2002) The IAB iron-meteorite complex: A group, five subgroups, numerous grouplets, closely related, mainly formed by crystal segregation in rapidly cooling melts. Gechimica et Cosmochimica Acta 66:2445-2473 
Wasson JT, Willis J, Wai CM, Kracher A (1980) Origin of iron meteorite groups IAB and IIICD. Zeits Naturforsch 35a:781-795

Weis D, Garcia MO, Rhodes JM, Jellinek M, Scoates JS (2011) Role of the deep mantle in generating the compositional asymmetry compositional asymmetry of the Hawaiian mantle plume. Nat Geosci 4:831-838, doi:10.1038/NGEO1328

Weyer S, Ionov DA (2007) Partial melting and melt percolation in the mantle: The message from $\mathrm{Fe}$ isotopes. Earth Planet Sci Lett 259:119-133

Wheat CG, McManus J (2005) The potential of ridge-flank hydrothermal systems on oceanic germanium and silicon balances. Geochim Cosmochim Acta 69:2021-2029

Wickman FE (1943) Some aspects of the geochemistry of igneous rocks and of differentiation by crystallization. Geol Foeren Stockholm Foerh (GFF) 65:371-396

Williams HM, Peslier AH, McCammon C, Halliday AN, Levasseur S, Teutsch N, Burg J-P (2005) Systematic iron isotope variations in mantle rocks and minerals: The effects of partial melting and oxygen fugacity. Earth Planet Sci Lett 235:435-452

Xue S, Yang Y-L, Hall GS, Herzog GF (1997) Germanium isotopic compositions in Canyon Diablo spheroids. Geochim Cosmochim Acta 61:651-655

Yee D, Grieb T, Mills W, Sedlak M (2007) Synthesis of long-term nickel monitoring in San Francisco Bay. Environ Res 105:20-33, doi:10.1016/j.envres.2007.02.005

Yokoyama T, Makishima A, Nakamura E (1999) Evaluation of the coprecipitation of incompatible trace elements with fluoride during silicate rock dissolution by acid digestion. Chem Geol 157:175187

Zhu JM, Johnson TM, Clark SK, Zhu XK (2008) High Precision Measurement of Selenium Isotopic Composition by Hydride Generation Multiple Collector Inductively Coupled Plasma Mass Spectrometry with a Se-74-Se-77 Double Spike. Chinese Journal of Analytical Chemistry 36:13851390, doi:10.1016/s1872-2040(08)60075-4 


\section{FIGURE CAPTIONS}

Figure 1: Schematic diagram of the continuous-flow hydride generator system used in Rouxel et al. (2006) and subsequent studies (Qi et al. 2011; Escoube et al. 2012; Escoube et al. 2015).

Figure 2: Experimental data of inter-diffusion isotopic fractionation of Ge between two $\mathrm{GeO}_{2}$ synthetic silicate melts of contrasted initial ${ }^{74} \mathrm{Ge}$ / ${ }^{70} \mathrm{Ge}$ ratios (low ${ }^{74} \mathrm{Ge}$ melt with ${ }^{74} \mathrm{Ge} /{ }^{70} \mathrm{Ge}=1.6969 \pm$ 0.0013, high ${ }^{74} \mathrm{Ge}$ melt with $\left.{ }^{74} \mathrm{Ge} /{ }^{70} \mathrm{Ge}=408.1 \pm 3.0\right)$, but similar ${ }^{76} \mathrm{Ge} /{ }^{70} \mathrm{Ge}$ ratios of $0.5193 \pm 0.0005$ and $0.5188 \pm 0.0009$, respectively (from Richter et al., 1999). Data are given for two different parallel profiles (profiles 1 and 2) along the length of the experimental glass cylinder. Curves correspond to model results of $\mathrm{Ge}$ isotopic ratios for different values of $\beta$ from 0 to 0.5 for comparison (Richter et al., 1999). (A) Ion probe diffusion profiles are given for ${ }^{74} \mathrm{Ge} /{ }^{70} \mathrm{Ge}$ and ${ }^{76} \mathrm{Ge} /{ }^{70} \mathrm{Ge}$ as a function of distance from the interface $\mathrm{X} \mu \mathrm{m}=0$. (B) ${ }^{74} \mathrm{Ge} /{ }^{70} \mathrm{Ge}$ versus ${ }^{76} \mathrm{Ge} /{ }^{70} \mathrm{Ge}$ variations. Larger Ge isotopic fractionation are observed for ${ }^{74} \mathrm{Ge} /{ }^{70} \mathrm{Ge}$ than for ${ }^{76} \mathrm{Ge} /{ }^{70} \mathrm{Ge}$ ratios, highlighting the effect of composition contrast on the degree of diffusive isotopic fractionation between two phases.

Figure 3: Experimental determination of Ge isotopic fractionation in coal and lignite during ashing and combustion processes (Qi et al., 2010). (A) at low temperature of $\mathrm{T}=600^{\circ} \mathrm{C}: \delta^{74 / 70} \mathrm{Ge}$ in ash and coal plot on $\approx 1.1$ line (slope of $0.963, \mathrm{R}^{2}=0.983$ ), indicating no isotopic fractionation; (B) at high temperature $\mathrm{T}>1400^{\circ} \mathrm{C}$ : lighter $\delta^{74 / 70} \mathrm{Ge}$ in volatile component (soot) than in the residue (cinder).

Figure 4: Synchrotron Ge K-edge $\mu$ XANES spectra at the Ge K-edge (a) for standards compounds and Tres Marias sphalerite (Mexico, Cook et al., 2015); (b)(c) from Belissont et al. (2016) : (b) for $\mathrm{Ge}^{2+}(\mathrm{GeS})$ compounds, and $\mathrm{Ge}^{4+}$ reference materials of renierite $(\mathrm{Rn})$, gernanite $(\mathrm{Gm})$, briartite $(\mathrm{Brt})$ chalcopyrite (Cp), covellite (cv), and (c) St-Salvy-France (64W, 62E, SAL-UN) and Kipushi-D.R Congo (A38) samples.

Figure 5: Ge isotopic compositions of magmatic, non-magmatic and ungrouped iron meteorites, pallasite, and Earth silicate samples, relative to NIST3120a Ge standard. Irons and silicate earth (full symbols) data are from Luais (2007) and Luais et al. (2014); data for Toluca IAB iron and silicates (empty symbols) are from Escoube et al. (2012).

Figure 6: Modelling evaporation processes for $\mathrm{Ge}$ isotopic compositions of IIE irons $\left(\delta^{74 / 70} \mathrm{Ge}_{\text {NIST3120a) }}\right.$ using Raleigh type fractionation (modified from Luais 2007, 2012). The data can be modelled using $\beta<0.5$ for the three germanium model compounds: Ge metal, GeO and GeS species. A 
smaller isotope mass fractionation is shown for heavier molecular species (see sections "Theoretical considerations" and "diffusion of Ge" for discussion).

Figure 7: Ge isotopic composition of terrestrial mantle derived rocks. Data are average with 2 sigma error bars (s.d.) from Escoube et al. (2012); Luais (2012); Rouxel et al. (2006); Lalonde and Rouxel (unpublished, see Table 2) and Qi et al. (2011).. The average of $\delta^{74 / 70} \mathrm{Ge}_{\text {NIST3120a }}$ of $0.58 \pm 0.21$ (2б) \%o is calculated for the Earth mantle-crust system.

Figure 8: Ge isotopic composition of mantle-derived rocks in function of $\mathrm{NBO} / \mathrm{T}$ parameter (from Luais, 2012). NBO/T quantifies the number of oxygen atoms that are not shared by two tetrahedrons (NBO: nonbridging oxygen), relative to the proportion of tetrahedrally coordinated cations. The serpentine and Hawaiian basalt samples (in brackets) are excluded from the regression line.

Figure 9: Ge isotopic compositions of sulfides. Data from St-Salvy (Luais, 2007, 2012; Belissont et al. 2014), Navan Irish district and Lucky Strike seafloor hydrothermal system (Escoube et al. 2012), China (Tianqiao, Shanshulin and Jinding sites, Meng et al. 2015).

Figure 10: Ge isotopic composition versus Ge content in sphalerites from St-Salvy (Luais 2007, 2012, Belissont et al. 2014) and Navan Irish and Lucky Strike deposits (Escoube et al. 2012). Iron meteorite data from Luais $(2007,2012)$, and Earth mantle and crust data from Rouxel (2006), Escoube et al. (2012) and Luais (2012).

Figure 11: Modelling Ge isotopic fractionation in sphalerite from St-Salvy using Rayleigh laws for kinetic fractionation during sphalerite precipitation, (Belissont et al. 2014), as a function of the fraction $f$ of residual Ge in solution. (A) For given values of $\delta^{74 / 70} \mathrm{Ge}_{\text {fluid }}=1$ and $\alpha_{\text {sphalerite-fluid }}$ isotopic fractionation factor $=0.997$; Ge isotopic fractionation curves are given for total sphalerite (i.e. accumulating in the system), instantaneous sphalerite (i.e. produced at in an infinitely short time), and remaining solution, (B) total sphalerite composition for a range of $\delta^{74 / 70} \mathrm{Ge}_{\text {fluid }}$ values, (C) total sphalerite for different $\alpha_{\text {sphalerite-fluid }}$ values. Modeling curves result in negative $\delta^{74 / 70} \mathrm{Ge}$ versus Ge and (1-f) correlations, and do not fit the St-Salvy sphalerite data (filled circles).

Figure 12: Schematic model of Ge/Si fractionation during weathering (Froelich et al. 1992; Kurtz et al. 2002). In this model, Ge is partitioned into secondary aluminosilicates (clays), resulting in streamwaters with low $\mathrm{Ge} / \mathrm{Si}$. More intense weathering releases the $\mathrm{Si}$ (and) Ge otherwise stored in clays, contributing higher $\mathrm{Ge} / \mathrm{Si}$ ratios to streamwater. The $\mathrm{Ge} / \mathrm{Si}$ ratio of streamwater reflects the balance of these two processes. 
Figure 13: Germanium isotope and $\mathrm{Ge} / \mathrm{Si}$ ratios of various mantle-derived rocks and deep-sea clays defining a preliminary bulk crustal value (solid horizontal line). $\delta^{74 / 70} \mathrm{Ge}$ and $\mathrm{Ge} / \mathrm{Si}$ values of glauconite (GL-O) other marine sediments and seawater are also shown for comparison. Data from Rouxel et al. (2006), Guillermic et al. (2016) and Rouxel and De La Rocha (unpublished) reported in Table 6.

Figure 14: Rayleigh functions are fitted to whole (uncleaned) diatom $\delta^{74 / 70} \mathrm{Ge}$ data (diamonds) and cleaned opal $\delta^{74 / 70} \mathrm{Ge}$ data (squares). The theoretical $\delta^{74 / 70} \mathrm{Ge}$ of the whole diatom cell is represented by the thinner dashed line, which is calculated using $\alpha=0.9990$. Ge isotope composition of diatom organic matter is determined by mass balance, yielding $\alpha=0.9984$. Hence, the theoretical accumulating organic matter would have the value of the solid black line. As $f$ (fraction of Ge removed from in solution) increases, the resulting solution would become progressively isotopically heavier (thicker dashed lines corresponding to $\alpha=0.9990$ ). Data and isotopic model are from Mantoura (2006).

Figure 15: Ge isotope composition and Ge concentration in seawater from North Pacific, North Atlantic and Southern Ocean sectors (surface and deep seawater are reported). (*) NF refers to nonfiltered seawater, while other values correspond to filtered seawater $(<0.2 \mu \mathrm{m})$. The average $\mathrm{Ge}$ isotope composition of deep seawater $\left(\delta^{74 / 70} \mathrm{Ge}\right.$ DSw $)$ is also reported, and is calculated using sample recovered below $300 \mathrm{~m}$ depth, corresponding typically to samples with Ge concentrations $>60 \mathrm{pM}$ for the Pacific and Southern Ocean sectors. Data are from Guillermic et al. (2016).

Figure 16: $\mathrm{Ge} / \mathrm{Si}$ and $\mathrm{Ge}$ isotope composition of seafloor hydrothermal fluids from Loihi Seamount (referred as low-temperature (LT) fluids) near Hawaii and East Pacific Rise (EPR) at 9 $50^{\prime} \mathrm{N}$ (referred as high-temperature (HT) fluids). By comparison, Fe oxyhydroxide-rich deposits (FeOx-rich) at Loihi Seamount are also enriched in Ge (relative to Si and fluid sources) but with significant enrichment in light Ge isotopes. Crustal and seawater values are shown for comparison. Data are from Escoube et al. (2015)

Figure 17: A schematic of the $\mathrm{Ge} / \mathrm{Si}$ and $\mathrm{Ge}$ isotope oceanic budget. The main sources of dissolved Ge into the ocean are wet and dry deposition from the atmosphere, input from rivers, resuspended sediment, and pore water along continental shelves and hydrothermal vents. Silicon fluxes ( $\mathrm{Si}$ x $10^{12}$ $\mathrm{mol} / \mathrm{yr}$ ) are after Treguer et al. (1995) while Ge fluxes (Ge x $10^{6} \mathrm{~mol} / \mathrm{yr}$ ) are estimated from measured $\mathrm{Ge} / \mathrm{Si}$ ratios (in $\mu \mathrm{mol} / \mathrm{mol}$ ) after Mortlock et al. (1993). The hydrothermal flux has been adjusted 
according to Elderfield and Shultz (1996). Silicon fluxes assume steady state. In order to maintain the current oceanic $\mathrm{Ge} / \mathrm{Si}$ at $0.72 \mu \mathrm{mol} / \mathrm{mol}, 4.1 \times 10^{6} \mathrm{~mol} / \mathrm{yr}$ must be sequestered in a nonopal sink (Froelich and King, 1997). Germanium isotope compositions (reported as $\delta^{74 / 70} \mathrm{Ge}$ ) of Ge sources and sinks are reported in Escoube et al. (2015). Germanium isotope composition of the non-opal sink is determined by mass balance and assuming steady state.

Figure 18: The $\mathrm{Ge} / \mathrm{Si}_{\text {opal }}$ and $\delta^{74 / 70} \mathrm{Ge}_{\text {opal }}$ record of samples from site ODP 1094, as reported by Mantoura (2006). Error bars are 95\% confidence interval for the data estimated by $2 \mathrm{x}$ the standard error of $n$ measurements. Age model data are from Mantoura (2006) and established by SchneiderMor et al. (2005) 


\section{TABLE CAPTIONS}

Table 1: Compilation of the natural abundances of Ge isotopes determined by different mass spectrometry techniques. The Ge isotope composition of double spike mixtures used is also shown for comparison.

Table 2: Average compositions of Ge isotope standards used by different research groups normalized against NIST 3120a isotopic standard.

Table 3: Compilation of published and unpublished values for georeference materials

Table 4: Lattice parameters for Ge -bearing metal, silicate, oxide and sulfide.

Table 5: Experimental determination of Ge partitioning coefficient $\mathrm{K} d$ in silicate mineral as a function of temperature and pressure.

Table 6: Ge isotope composition and Ge concentration of biogenic opal (sponges and diatoms) 


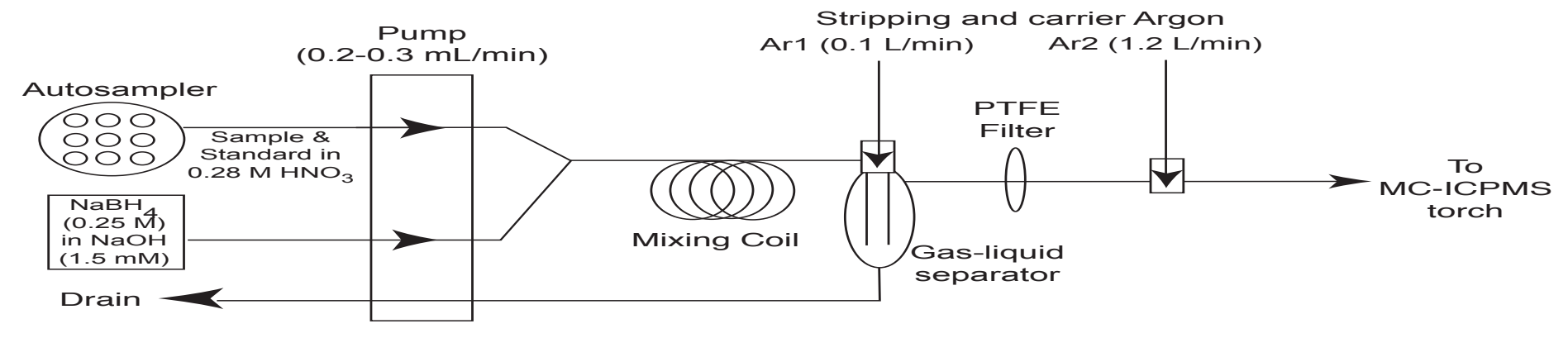



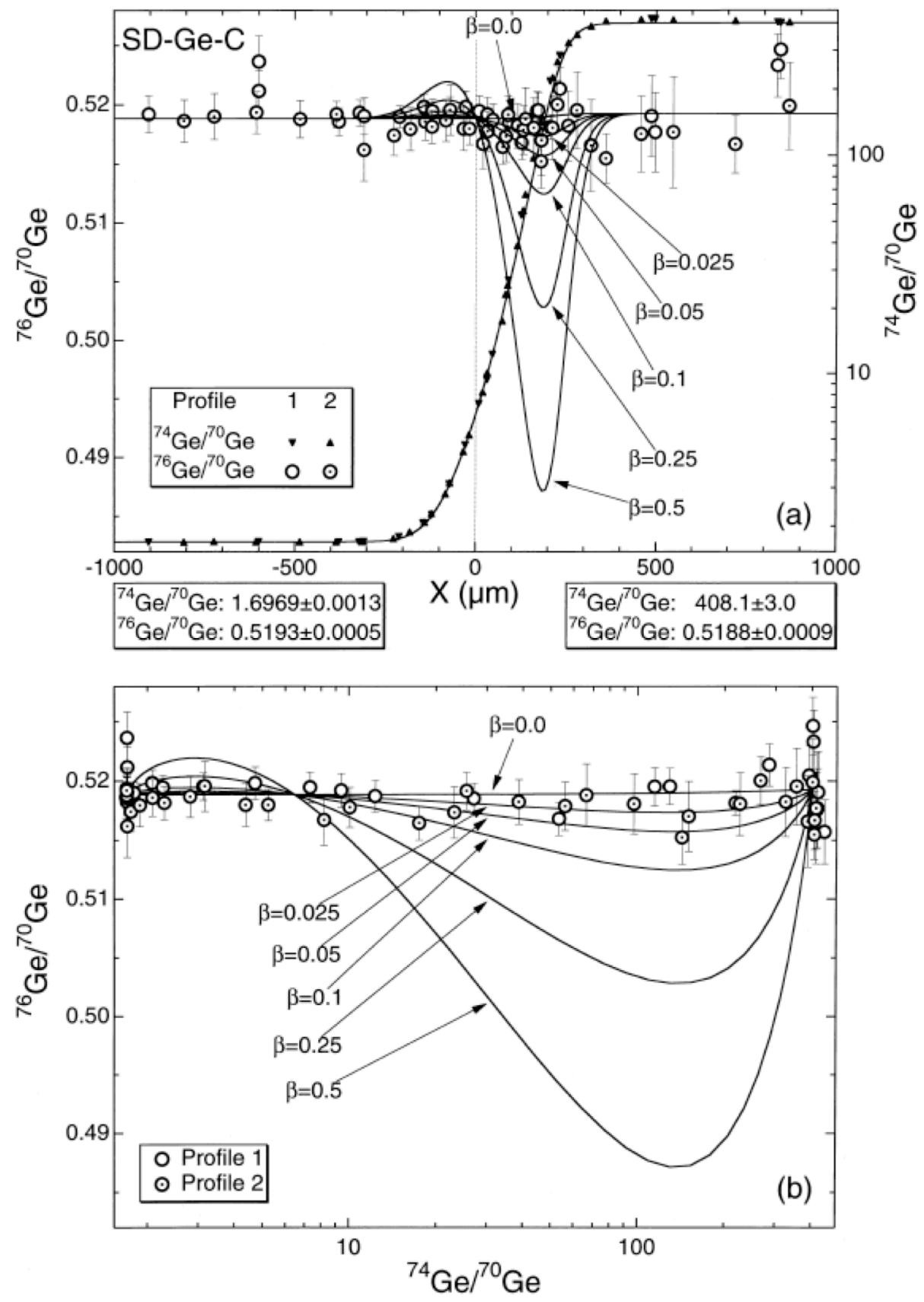

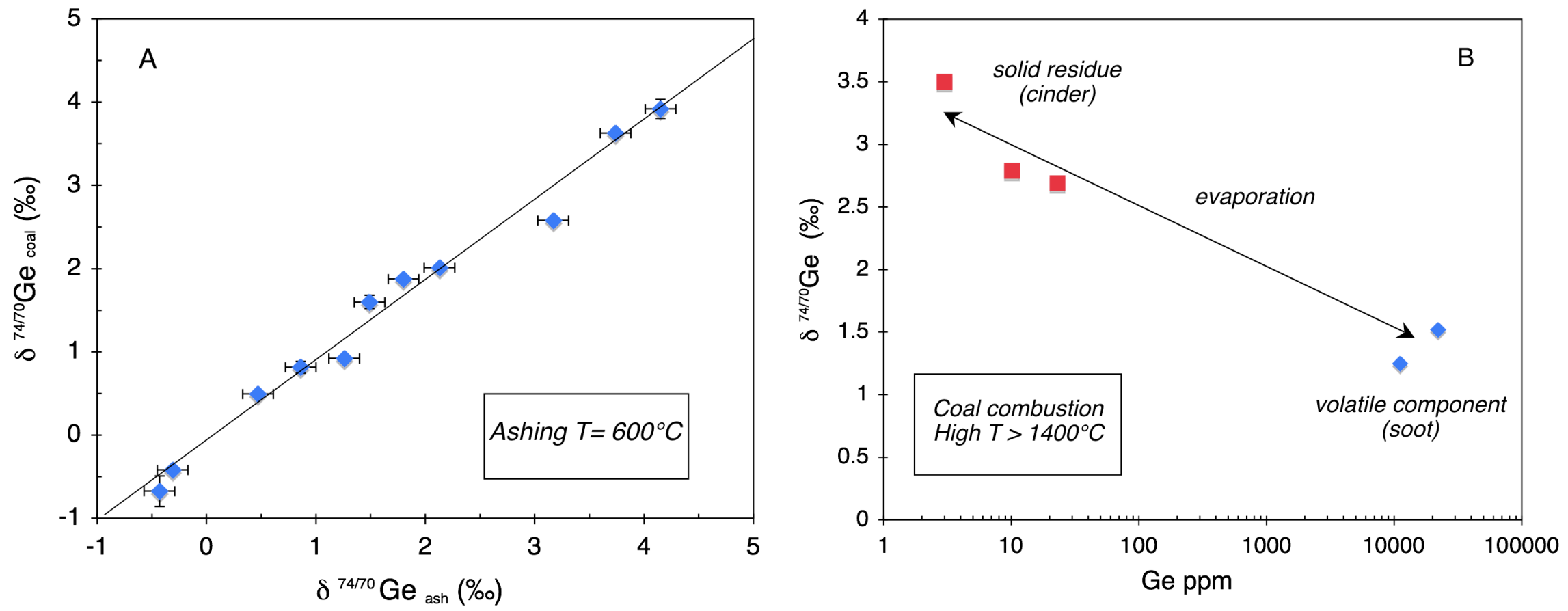

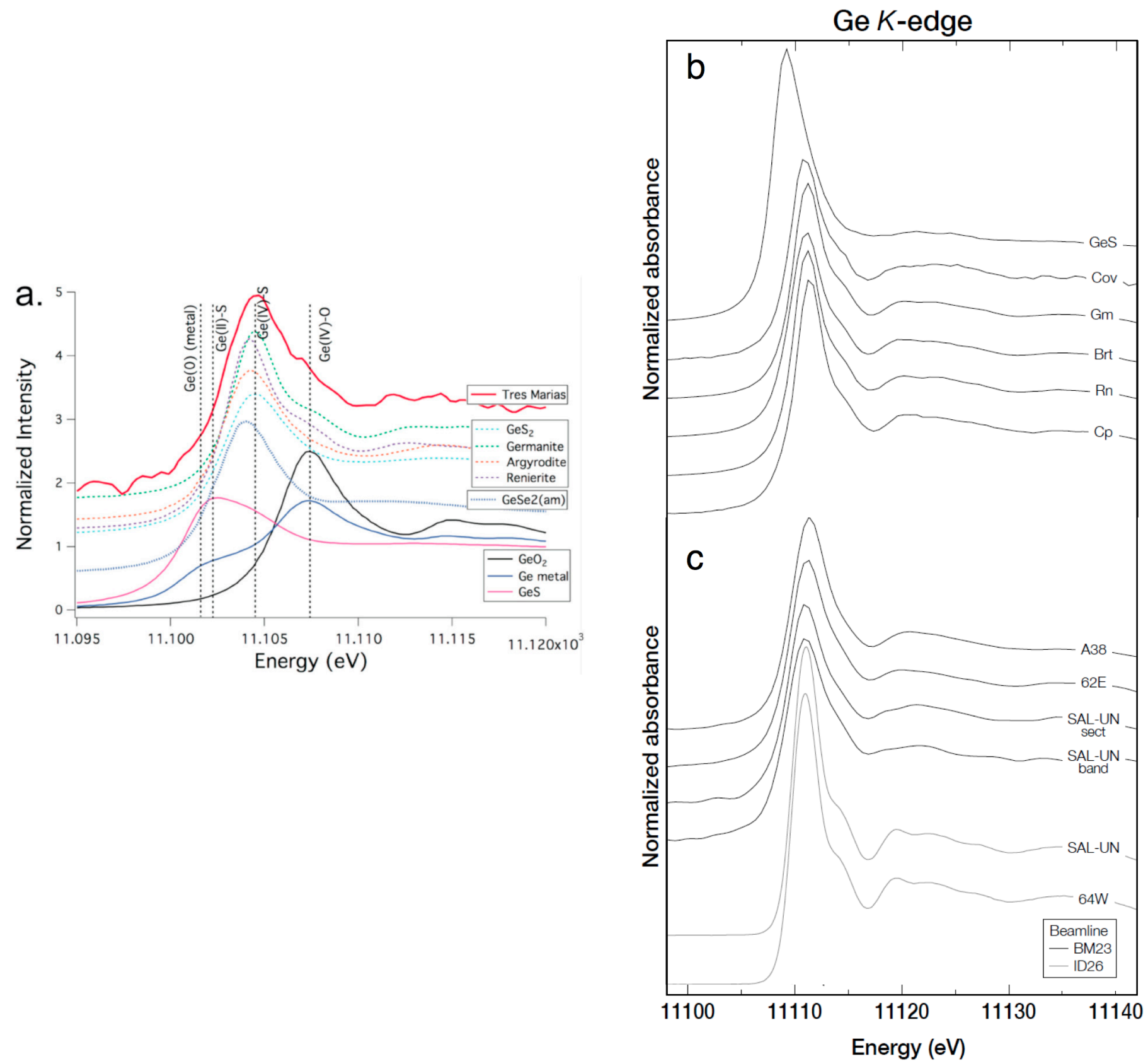

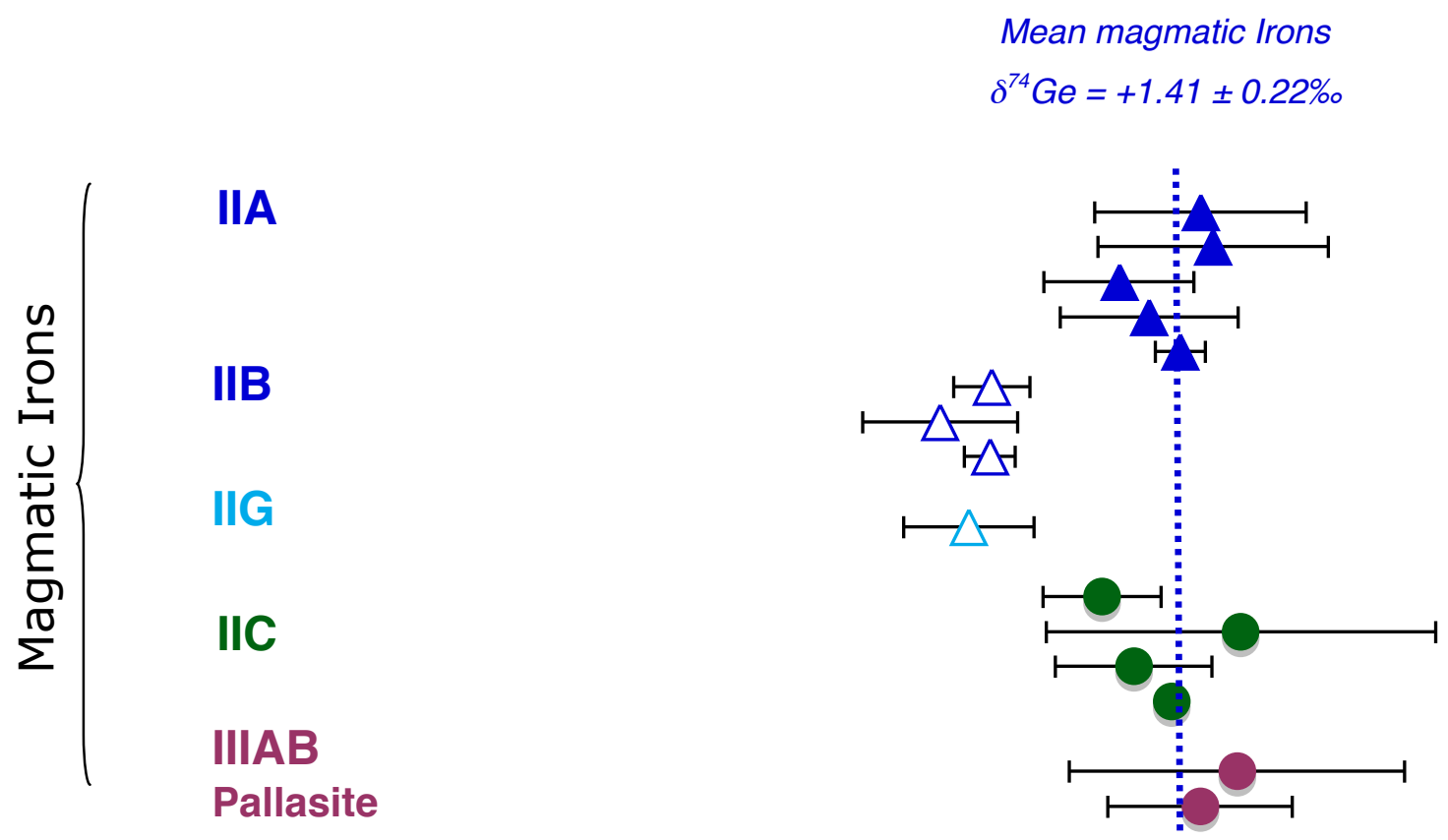

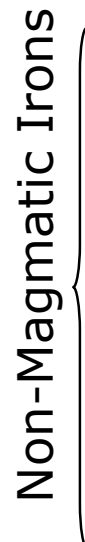

IAB
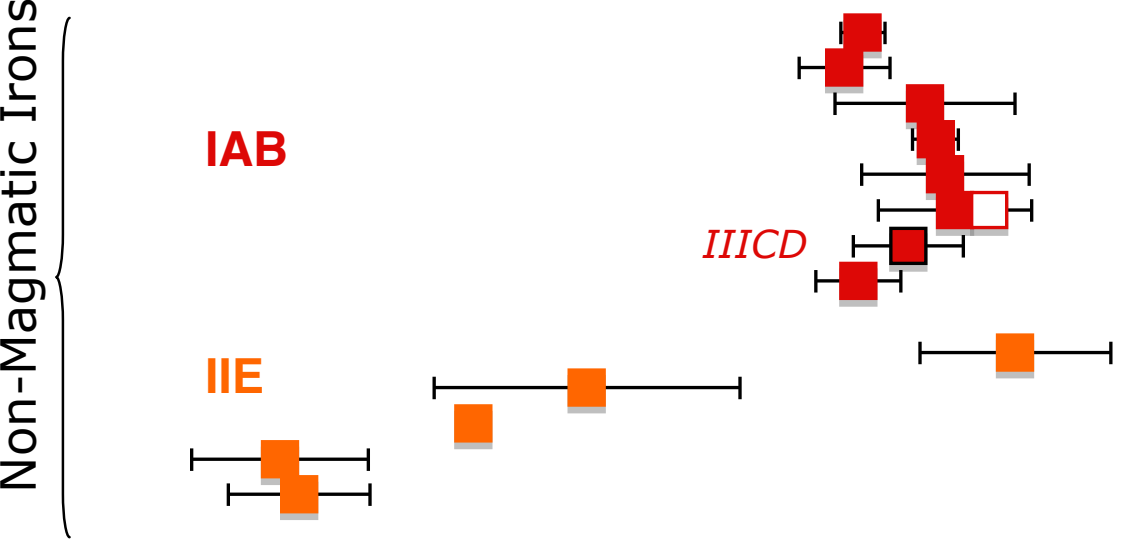

Ungrouped Irons
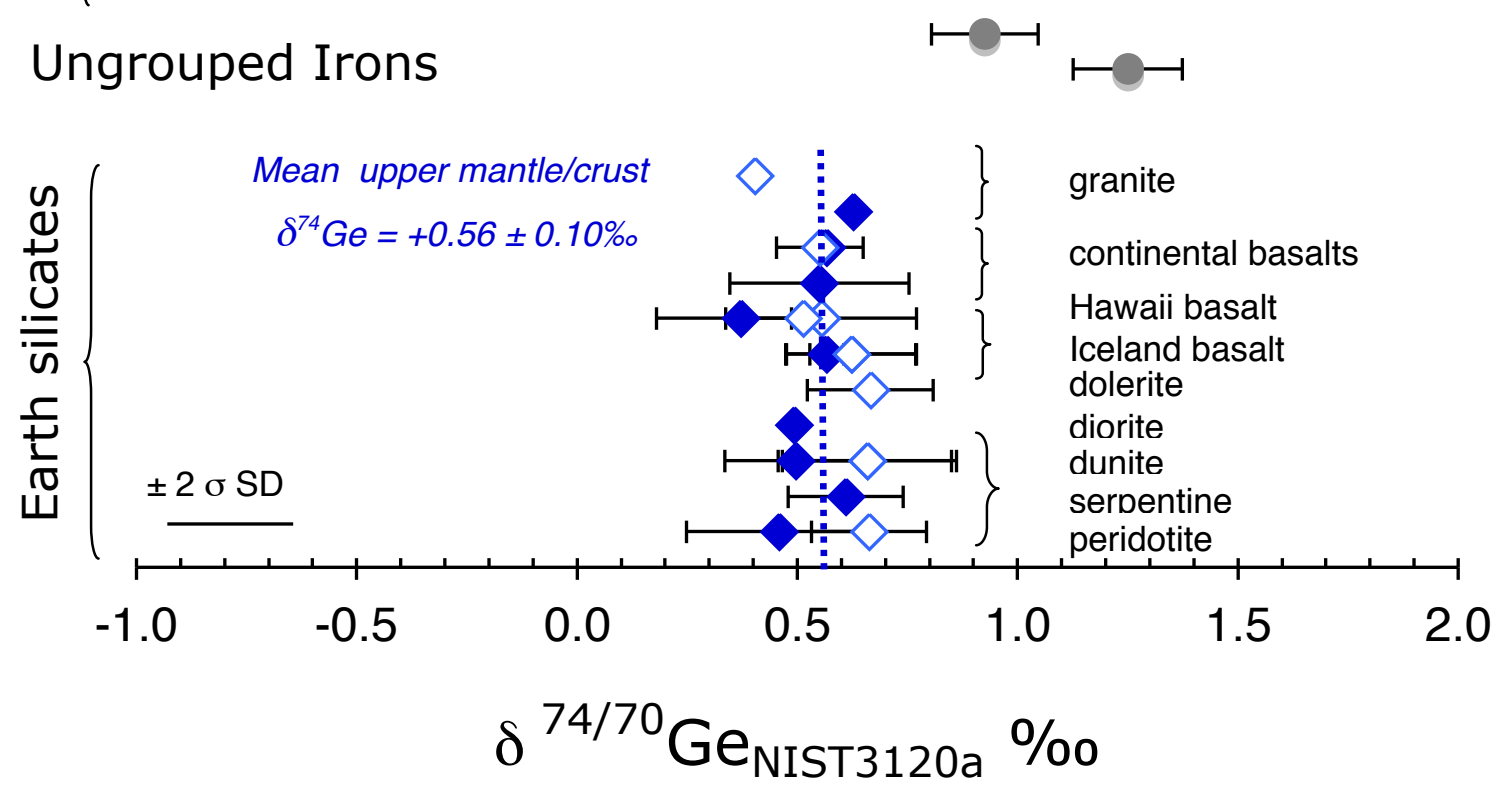


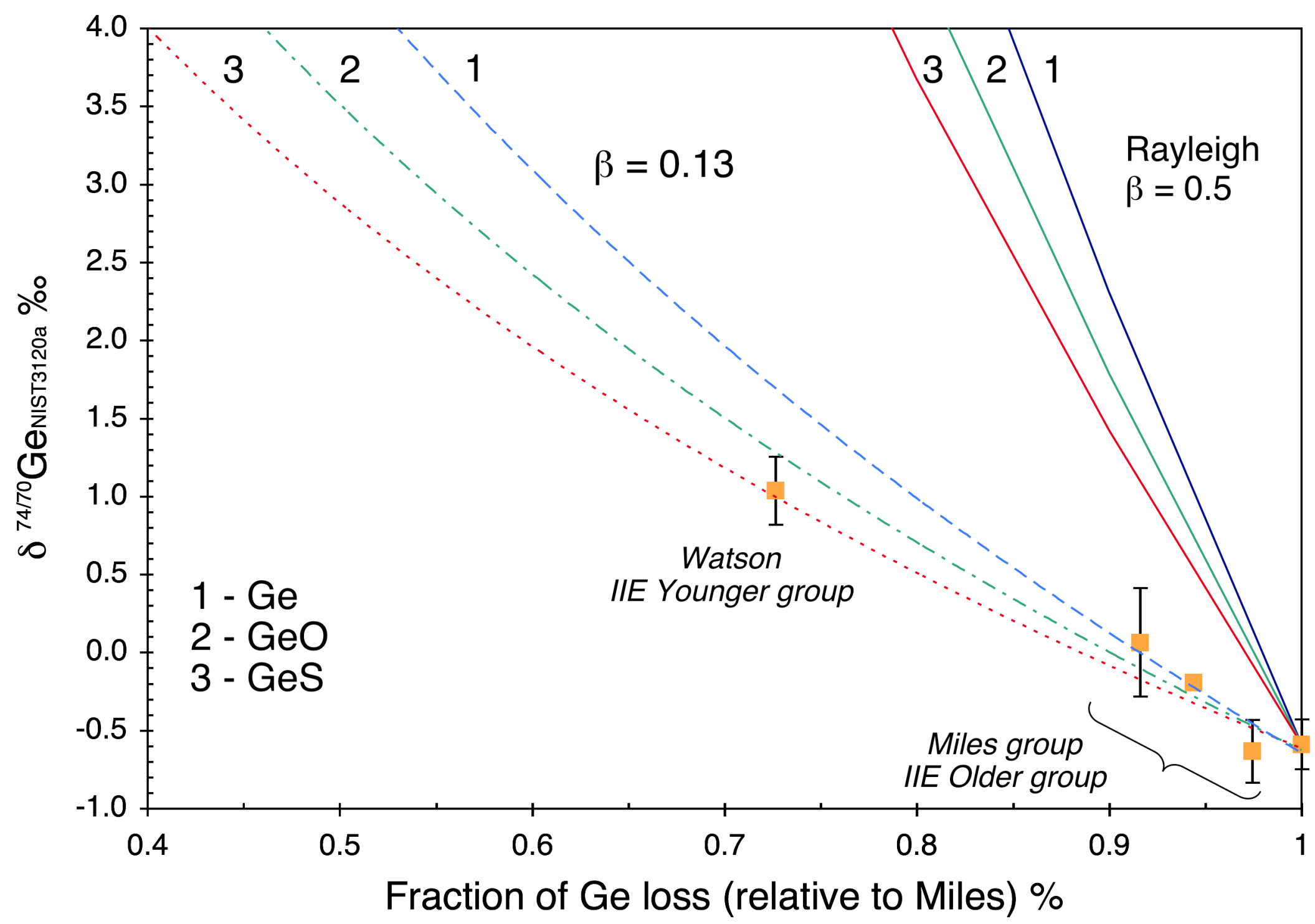




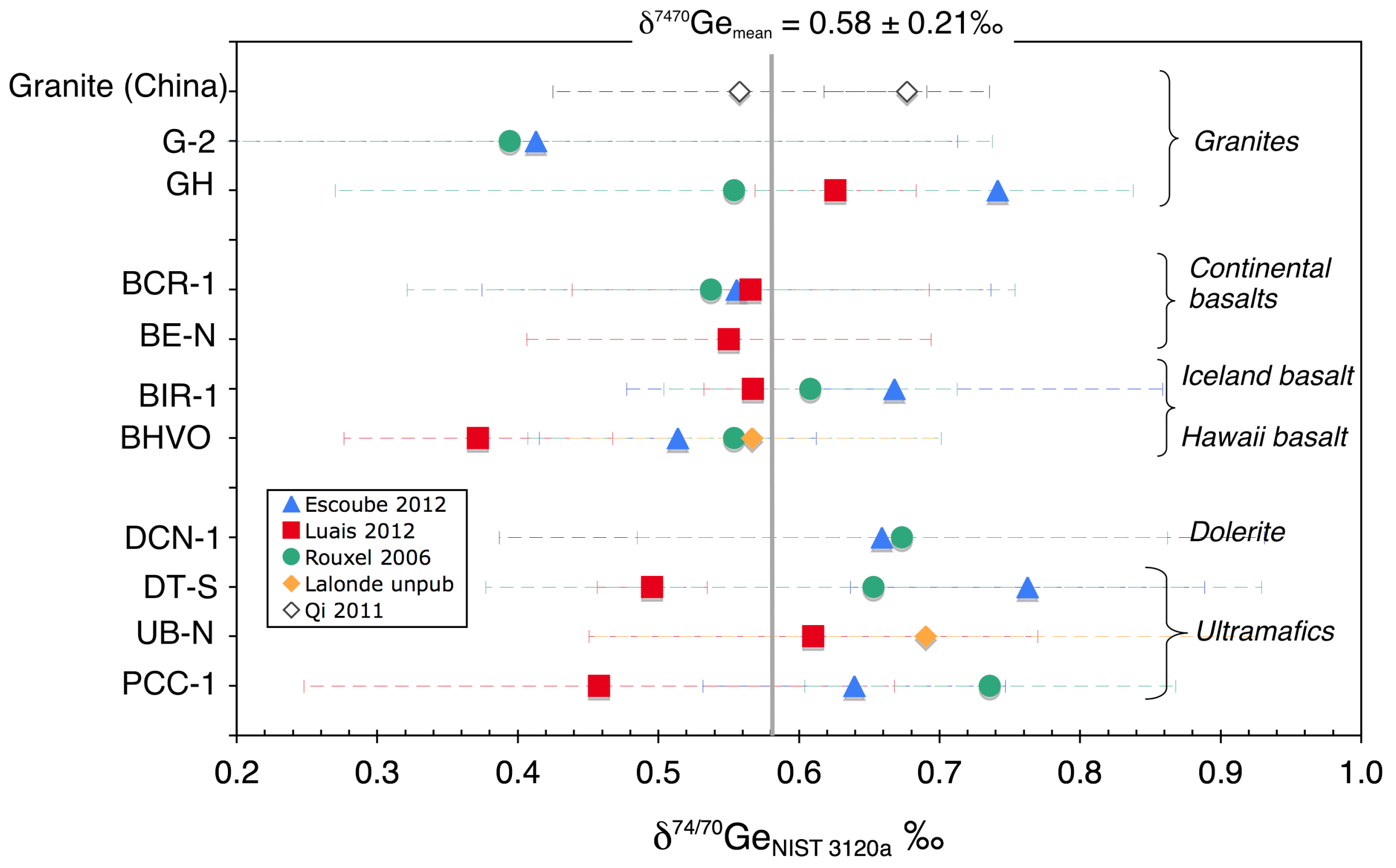




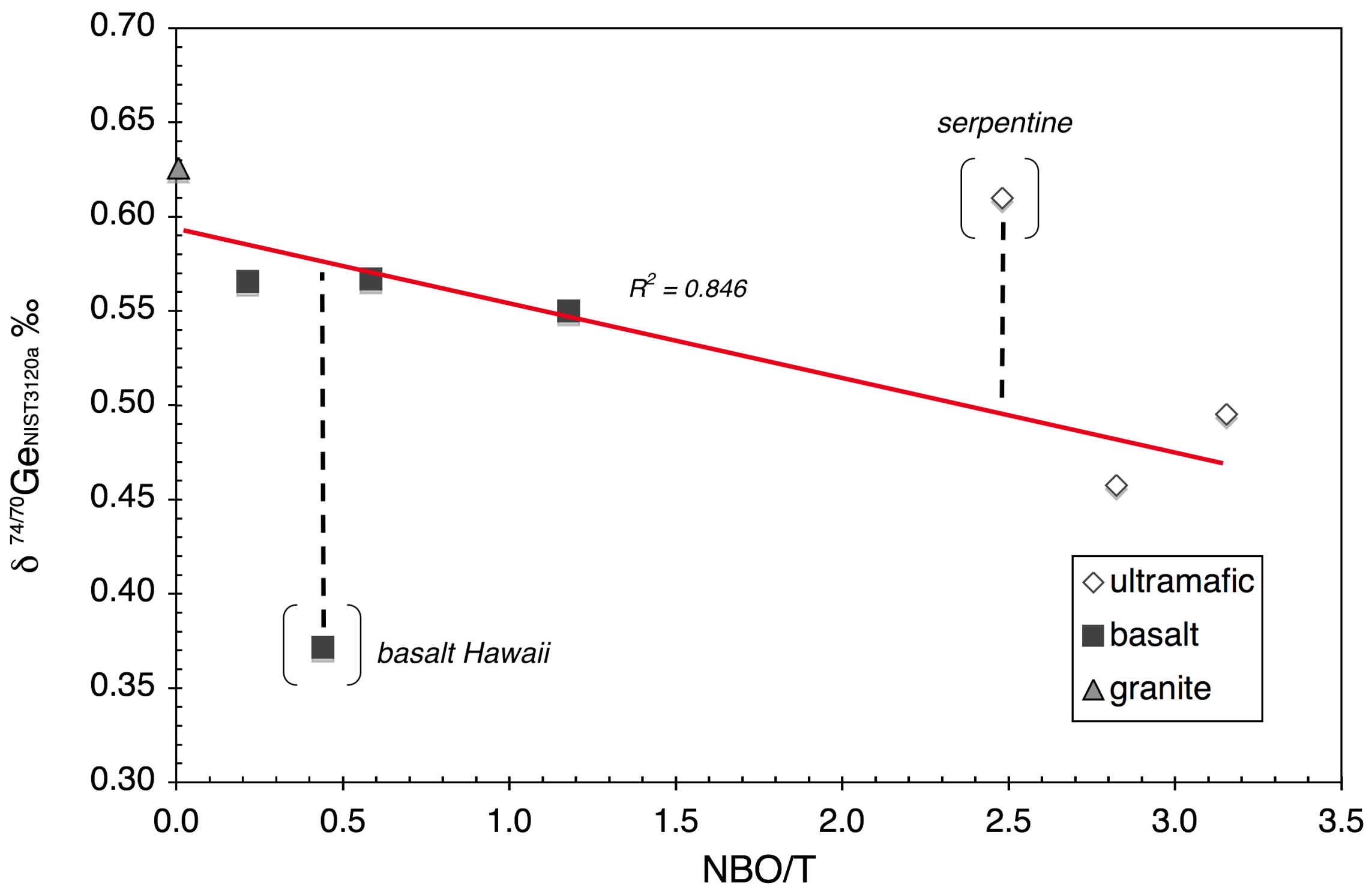




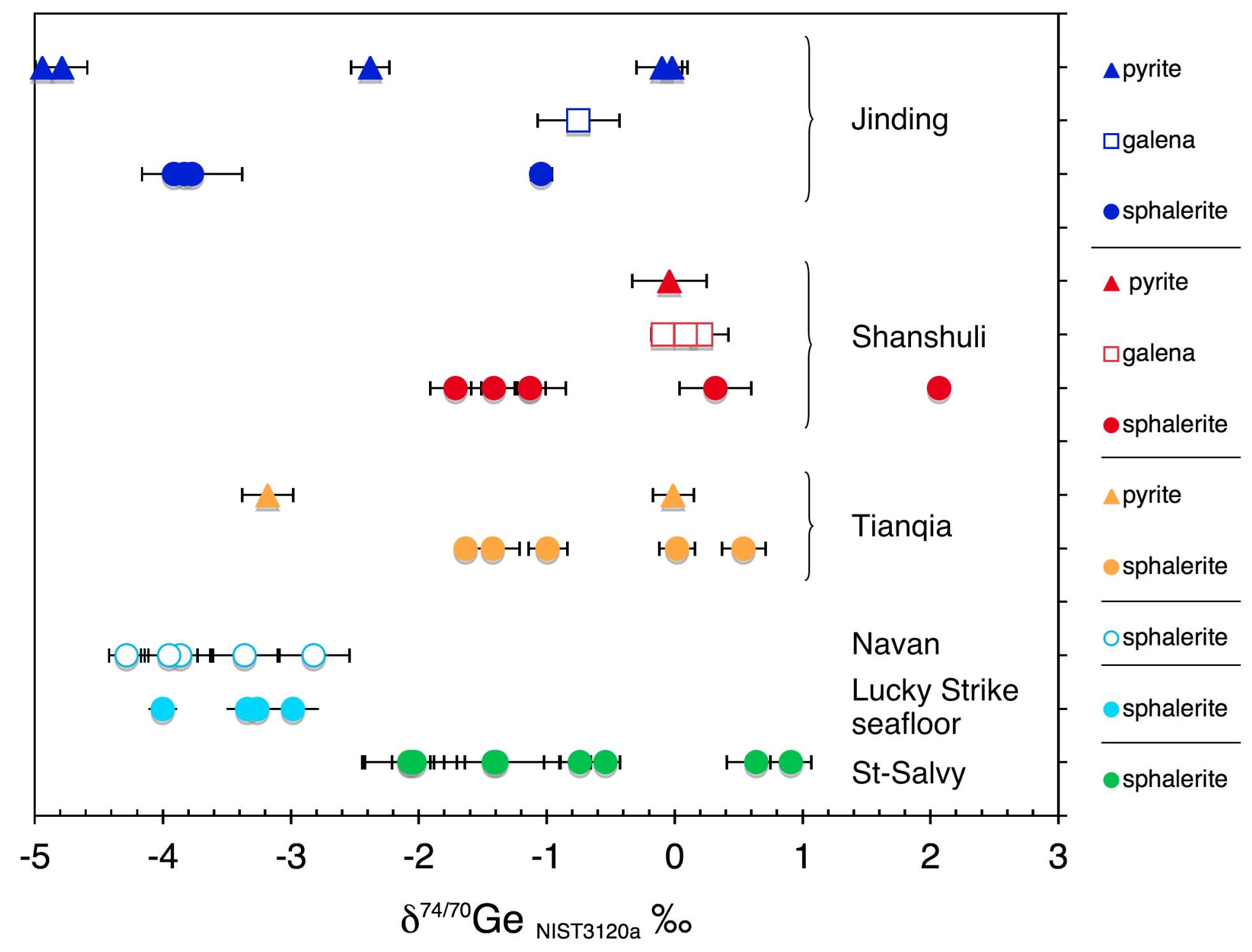




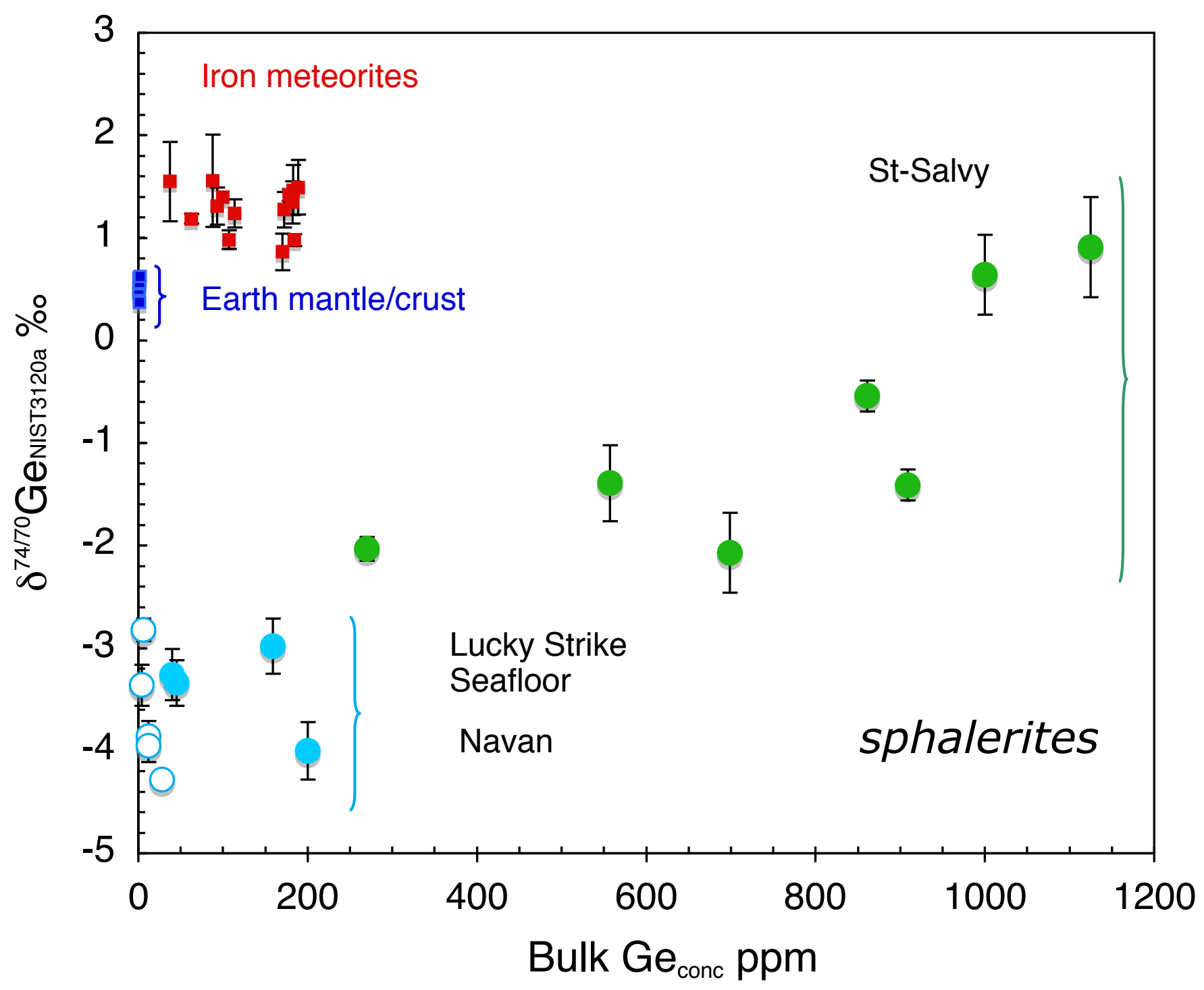




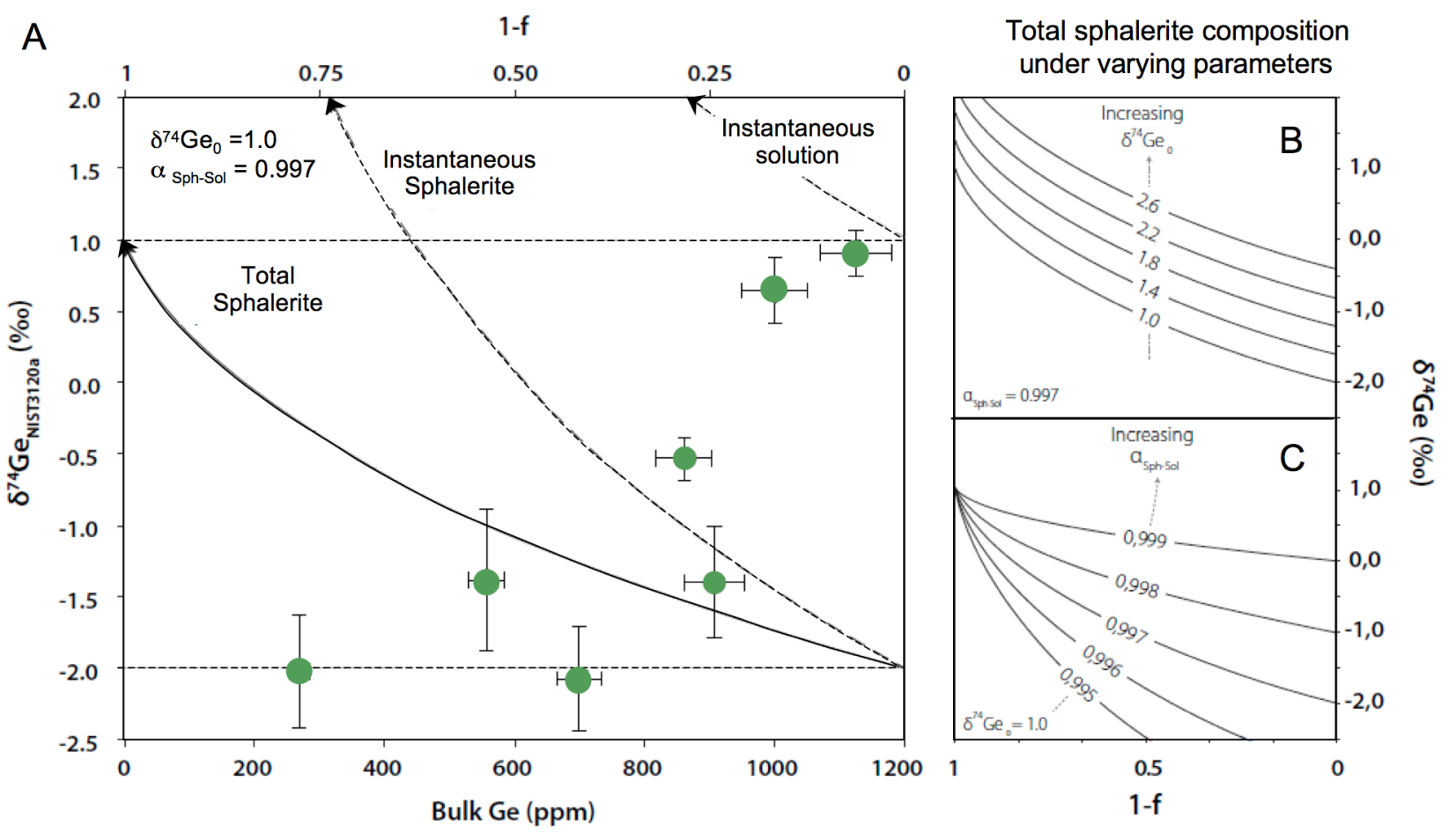


$\mathrm{Ge} / \mathrm{Si}(\mu \mathrm{mol} / \mathrm{mol})$

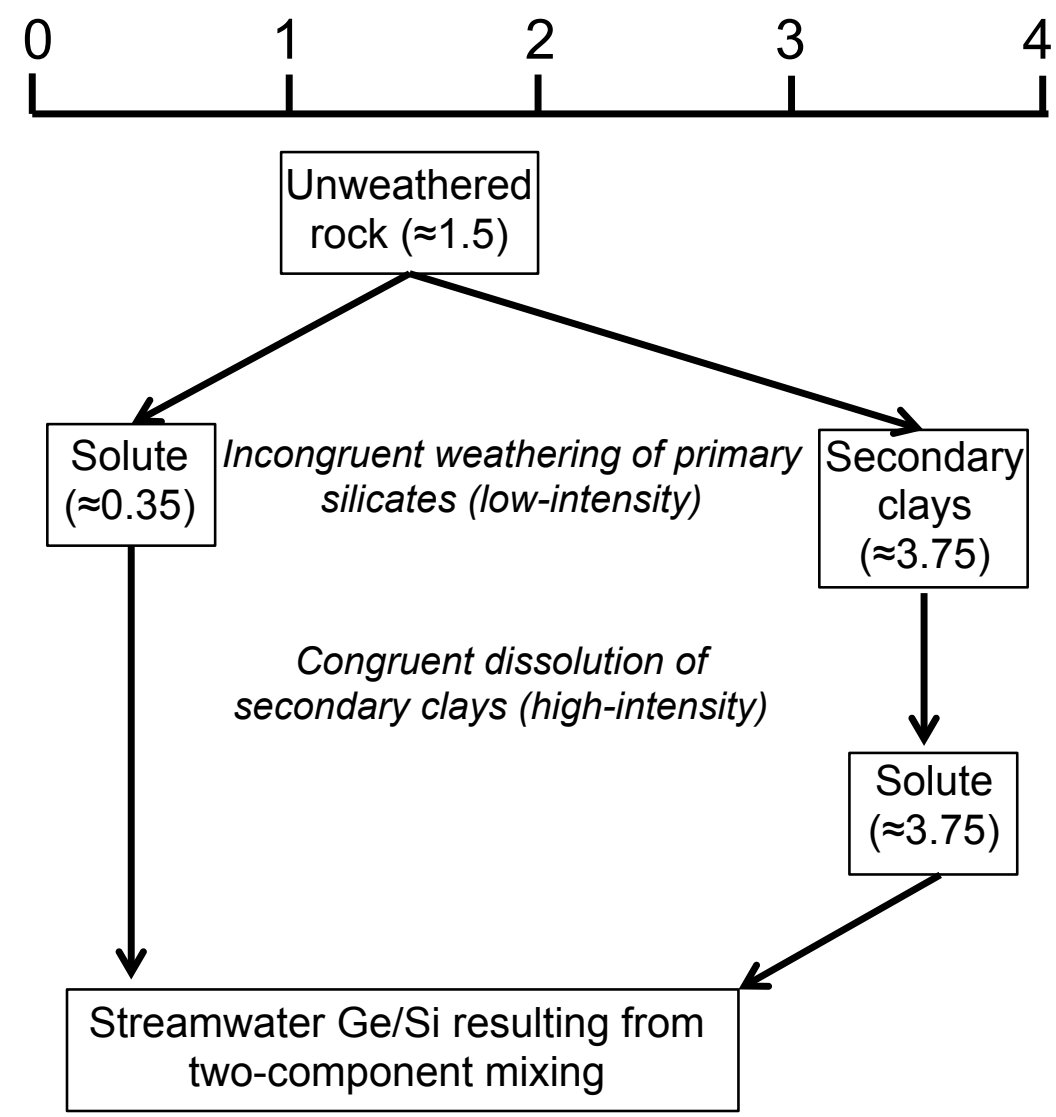

Figure 12 


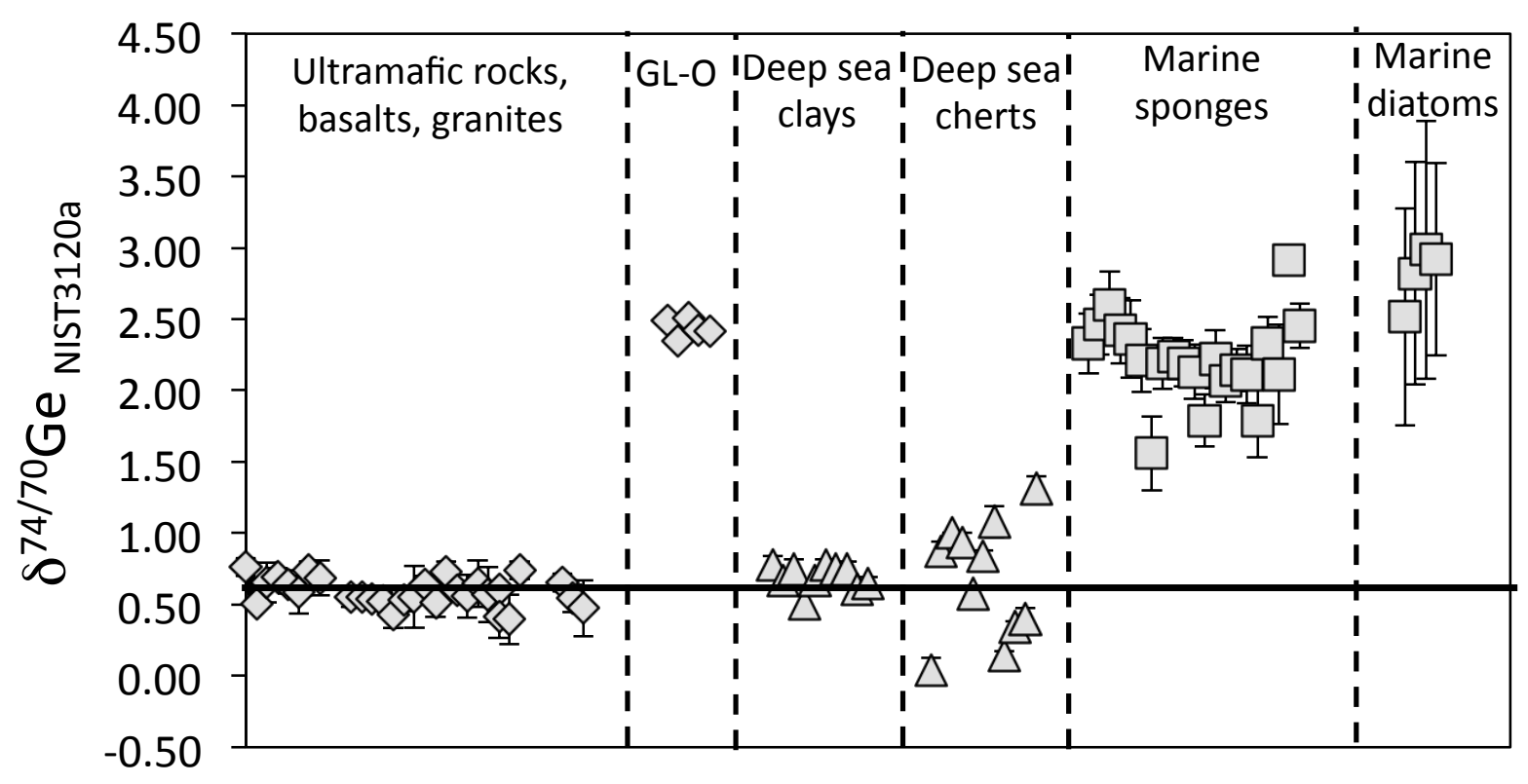

Figure 13 


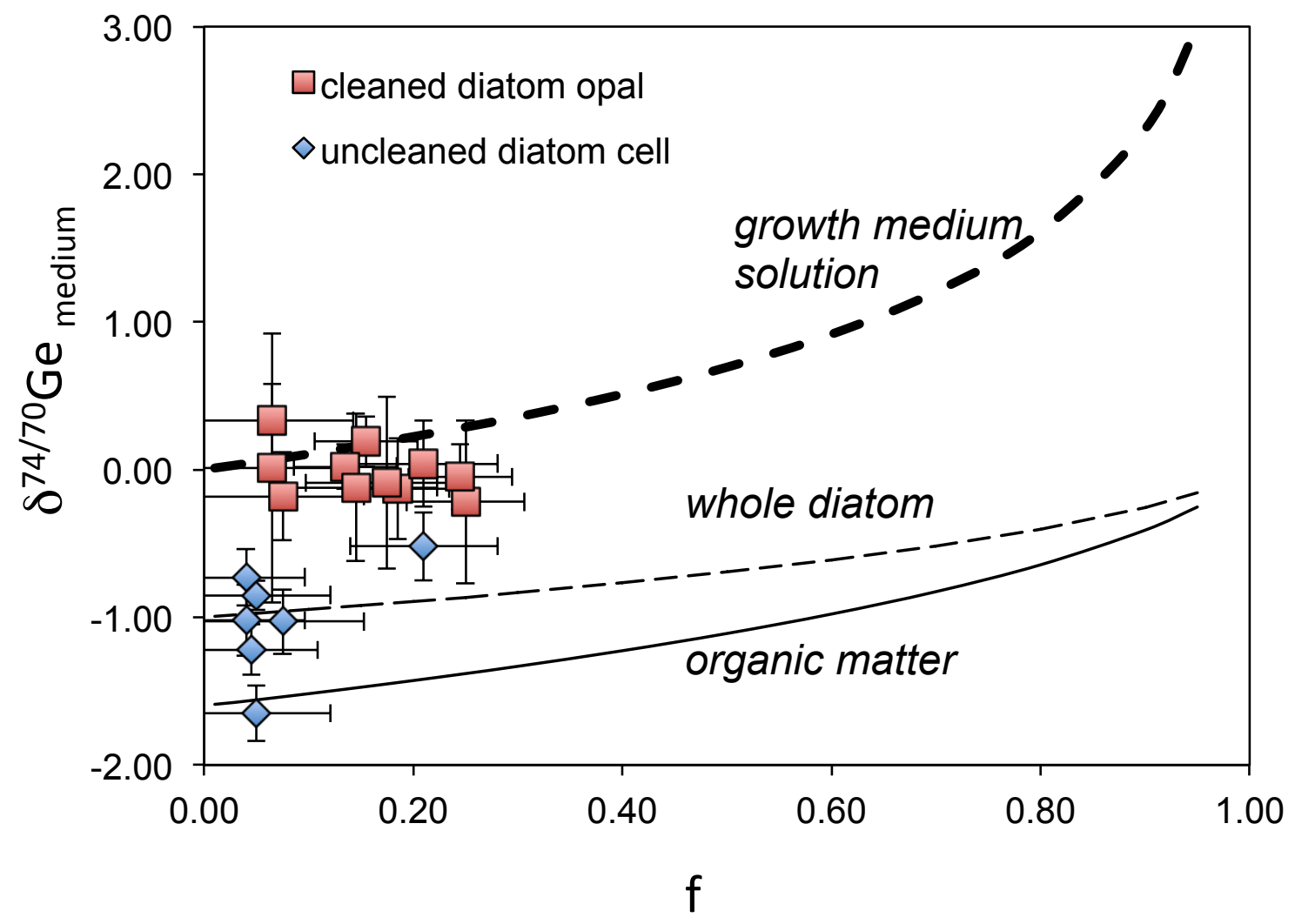

Figure 14 


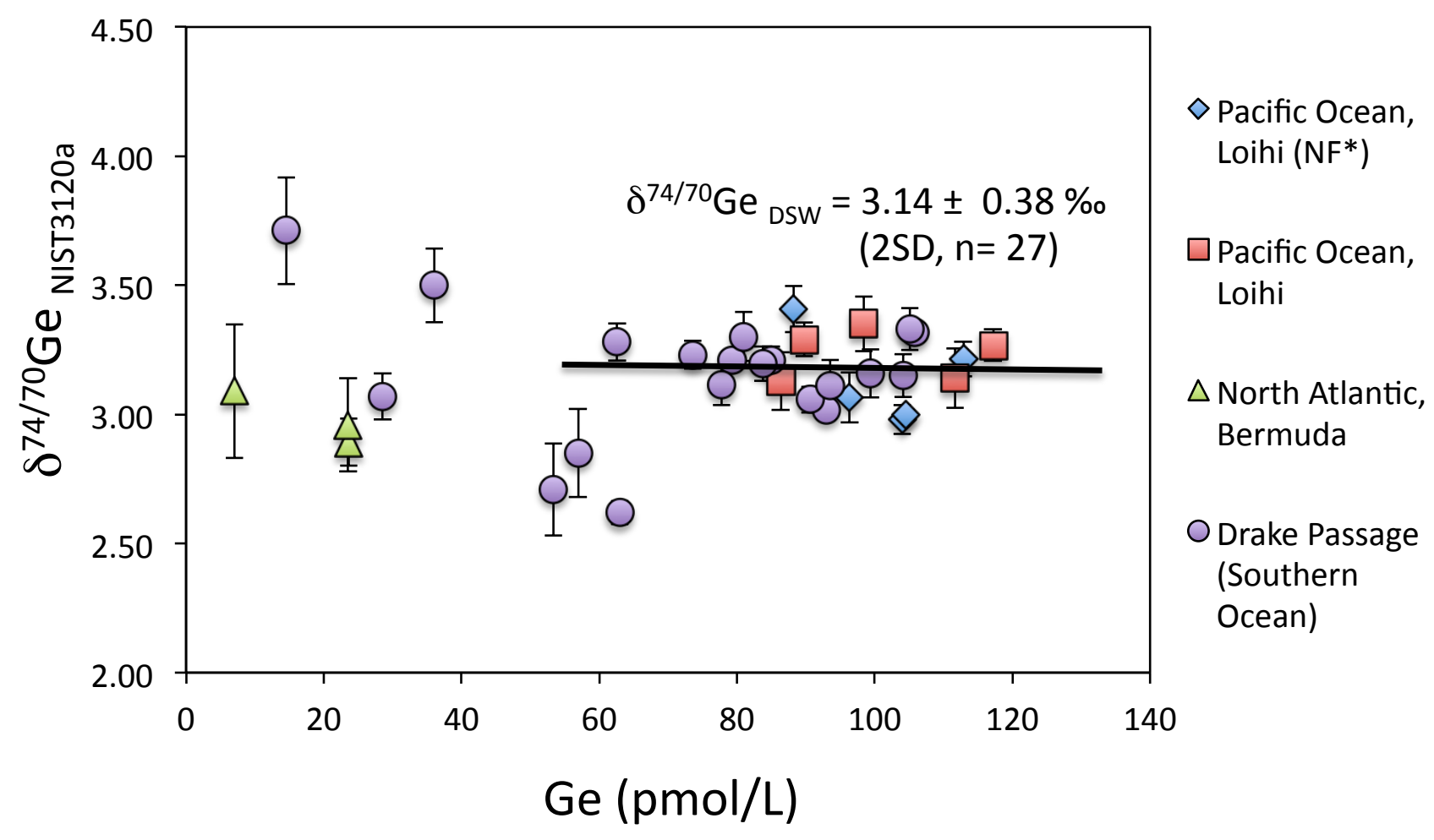

Figure 15 


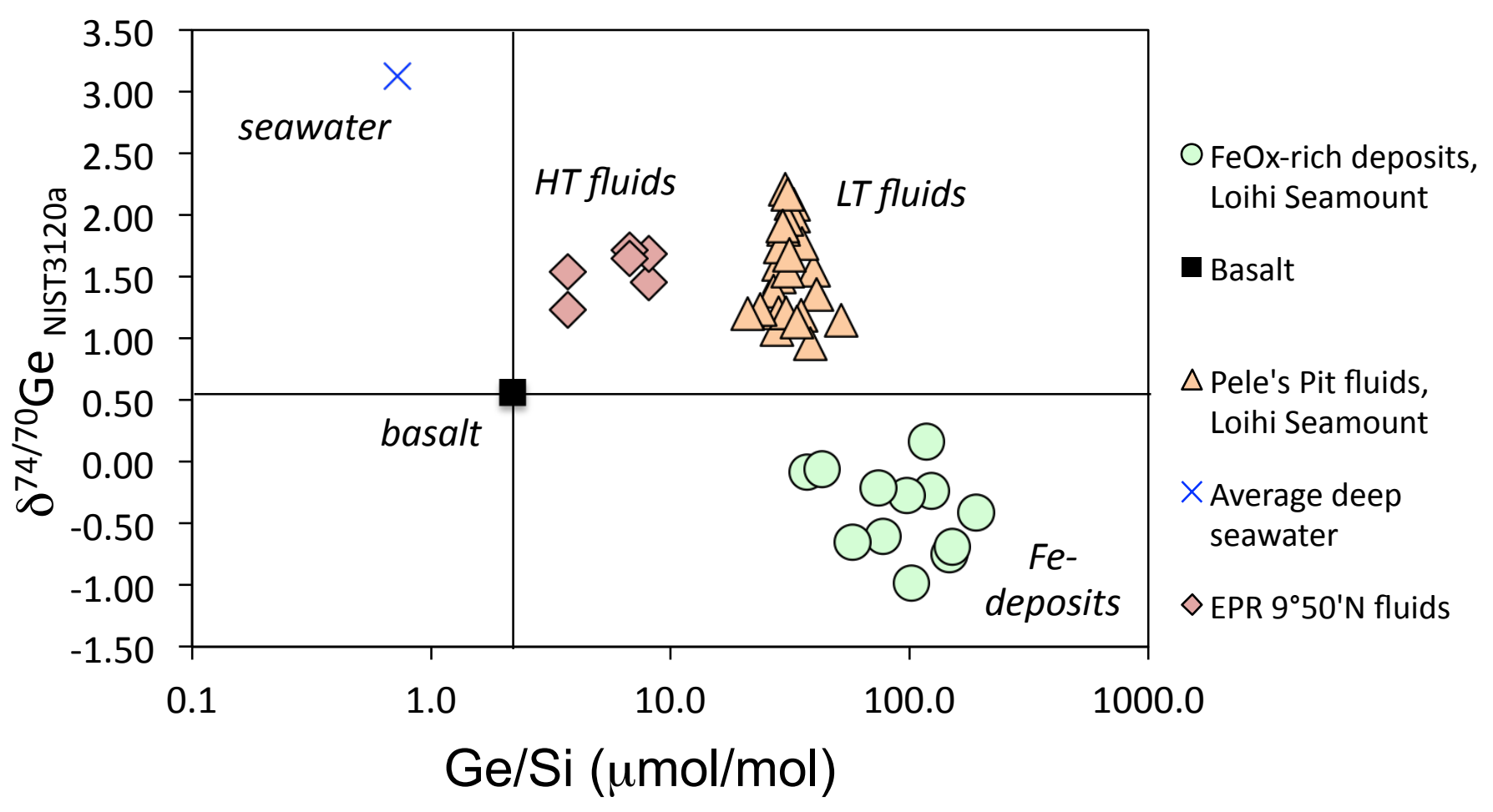

Figure 16 


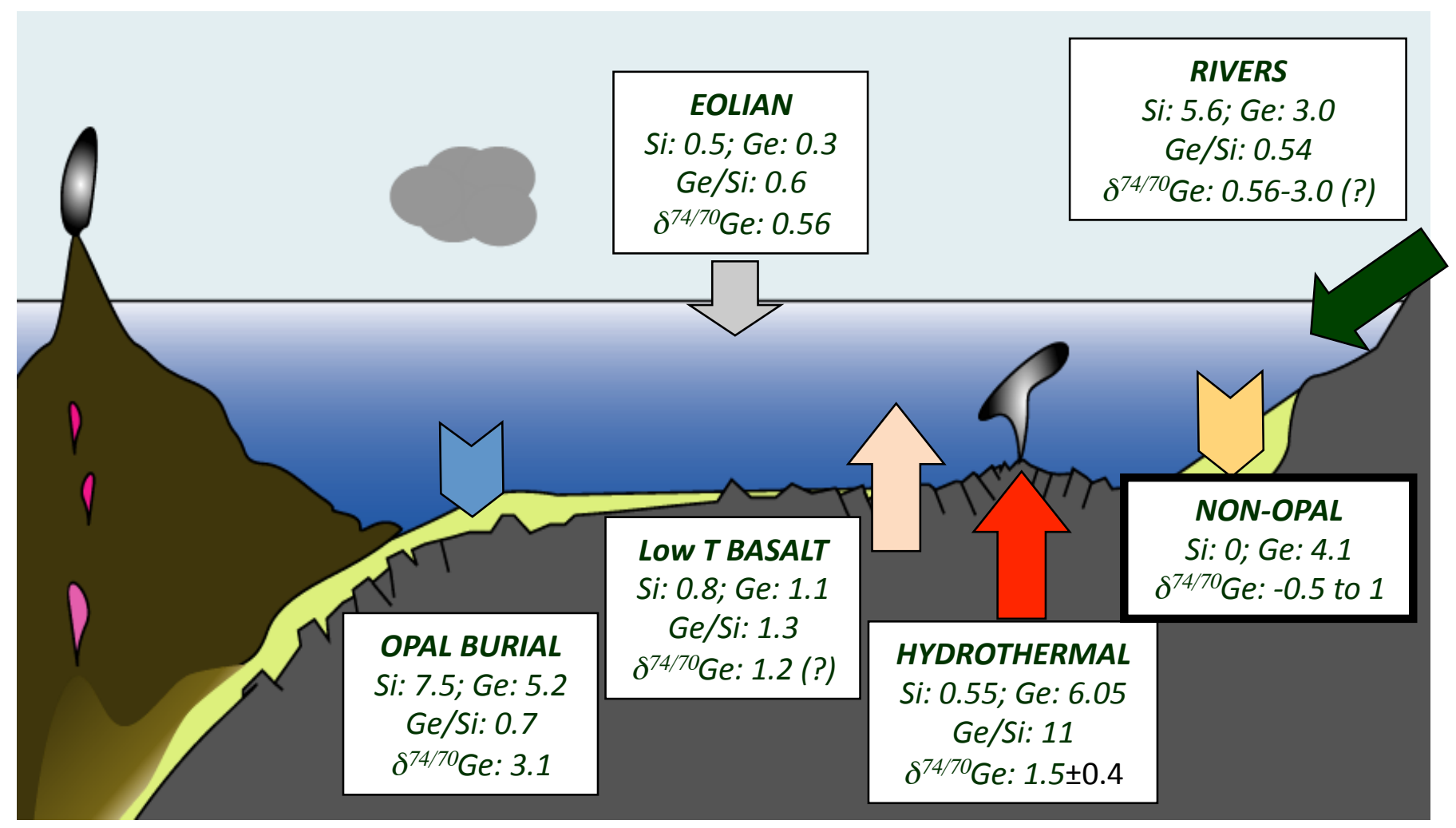

Figure 17 

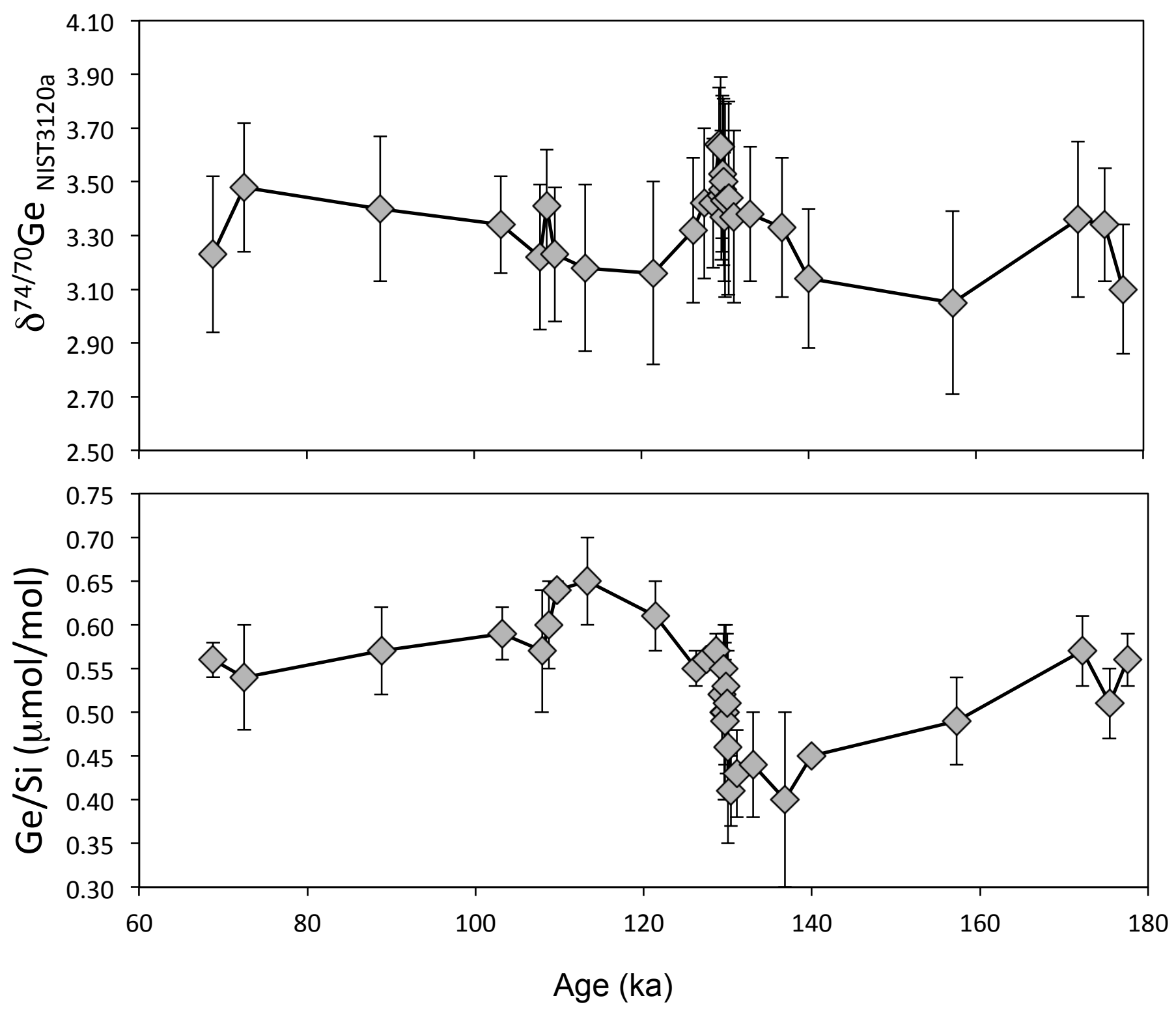

Figure 18 
Table 1: Compilation of the natural abundances of Ge isotopes determined by different mass spectrometry techniques. The Ge isotope composition of double spike mixtures used is also shown for comparison

\begin{tabular}{|c|c|c|c|c|c|c|c|c|c|}
\hline Ge material & ${ }^{74} \mathrm{Ge} /{ }^{70} \mathrm{Ge}$ & 1 s.d. & ${ }^{73} \mathrm{Ge} /{ }^{70} \mathrm{Ge}$ & 1 s.d. & ${ }^{72} \mathrm{Ge} /{ }^{70} \mathrm{Ge}$ & 1 s.d. & Method & Instrument/Lab & Reference \\
\hline $\mathrm{DS}\left(\mathrm{Ge}^{70}: \mathrm{Ge}^{73}\right)$ & 0.07614 & 0.00005 & 0.60707 & 0.00004 & 0.05626 & 0.00004 & $C S C, G a$ & Neptune/IFREMER & (1) \\
\hline NIST3120a & 1.76094 & 0.00003 & 0.37335 & 0.00001 & 1.32901 & 0.00002 & $C S C, G a$ & Neptune/IFREMER & (1) \\
\hline NIST3120a & 1.76137 & 0.00014 & 0.37447 & 0.00003 & 1.32934 & 0.00010 & $H G, G a$ & Neptune/WHOI & (2) \\
\hline NIST3120a & 1.76426 & 0.00139 & 0.37484 & 0.00028 & 1.33068 & 0.00096 & $H G, C u$ & Neptune/WHOI & (2) \\
\hline NIST3120a & 1.76738 & 0.00509 & 0.37494 & 0.00065 & 1.33145 & 0.00121 & $C S C, G a$ & Isoprobe/CRPG & (2) \\
\hline NIST3120a & 1.76460 & 0.00021 & 0.37426 & 0.00004 & 1.33073 & 0.00009 & $C S C, G a$ & Nu Plasma/LCABIE & (2) \\
\hline NIST3120a & 1.76223 & 0.00057 & 0.37411 & 0.00014 & 1.32979 & 0.00014 & $H G, G a$ & Nu Plasma/LCABIE & (2) \\
\hline Aldrich \#01704KZ & 1.76367 & 0.00283 & 0.37370 & 0.00151 & 1.33106 & 0.00070 & $C S C, G a$ & Isoprobe /CRPG & (2) \\
\hline In house & 1.77000 & 0.00014 & 0.37520 & 0.00015 & 1.33300 & 0.00070 & $G a$ & Nu Plasma/OSU & (3) \\
\hline JMC \#301230Sn & 1.76641 & 0.00223 & 0.37499 & 0.01331 & 1.33199 & 0.00092 & $C S C, G a$ & Isoprobe /CRPG & (2) \\
\hline JMC \#301230Sn & 1.74337 & - & 0.37189 & - & 1.32360 & - & $G a$ & VG-P54 & (4) \\
\hline Ge metal (Aldrich) & 1.77937 & - & 0.37807 & - & 1.33712 & - & $C S C, G a$ & Neptune & (5) \\
\hline In house & 1.69449 & 0.00598 & 0.36383 & 0.00090 & 1.30315 & 0.00276 & & TIMS & (6) \\
\hline In house & 1.74228 & 0.00370 & 0.37107 & 0.00067 & 1.31927 & 0.00491 & & TIMS-VG-354 & (7) \\
\hline In house & 1.73038 & - & 0.37189 & - & 1.31833 & - & & TIMS & (8) \\
\hline In house & 1.78101 & - & 0.37821 & - & 1.33699 & - & & gas MS & (9) \\
\hline In house & 1.71516 & - & 0.36800 & - & 1.30938 & - & & SIMS & (10) \\
\hline
\end{tabular}

(1) Escoube et al., 2012; (2) this study; (3) Siebert et al., 2006; (4) Hirata, 1997; (5) Yang and Meija, 2010

(6) Green et al., 1986; (7) Chang et al., 1999; (8) Shima, 1963; (9) Reynolds et al., 1953; (10) Nishimura et al. 1988

CSC: cyclonic spray chamber; HG: hydride generation

s.d.: standard deviation

DS (Ge70:Ge73): Ge double spike 
Table 2: Average compositions of Ge isotope standards used by different research groups normalized against NIST 3120a isotopic standard.

\begin{tabular}{|c|c|c|c|c|c|c|c|c|c|c|}
\hline Lab & Method & nb\# & $\begin{array}{c}\delta^{74 / 70} \mathbf{G e} \\
\text { NIST3120a }\end{array}$ & $2 s$ & $\begin{array}{c}\delta^{73 / 70} \mathrm{Ge} \\
\text { NIST3120a }\end{array}$ & $2 s$ & $\begin{array}{c}\delta^{72 / 70} \mathrm{Ge} \\
\text { NIST3120a }\end{array}$ & $2 s$ & $\begin{array}{c}\delta^{74 / 72} \mathbf{G e} \\
\text { NIST3120a }\end{array}$ & $2 s$ \\
\hline \multicolumn{3}{|c|}{ "ARISTAR" standard } & $\underline{-0.64}$ & $\underline{0.18}$ & $\underline{-0.54}$ & $\underline{0.18}$ & $\underline{-0.38}$ & $\underline{0.26}$ & $\underline{-0.28}$ & $\underline{0.03}$ \\
\hline \#1 & HG SSB & 11 & -0.58 & 0.12 & $n d$ & & -0.30 & 0.09 & -0.28 & 0.04 \\
\hline$\# 1$ & $\mathrm{HG} \quad \mathrm{Ga}$ & 11 & -0.57 & 0.08 & $n d$ & & -0.30 & 0.05 & -0.28 & 0.07 \\
\hline$\# 2$ & CSC SSB & 4 & -0.59 & 0.02 & -0.47 & 0.04 & -0.33 & 0.01 & -0.26 & 0.01 \\
\hline$\# 2$ & CSC DS & 4 & -0.61 & 0.11 & -0.46 & 0.08 & -0.31 & 0.06 & -0.30 & 0.06 \\
\hline$\# 3$ & $\mathrm{CSC} \mathrm{Ga}$ & 6 & -0.76 & 0.28 & -0.61 & 0.20 & -0.41 & 0.17 & $n d$ & \\
\hline \#3 & CSC SSB & 6 & -0.75 & 0.28 & -0.63 & 0.20 & -0.63 & 0.17 & $n d$ & \\
\hline \multicolumn{3}{|c|}{ "JMC" standard } & $\underline{-0.32}$ & $\underline{0.10}$ & $\underline{-0.23}$ & $\underline{0.12}$ & $\underline{-0.16}$ & $\underline{0.07}$ & $\underline{-0.16}$ & $\underline{0.05}$ \\
\hline \#1 & HG SSB & 4 & -0.33 & 0.33 & $n d$ & & -0.15 & 0.27 & -0.18 & 0.06 \\
\hline$\# 1$ & $\mathrm{HG} \quad \mathrm{Ga}$ & 4 & -0.31 & 0.29 & $n d$ & & -0.14 & 0.25 & -0.17 & 0.06 \\
\hline \#2 & CSC SSB & 4 & -0.23 & 0.02 & -0.14 & 0.04 & -0.11 & 0.03 & -0.12 & 0.03 \\
\hline$\# 2$ & CSC DS & 4 & -0.32 & 0.07 & -0.24 & 0.05 & -0.16 & 0.04 & -0.16 & 0.04 \\
\hline$\# 3$ & $\mathrm{CSC} \mathrm{Ga}$ & 8 & -0.37 & 0.04 & -0.25 & 0.02 & -0.19 & 0.07 & $n d$ & \\
\hline \#3 & CSC SSB & 8 & -0.37 & 0.16 & -0.28 & 0.14 & -0.20 & 0.06 & $n d$ & \\
\hline \multicolumn{3}{|c|}{ "SPEX" standard } & $\underline{-0.71}$ & 0.21 & $\underline{-0.56}$ & $\underline{0.15}$ & -0.37 & $\underline{0.16}$ & $\underline{-0.31}$ & $\underline{0.08}$ \\
\hline \#1 & HG SSB & 1 & -0.59 & nd & $n d$ & & -0.28 & nd & -0.31 & nd \\
\hline$\# 1$ & $\mathrm{HG} \quad \mathrm{Ga}$ & 1 & -0.60 & nd & nd & & -0.28 & nd & -0.31 & nd \\
\hline$\# 1$ & HG SSB & 5 & -0.84 & 0.16 & nd & & -0.48 & 0.10 & -0.36 & 0.08 \\
\hline$\# 1$ & $\mathrm{HG} \quad \mathrm{Ga}$ & 5 & -0.81 & 0.11 & $n d$ & & -0.46 & 0.09 & -0.35 & 0.04 \\
\hline$\# 2$ & CSC SSB & 3 & -0.61 & 0.04 & -0.51 & 0.09 & -0.33 & 0.03 & -0.28 & 0.05 \\
\hline$\# 2$ & CSC DS & 4 & -0.63 & 0.13 & -0.48 & 0.10 & -0.32 & 0.06 & -0.31 & 0.06 \\
\hline$\# 3$ & $\mathrm{CSC} \mathrm{Ga}$ & 10 & -0.81 & 0.19 & -0.62 & 0.24 & -0.41 & 0.11 & $n d$ & \\
\hline$\# 3$ & CSC SSB & 10 & -0.79 & 0.18 & -0.62 & 0.16 & -0.41 & 0.12 & $n d$ & \\
\hline$\# 4$ & CSC SSB & 14 & -0.64 & 0.42 & $n d$ & & $n d$ & 0.00 & -0.23 & 0.26 \\
\hline$\# 4$ & $\mathrm{CSC} \mathrm{Ga}$ & 14 & -0.79 & 0.18 & $n d$ & & $n d$ & 0.00 & -0.31 & 0.04 \\
\hline \multicolumn{3}{|c|}{ "ALDRICH" standard } & -2.01 & $\underline{0.23}$ & -1.54 & $\underline{0.17}$ & $\underline{-1.03}$ & $\underline{0.12}$ & -0.97 & $\underline{0.15}$ \\
\hline$\# 2$ & CSC SSB & 4 & -1.88 & 0.03 & -1.46 & 0.07 & -0.97 & 0.02 & -0.92 & 0.03 \\
\hline$\# 2$ & CSC DS & 4 & -2.14 & 0.06 & -1.61 & 0.05 & -1.08 & 0.03 & -1.05 & 0.03 \\
\hline$\# 2$ & HG DS & 6 & -1.90 & 0.10 & -1.44 & 0.08 & -0.96 & 0.05 & -0.94 & 0.05 \\
\hline$\# 3$ & $\mathrm{CSC} \quad \mathrm{Ga}$ & 84 & -2.08 & 0.26 & -1.61 & 0.20 & -1.08 & 0.16 & $n d$ & \\
\hline \#3 & CSC SSB & 84 & -2.05 & 0.22 & -1.60 & 0.20 & -1.06 & 0.14 & nd & \\
\hline
\end{tabular}

Lab 1: WHOI; Lab 2: IFREMER; Lab 3: CRPG; Lab 4: LCBIE. "nd”, not determined.

SSB: sample-sample bracketing; DS: double spike correction; Ga: external normalisation to Ga.

CSC: cyclonic spray chamber; HG: hydride generation 
Table 3: Compilation of published and unpublished values for georeference materials

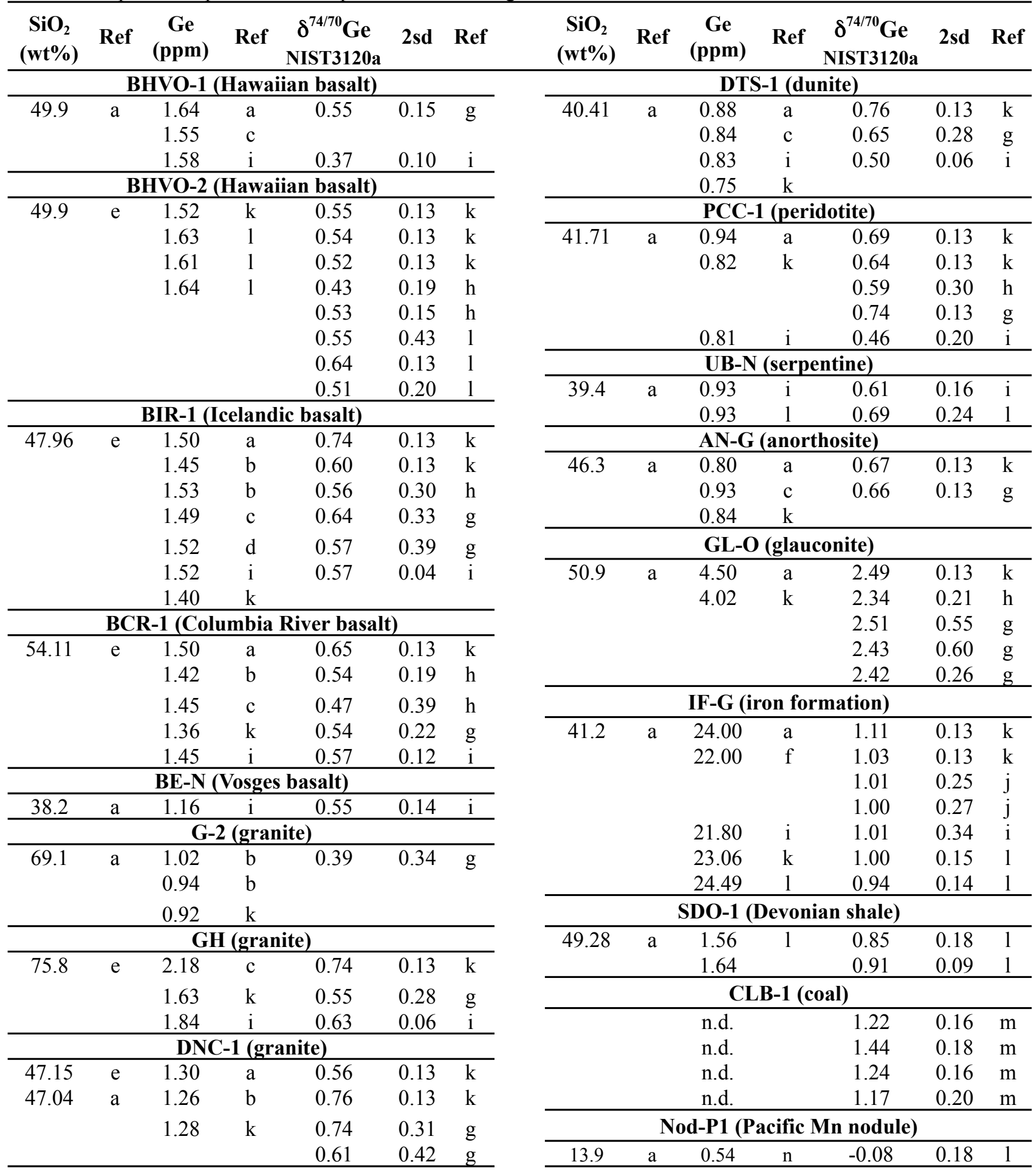

References: a: Govindaraju (1994); b: Mortlock and Froelich (1987, 1996); c: Halicz (1990); d: Kurtz et al. (2002); e: USGS; f: Frei and Polat (2007); g: Rouxel et al. (2006); h: Escoube et al. (2012) (double-spike, WHOI); i: Luais (2012); j: Rouxel, unpublished; k: Escoube et al. (2012) (double-spike, Ifremer); 1: Lalonde and Rouxel, unpublished; m: Qi et al. (2011); n : Axelsson et al., 2002. 
Table 4: Lattice parameters for Ge in metal, silicate, oxides and sulfides.

\begin{tabular}{|c|c|c|c|c|c|}
\hline & $\begin{array}{l}\text { Oxidation } \\
\text { state }\end{array}$ & $\begin{array}{c}\mathrm{Ge}-\mathrm{Fe} \\
(\AA) \\
\end{array}$ & $\begin{array}{c}\mathrm{Ge}-\mathrm{O} \\
(\AA)\end{array}$ & $\begin{array}{l}\text { Ge-S } \\
(\AA)\end{array}$ & References \\
\hline Fe-Ni metal & 0 & 2.494 & & & Cavell et al., 2004 \\
\hline $\begin{array}{l}\text { Silicates } \\
\text { olivine }\end{array}$ & $4^{+}$ & & 1.79 & & Li et al., 2009 \\
\hline K-felspar & $4^{+}$ & & 1.758 & & Li et al., 2009 \\
\hline Albite & $4^{+}$ & & 1.76 & & Li et al., 2009 \\
\hline Quartz & $4^{+}$ & & 1.753 & & Li et al., 2009 \\
\hline $\begin{array}{l}\text { Oxides } \\
\text { Brunogierite } \\
\left(\mathrm{Fe}^{2+}\right)_{2} \mathrm{Ge}^{4+} \mathrm{O}_{4}\end{array}$ & $4^{+}$ & & 1.771 & & $\begin{array}{l}\text { Cempirek and Groat, } \\
2013\end{array}$ \\
\hline Sulfides & & & & & \\
\hline$\left[\mathrm{Ge}(\mathrm{II}) \mathrm{S}_{4} \mathrm{Zn}_{2}\right]^{2-}$ & $2^{+}$ & & & 2.257 & Li et al., 2009 \\
\hline$\left[\mathrm{Ge}(\mathrm{II}) \mathrm{S}_{4} \mathrm{Zn}_{4}\right]^{2}$ & $2^{+}$ & & & 2.267 & Li et al., 2009 \\
\hline$\left[\mathrm{Ge}(\mathrm{IV}) \mathrm{S}_{4} \mathrm{Zn}_{2}\right]^{0}$ & $4^{+}$ & & & 2.275 & Li et al., 2009 \\
\hline Sphalerite & $4^{+}$ & & & & $\begin{array}{l}\text { Cook et al., } 2015 \\
\text { Belissont et al., } 2016\end{array}$ \\
\hline
\end{tabular}


Table 5 : Experimental determination of Ge mineral-liquid partition coefficients in silicate minerals as a function of temperature and pressure.

\begin{tabular}{|c|c|c|c|c|}
\hline Mineral & $\mathrm{D}(\mathrm{Ge})_{\text {mineral/liquid }}$ & Temperature/Pressure & References & $\begin{array}{c}\mathrm{D}(\mathrm{Ge}) / \mathrm{D}(\mathrm{Si}) \\
\text { Malvin and Drake (1987) }\end{array}$ \\
\hline Anorthite & 0.5 & $1300^{\circ} \mathrm{C}$ & Malvin and Drake, 1987 & $0.58 \pm 0.05$ \\
\hline \multirow[t]{5}{*}{ Olivine } & 0.65 & $1300^{\circ} \mathrm{C}$ & Malvin and Drake, 1987 & $0.73 \pm 0.02$ \\
\hline & $\begin{array}{l}0.68 \pm 0.06 \\
0.54 \pm 0.04\end{array}$ & $\begin{array}{c}1300-1450^{\circ} \mathrm{C}, 1 \mathrm{~atm} \\
20 \mathrm{kbar}\end{array}$ & $\begin{array}{c}\text { Capobianco and Watson, } \\
1982\end{array}$ & \\
\hline & $0.43 \pm 0.01$ & $\begin{array}{c}1450-1650^{\circ} \mathrm{C}, 3 \mathrm{GPa} \\
(30 \mathrm{kbar})\end{array}$ & Davis et al., 2013 & \\
\hline & 0.55 & $1100^{\circ} \mathrm{C}-2 \mathrm{GPa}$ & Adam and Green, 2006 & \\
\hline & $0.95 \pm 0.04$ & $1075^{\circ} \mathrm{C}-1 \mathrm{GPa}$ & Adam and Green, 2006 & \\
\hline Clinopyroxene & 1.1 to 1.52 & $\begin{array}{c}\text { Variable } \mathrm{P}, \mathrm{T} \\
1075 \text { to } 1170^{\circ} \mathrm{C}-1-3 \mathrm{GPa}\end{array}$ & Adam and Green, 2006 & \\
\hline Diopside & $\begin{array}{c}1.4 \\
0.87 \pm 0.03\end{array}$ & $\begin{array}{c}1300^{\circ} \mathrm{C} \\
1450-1650^{\circ} \mathrm{C}, 3 \mathrm{GPa}\end{array}$ & $\begin{array}{c}\text { Malvin and Drake, } 1987 \\
\text { Davis et al., } 2013\end{array}$ & $1.4 \pm 0.02$ \\
\hline Orthopyroxene & $\begin{array}{l}0.87 \pm 0.02 \\
0.75 \pm 0.28 \\
1.36 \pm 0.07\end{array}$ & $\begin{array}{c}1450-1650^{\circ} \mathrm{C}, 3 \mathrm{GPa} \\
1160^{\circ} \mathrm{C}-2.7 \mathrm{GPa}\end{array}$ & $\begin{array}{c}\text { Davis et al., } 2013 \\
\text { Adam and Green, } 2006\end{array}$ & \\
\hline Amphibole & $\begin{array}{c}1.61 \pm 0.06 \\
1.109-0.03\end{array}$ & $\begin{array}{r}1050^{\circ} \mathrm{C}-2 \mathrm{GPa} \\
1025^{\circ} \mathrm{C}-1 \mathrm{GPa}\end{array}$ & Adam and Green, 2006 & \\
\hline Mica & $\begin{array}{c}0.51-0.54 \pm 0.02-0.05 \\
1.08 \pm 0.05\end{array}$ & $\begin{array}{c}1160-1100^{\circ} \mathrm{C}-2.7-2.5 \mathrm{GPa} \\
1025^{\circ} \mathrm{C}-1 \mathrm{GPa}\end{array}$ & Adam and Green, 2006 & \\
\hline Spinel & $\begin{array}{c}0.11 \\
0.40 \pm 0.04\end{array}$ & $\begin{array}{c}1300^{\circ} \mathrm{C} \\
1450-1650^{\circ} \mathrm{C}, 3 \mathrm{GPa}\end{array}$ & $\begin{array}{l}\text { Malvin and Drake, } 1987 \\
\text { Davis et al., } 2013\end{array}$ & $21 \pm 12$ \\
\hline$\overline{\text { Garnet }}$ & $1.51 \pm 0.03$ & $1450-1650^{\circ} \mathrm{C}, 3 \mathrm{GPa}$ & Davis et al., 2013 & \\
\hline
\end{tabular}

$\mathrm{D}(\mathrm{Ge})_{\text {mineral-liquid }}$ values for fractionnal crystallisation (Malvin and Drake, 1987; Capobianco and Watson, 1982; Adam and Green 2006) and partial melting (Davis et al. 2013).

$\mathrm{D}(\mathrm{Ge}) / \mathrm{D}(\mathrm{Si})$ : exchange coefficient for $\mathrm{Ge}$ and $\mathrm{Si}$. 
Table 6: Ge isotope composition and Ge concentration of biogenic opal

\begin{tabular}{|c|c|c|c|c|}
\hline $\begin{array}{r}\delta^{74 / 70} \mathrm{Ge} \\
\text { NIST3120 }\end{array}$ & $1 \mathrm{~s}$ & Ge (ppm) & Specimen & Ref \\
\hline \multicolumn{5}{|c|}{ North East Pacific $\left(34^{\circ} 45^{\prime} \mathrm{N} ; 1^{\circ}{ }^{\circ} \mathrm{W}\right) ; 4000 \mathrm{~m}$ detph } \\
\hline 2.33 & 0.18 & 0.21 & Hyalonema bianchoratum & (1) \\
\hline 2.46 & 0.15 & 0.21 & Hyalonema bianchoratum & (1) \\
\hline 2.60 & 0.12 & 0.23 & Hyalonema bianchoratum & (1) \\
\hline 2.42 & 0.12 & 0.23 & Hyalonema bianchoratum & (1) \\
\hline 2.36 & 0.12 & 0.27 & Hyalonema bianchoratum & (1) \\
\hline 2.21 & 0.12 & 0.22 & Hyalonema bianchoratum & (1) \\
\hline 1.56 & 0.22 & 0.26 & Bathydorus laevis ssp. spinosu & (1) \\
\hline \multicolumn{5}{|c|}{ North East Pacific $\left(34^{\circ} 45^{\prime} \mathrm{N} ; 1^{\circ}{ }^{\circ} \mathrm{W}\right) ; 4000 \mathrm{~m}$ detph } \\
\hline 2.19 & 0.22 & 0.18 & Axinella mexicana sp. & (1) \\
\hline \multicolumn{5}{|c|}{ Southern Ocean - Burdwood Bank } \\
\hline 2.24 & 0.04 & 0.13 & Unidentified Hexactinellid & $(2)$ \\
\hline 2.19 & 0.05 & 0.16 & Unidentified Demosponge & (2) \\
\hline 2.13 & 0.04 & 0.19 & Mycalidae & (2) \\
\hline 1.79 & 0.05 & 0.18 & Unidentified Demosponge & (2) \\
\hline 2.22 & 0.04 & 0.20 & Unidentified Demosponge & (2) \\
\hline \multicolumn{5}{|c|}{ Southern Ocean - Drake Passage } \\
\hline 2.07 & 0.04 & 0.15 & Unidentified Demosponge & (2) \\
\hline 2.14 & 0.07 & 0.15 & Unidentified Demosponge & (2) \\
\hline 2.11 & 0.03 & 0.20 & Unidentified Demosponge & (2) \\
\hline 1.79 & 0.02 & 0.25 & Unidentified Demosponge & (2) \\
\hline 2.33 & 0.08 & 0.18 & Aceolocalyx & (2) \\
\hline \multicolumn{5}{|c|}{ Southern Ocean - Scotia Sea } \\
\hline 2.11 & 0.02 & 0.35 & Acoelocalyx & (2) \\
\hline 2.91 & 0.06 & 0.05 & Acoelocalyx & (2) \\
\hline 2.45 & 0.09 & 0.16 & Acoelocalyx & (2) \\
\hline \multicolumn{5}{|c|}{ Southern Ocean, Indian Sector } \\
\hline 2.51 & 0.27 & 0.76 & & (3) \\
\hline 2.82 & 0.19 & 0.78 & Holocene diatoms, Core & (3) \\
\hline 2.99 & 0.05 & 0.90 & $\mathrm{RC} 11-94$ & (3) \\
\hline 2.92 & 0.07 & 0.67 & & (3) \\
\hline
\end{tabular}

Reference: (1) Rouxel et al. (2006); (2) Guillermic et al. (2016); (3)

Rouxel and De La Rocha, unpublished (pooled cleaned diatoms studied in De La Rocha et al., 1998) 